AUTARQUIA ASSOCIADA À UNIVERSIDADE DE SÃO PAULO

\title{
DETERMINAÇÃO DE METAIS EM ÓLEOS LUBRIFICANTES UTILIZANDO A TÉCNICA DE ESPECTROMETRIA DE EMISSÃO ÓPTICA COM PLASMA INDUZIDO POR LASER
}

Luana Flávia Nogueira Alves

Dissertação apresentada como parte dos
requisitos para obtenção do Grau de
Mestre em Ciências na Área
de Tecnologia Nuclear-Materiais

Orientador:

Prof. Dr. Jorge Eduardo de Souza Sarkis 


\section{INSTITUTO DE PESQUISAS ENERGÉTICAS E NUCLEARES}

Autarquia associada à Universidade de São Paulo

\section{DETERMINAÇÃO DE METAIS EM ÓLEOS LUBRIFICANTES UTILIZANDO A TÉCNICA DE ESPECTROMETRIA DE EMISSÃO ÓPTICA COM PLASMA INDUZIDO POR LASER}

Luana Flávia Nogueira Alves

Dissertação apresentada como parte dos
requisitos para obtenção do Grau de
Mestre em Ciências na Área
de Tecnologia Nuclear-Materiais

Orientador:

Prof. Dr. Jorge Eduardo de Souza Sarkis

Versão Corrigida

Versão Original disponível no IPEN

São Paulo

2016 


\section{AGRADECIMENTOS}

Agradeço ao meu orientador Jorge Eduardo de Sousa Sarkis, por ter me aceitado como sua orientanda e por ter se tornado mais do que um orientador, um amigo, amigo este que me orienta além do âmbito acadêmico.

Gostaria de agradecer a pessoa quem mais me incentivou e me auxiliou passo a passo nos caminhos rumo a este mestrado, meu querido amigo: Marcelo Muniz.

Agradecer ao meu (ex) chefe, Luiz Bizaio, por me proporcionar a possibilidade de abertura de tempo para o trabalho intercalando com os estudos.

As colegas do laboratório Cristina Zampieri, Luciana Vieira de Santana e Mariana Ayumi pela amizade.

A querida Isabela Leal Bordon pelas palavras amigas, pela ajuda e colaboração neste trabalho.

A professora Ivone Mulako Sato, Olívio Pereira de Oliveira Junior, Afonso Rodrigues de Aquino pelas recomendações e amizade.

Aos colegas João Cristiano Ulrich e Marcos Antonio Hortellani pela ajuda e paciência.

Ao meu irmão Demian Felipe Nogueira Alves pelo carinho.

E agradecer principalmente a minha querida mãe e melhor amiga: Márcia Nogueira, pela paciência, por estar sempre ao meu lado me apoiando e por acreditar em mim. 


\section{DEDICATÓRIA}

Dedico este trabalho de mestrado a uma das pessoas mais inteligentes e humildes que já conheci: meu querido e falecido pai, José Carlos Ferreira Alves. 
"Se não fossem os sonhos morreríamos com tanta realidade" - autor desconhecido - Ushuaia - Patagônia 


\title{
DETERMINAÇÃO DE METAIS EM ÓLEOS LUBRIFICANTES UTILIZANDO A TÉCNICA DE ESPECTROMETRIA DE EMISSÃO ÓPTICA COM PLASMA INDUZIDO POR LASER
}

\section{Luana Flávia Nogueira Alves}

\begin{abstract}
RESUMO
Neste trabalho foi desenvolvido uma metodologia para a determinação de metais $(\mathrm{Cr}, \mathrm{Cu}, \mathrm{Fe}, \mathrm{Mg}, \mathrm{Mo}, \mathrm{Pb})$, em óleos lubrificantes e estes quantificados pela técnica de espectrometria de emissão optica com plasma induzido por laser (LIBS). As amostras de óleo usadas foram coletadas em oficina de troca de óleo, variando-se a quilometragem, ano, marca do carro e a marca do óleo, com o preenchimento de formulários contendo as informações necessárias à pesquisa. A preparação de amostras foi realizada com o depósito ds mesmas em substrato de papel e sequente otimização dos parâmetros instrumentais. Para a calibração, foi utilizado o padrão de óleo S-21 multielementar da Conostan (SCP Science, Champlain, NY). Para a avaliação da exatidão do método desenvolvido foi utilizado o padrão de óleos lubrificantes (SRM 1084a) obtidos junto ao Instituto Nacional de Padrões e Tecnologia (NIST, Gaithersburg, MD). O método proposto apresentou as seguintes vantagens quando comparado com métodos de análise tradicionais (espectrometria de absorção atômica ou espectrometria de emissão optica acoplado ao plasma indutivo com diluição da amostra): mais rápida, sem desgaste do equipamento (em função da não introdução de solvente), geração de resíduo praticamente nula e menor consumo de reagentes. O método desenvolvido foi aplicado em amostras reais e o tratamento de dados realizado por análise estatística (equação de Stuarges, teste não paramétrico de Kruskalwallis).

Palavras- chave: LIBS, análise de metais, estatística multivariada, óleo lubrificante, validação de metodologia.
\end{abstract}




\title{
DETERMINATION OF METALS IN LUBRICATING OILS BY LASER INDUCED BREAKDOWN SPECTROSCOPY
}

\section{Luana Flávia Nogueira Alves}

\begin{abstract}
In this work was developed a methodology for the determination of metals $(\mathrm{Cr}, \mathrm{Cu}$, $\mathrm{Fe}, \mathrm{Mg}, \mathrm{Mo}, \mathrm{Pb}$ ) in lubricating oils and these were quantified by Laser Induced Breakdown Spectroscopy (LIBS). Used oil samples used were collected in shop oil change, varying the mileage year, car make and oil brand with forms containing the information necessary for research filling out. For the calibration, the standard of 500ppm oil of S-21 multielement Conostan (SCP Science, Champlain, NY) was used, which was diluted with blank oil to achieve concentrations from 12.5 to 500 ppm necessary for the construction of analytical curve. For evaluating the accuracy of the method developed, we analyzed the standard of lubricating oils (SRM 1084th) obtained from the National Institute of Standards and Technology (NIST, Gaithersburg, MD). The proposed method has the following advantages compared to traditional methods of analysis (AAS or ICPOES with sample dilution): faster, without wear of the equipment (due to the introduction of non-solvent), generating virtually no residue and lower consumption reagents. The developed method was applied to real samples and the total processing performed by statistical analysis.
\end{abstract}




\section{SUMÁRIO}

1 INTRODUÇÃ

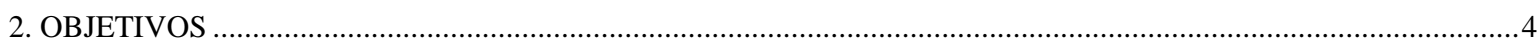

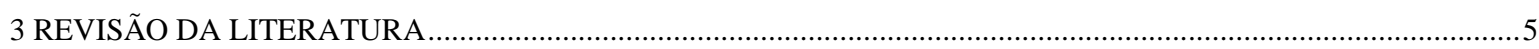

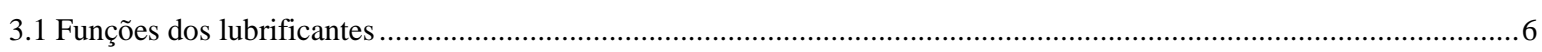

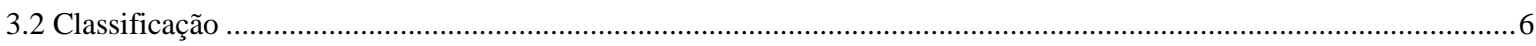

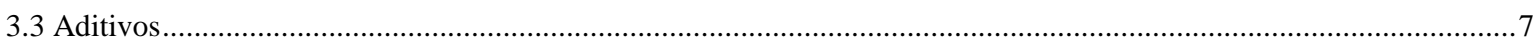

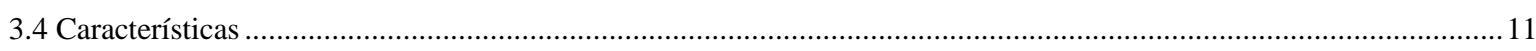

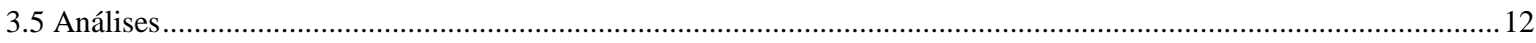

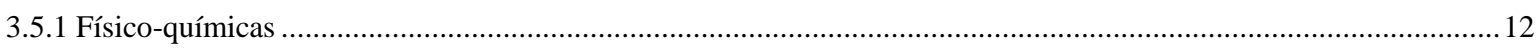

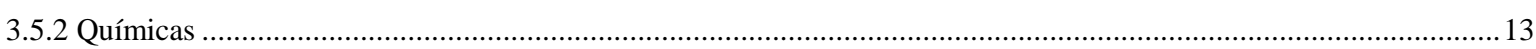

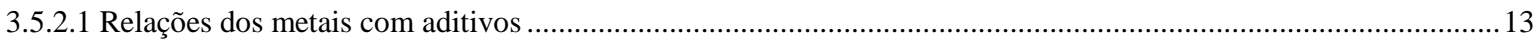

3.5.2.2 Elementos determinados em óleo queimado e suas relaç̃es com o desgaste do motor: ............................................14

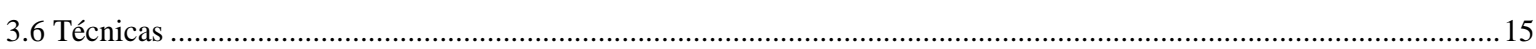

3.6.1 Espectrometria de absorção atômica (AAS) ……………………………………………………………….... 15

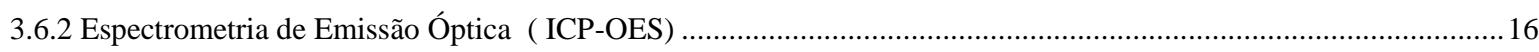

3.6.3 Espectrometria de massa acoplada ao plasma indutivo (ICP-MS) ……………………………………………....... 16

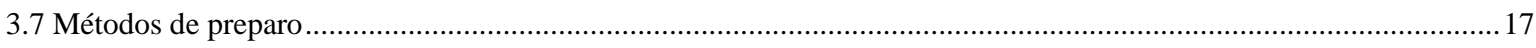

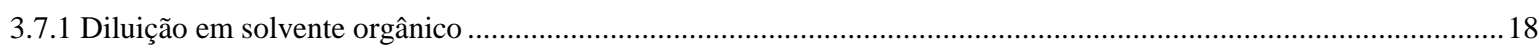

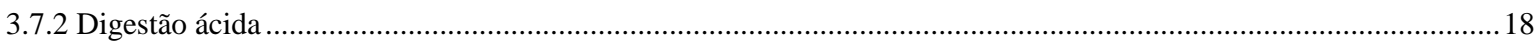

4 ESPECTROMETRIA DE EMISSÃO ÓPTICA COM PLASMA INDUZIDO POR LASER (LIBS) ..............................19

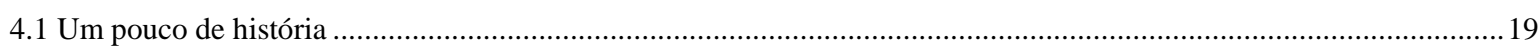

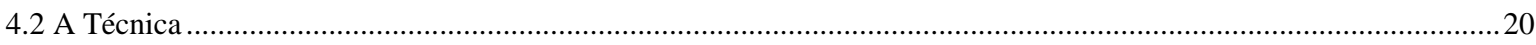

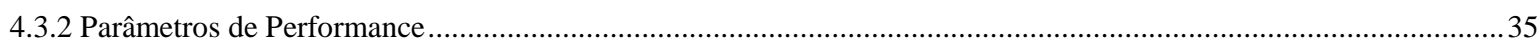

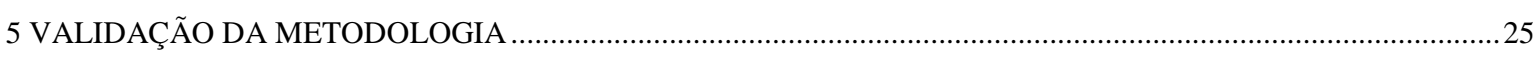

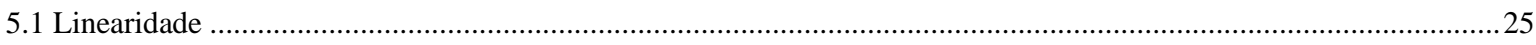

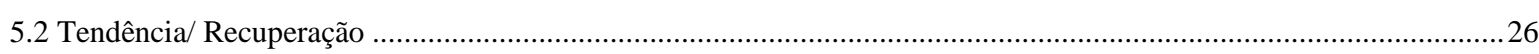

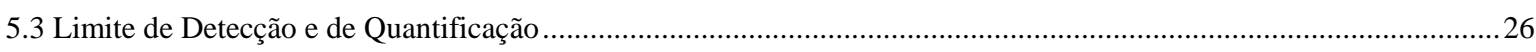

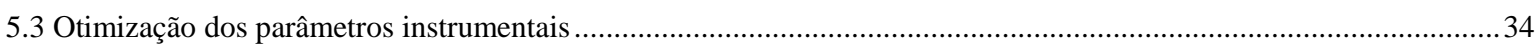

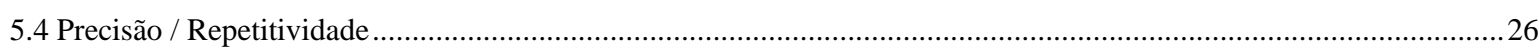

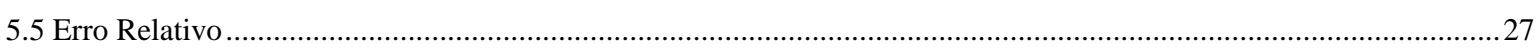

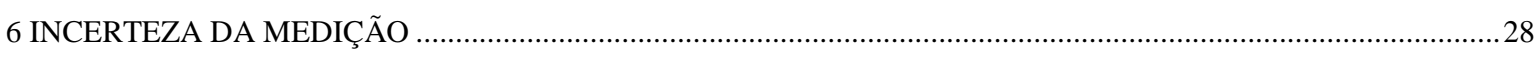

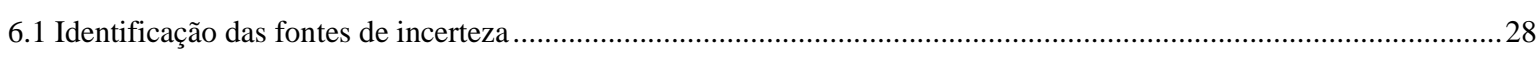

7 FERRAMENTAS ESTATISTICAS UTILIZADAS NA AVALIAÇÃO DOS RESULTADOS: QUIMIOMETRIA ......31

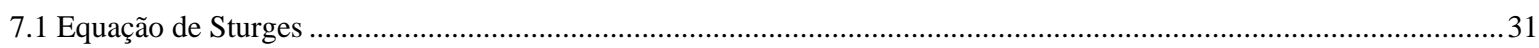

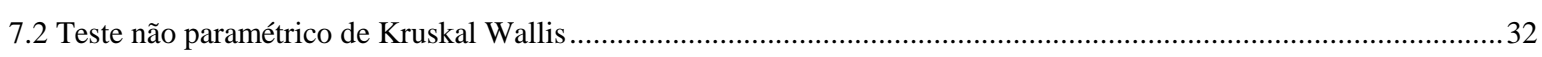

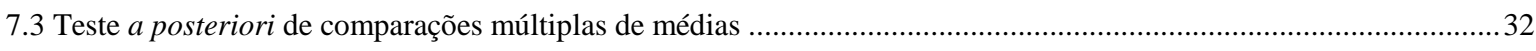

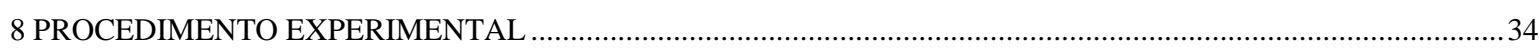

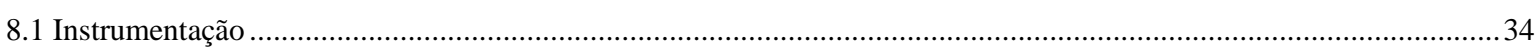

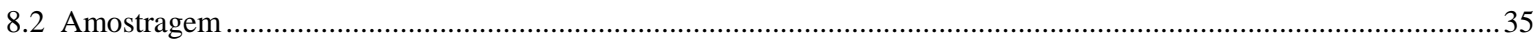

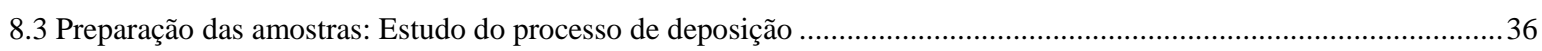

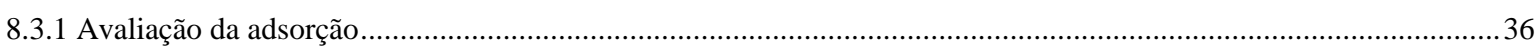

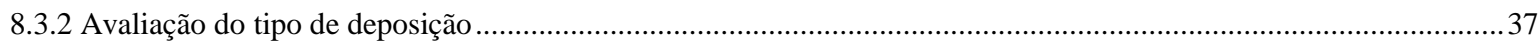




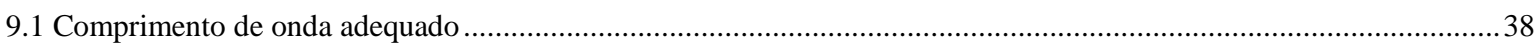

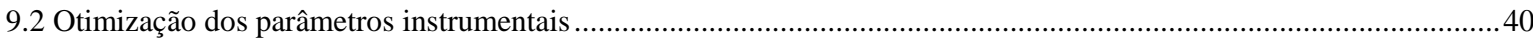

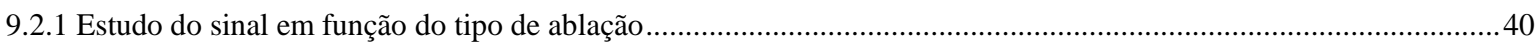

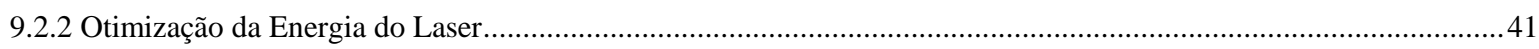

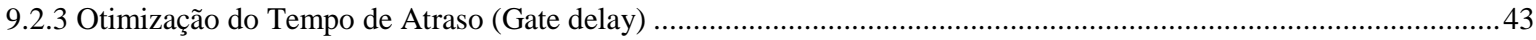

9.2.4 Otimização do diâmetro da área de interação do laser (Spot Size) .......................................................................4

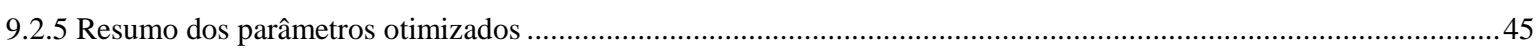

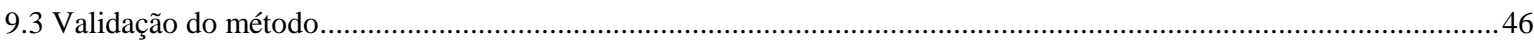

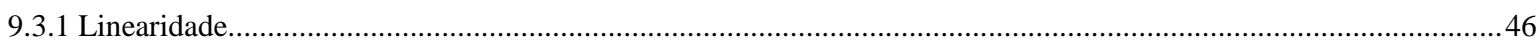

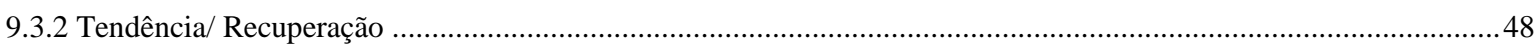

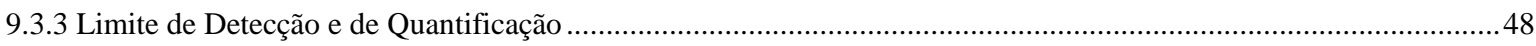

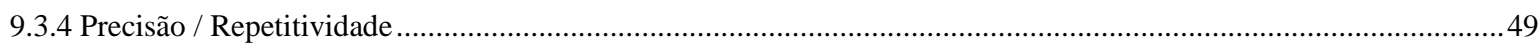

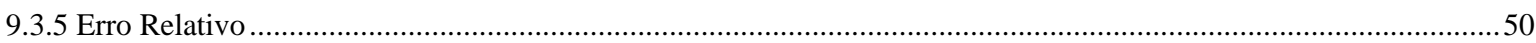

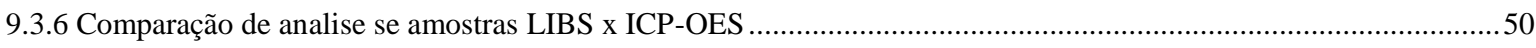

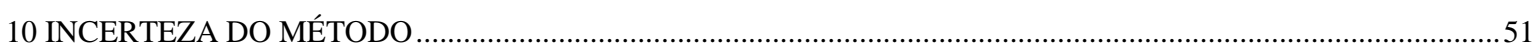

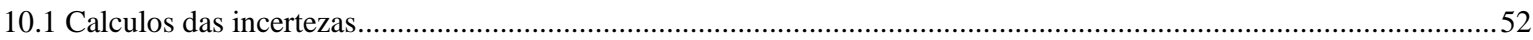

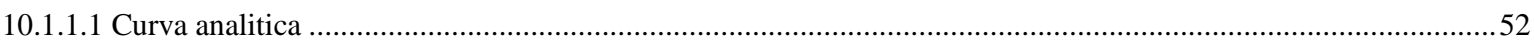

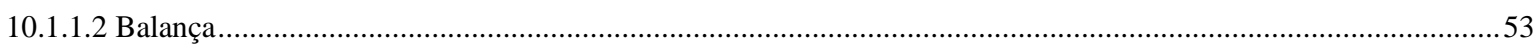

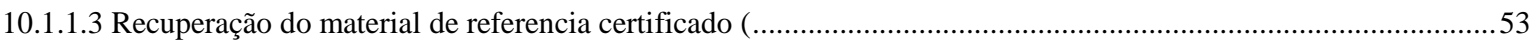

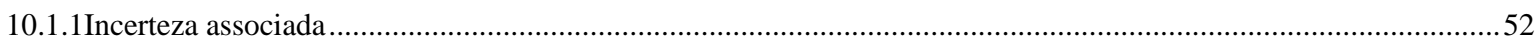

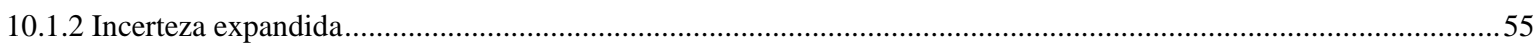

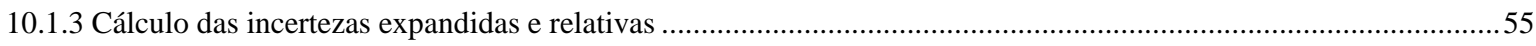

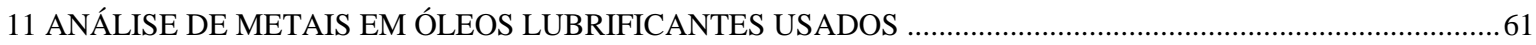

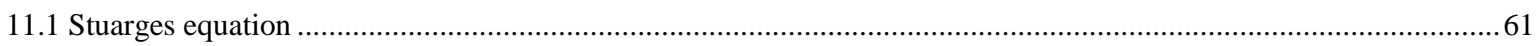

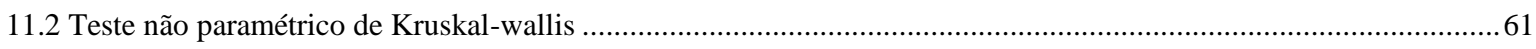

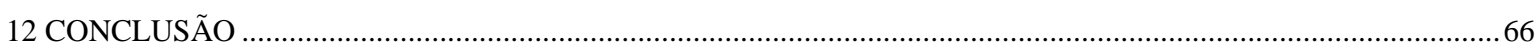

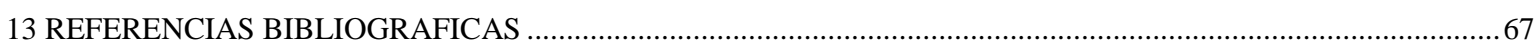

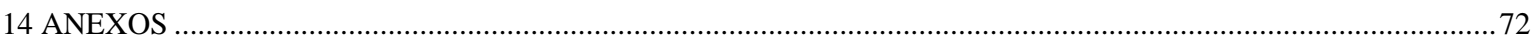

15 APÊNDICE 


\section{LISTA DE FIGURAS}

FIGURA 1: Esquema do processo de obtenção de óleos básicos a partir do petróleo.

FIGURA 2 - Número de trabalhos sobre Espectrometria de Emissão Óptica com Plasma Induzido por Lasers entre 1994 e 2014

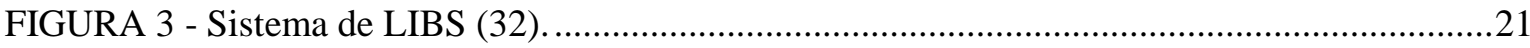

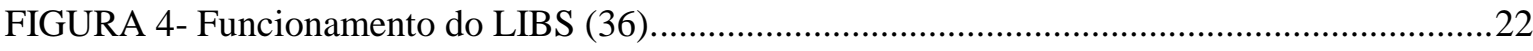

FIGURA 5 - Diagrama de causa-efeito das fontes de incerteza associada à medição. .......................28

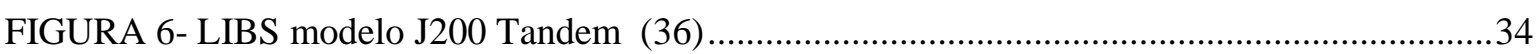

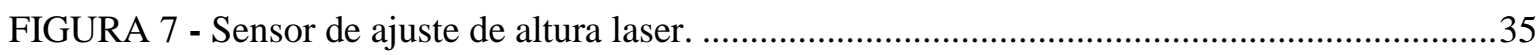

FIGURA 8 - Deposição das no papel utilizando suporte para tubos de ensaio de isopor.................36

FIGURA 9 - Intensidade de sinal(cps) em função de diferentes tipos de deposições........................37

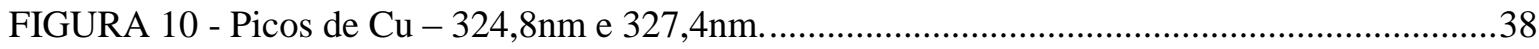

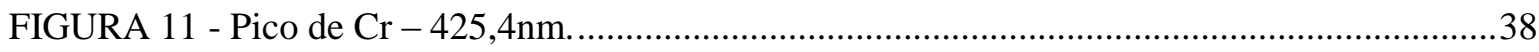

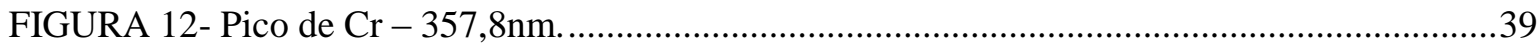

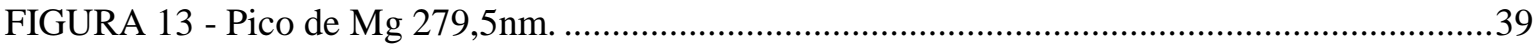

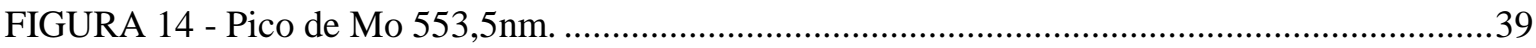

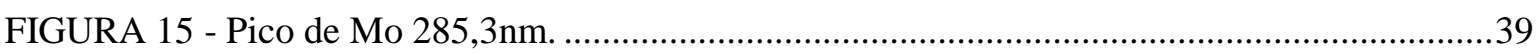

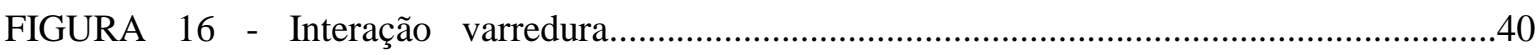

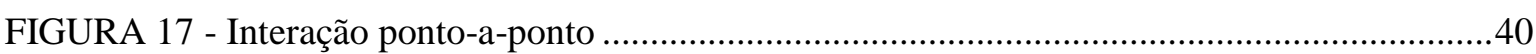

FIGURA 18 - Estudo da variação da intensidade do sinal (cps) em função do número de pulsos...41

FIGURA 19 - Estudo da variação da intensidade de sinal (cps) em função da energia do laser(mJ) para os elememtos $\mathrm{Cu}, \mathrm{Cr}$ e $\mathrm{Fe}$..

FIGURA 20 - Estudo da variação da intensidade de sinal (cps) em função da Energia do Laser(mJ)

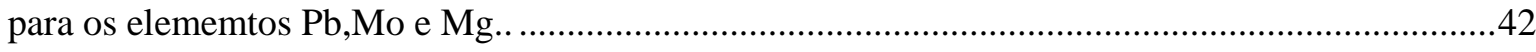

FIGURA 21 - Estudo da variação do tempo de atraso ( $\mu$ s), para os elementos $\mathrm{Cu}, \mathrm{Cr}, \mathrm{Pb}$ e Fe.......43

FIGURA 22 - Estudo da variação do tempo de atraso $(\mu \mathrm{s})$, para os elementos Mo e Mg.................44

FIGURA 23 - Estudo da variação da intensidade de sinal(cps) em função do diâmetro da cratera $(\mu \mathrm{m})$.

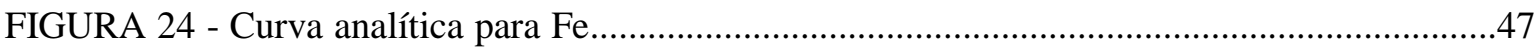

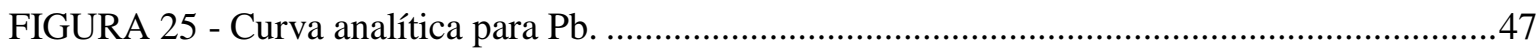

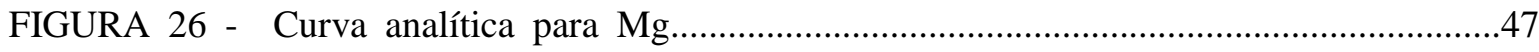

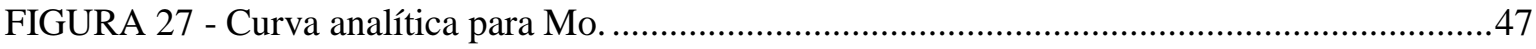

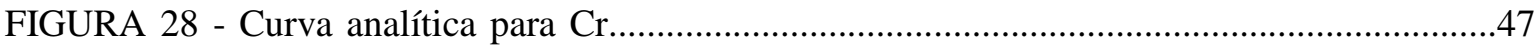

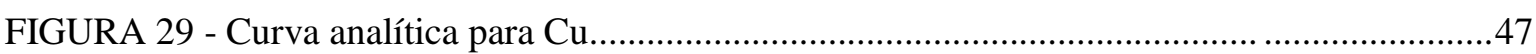

FIGURA 30 - Incertezas relativas para Mo com todos os pontos da curva. .......................................56

FIGURA 31 - Incertezas relativas para $\mathrm{Pb}$ com todos os pontos da curva........................................57 
FIGURA 32 - Incertezas relativas para Mo com a nova curva. .58

FIGURA 33 - Incertezas relativas para $\mathrm{Pb}$ com a nova curva........................................................59

FIGURA 34 - Comparação múltipla entre as classes para $\mathrm{Cu}$......................................................62

FIGURA 35 - Comparação múltipla entre as classes para $\mathrm{Cr}$.......................................................62

FIGURA 36 - Comparação múltipla entre as classes para $\mathrm{Pb}$......................................................63

FIGURA 37 - Comparação múltipla entre as classes para Fe ........................................................63

FIGURA 38 - Comparação múltipla entre as classes para Mo........................................................64

FIGURA 39 - Comparação múltipla entre as classes para Mg........................................................64 


\section{LISTA DE TABELAS}

TABELA 1 - Relação dos metais com aditivos

TABELA 2 - Metais de desgaste encontrados em análises de óleos lubrificantes usados e áreas de possíveis falhas de componentes de motor.

TABELA 3 - Resumo dos parâmetros otimizados..............................................................................45

TABELA 4 - Recuperação do padrão NIST SRM 1084a. .................................................................48

TABELA 5 - Limite de deteç̧ão e de quantificação. ..........................................................................48

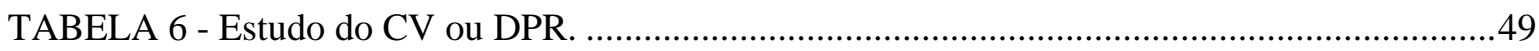

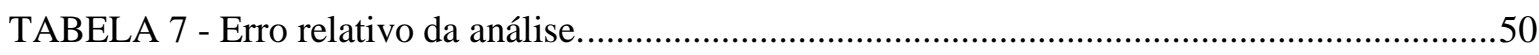

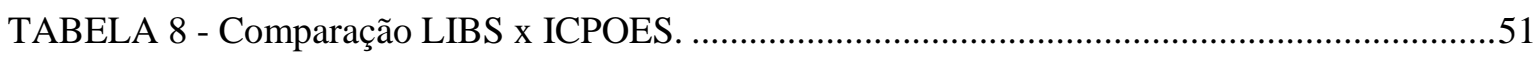

Tabela 9 - Concentração dos metais em ppm (mediana) em função do ano de fabricação................51

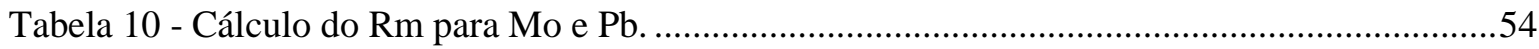

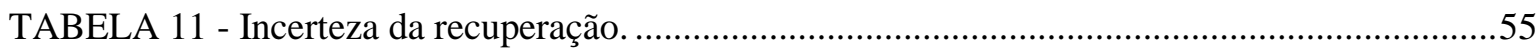

TABELA 12 - Incerteza expandida com todos os pontos da curva................................................55

TABELA 13 - Incertezas relativas para Mo com todos os pontos da curva. …….............................56

TABELA 14 - Incertezas relativas para $\mathrm{Pb}$ com todos os pontos da curva........................................57

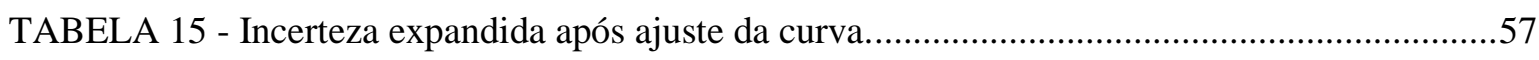

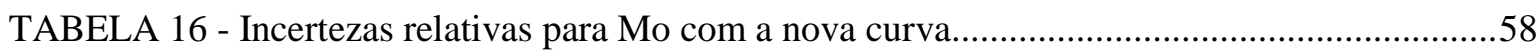

TABELA 17 - Incertezas relativas para $\mathrm{Pb}$ com a nova curva..........................................................58

TABELA 18 - Incerteza expandida calculada com todos os pontos da curva - 7 pontos de 12,5 a

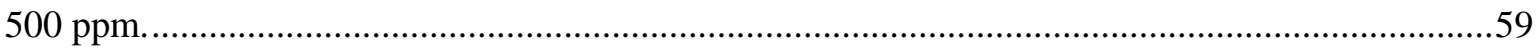

TABELA 19 - Incerteza expandida calculada reduzindo a curva para 100ppm. ............................60

TABELA 20 - Incerteza expandida calculada para a concentração de Fe $=120$ e 241 ppm - com a

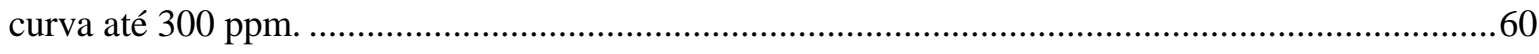

TABELA 21 - Divisão das classes de acordo com a equação de Sturges........................................61 


\section{LISTA DE ABREVIATURAS}

ANP - Agência Nacional do Petróleo

PMQL - Programa de Monitoramento da Qualidade dos Lubrificantes

AAS - Espectrometria de Absorção Atômica (atomic absorption spectrometry)

ICPOES - Espectrometria de Emissão Óptica Acoplado ao Plasma Indutivo (Inductively coupled plasma atomic emission spectroscopy)

ICP-MS - Espectrometria de Massa Acoplada ao Plasma Indutivo ( Inductively coupled plasma mass spectrometry)

FRX - Espectrometria de fluorescência de raios X

GFAAS - Espectrometria de Absorção Atômica com Forno de Grafite (Graphite furnace atomic absorption spectrometry)

LIBS - Espectrometria de emissão óptica com plasma induzido por laser (Laser Induced Breakdown Spectroscopy)

ABNT - Associação Brasileira de Normas Técnicas

ICCD - Dispositivo de carga acoplada intensificada (intensified charge-coupled device)

CCD - Dispositivo de carga acoplada (charge-coupled device)

MRC - Material de Referência Certificado ( instituto Nacional de Padrões e Tecnologia)

LD - Limite de detecção

LQ - Limite de quantificação

CV - Coeficiente de Variação

DPR - Desvio Padrão Relativo

ER - Erro Relativo 


\section{INTRODUÇÃO}

Chamamos de lubrificante qualquer material interposto entre duas superfícies, a fim de reduzir o atrito e desgaste. Além disso, a lubrificação é também utilizada para reduzir a oxidação, evitar a formação de ferrugem, proporcionar isolamento em transformadores, transmitir potência mecânica em máquinas hidráulicas e vedação contra a poeira entre outros. (1)

Com o intuito de atribuir certas propriedades especiais aos óleos ou melhorar algumas já existentes, aditivos são adicionados aos óleos básicos (que agora são chamados de lubrificantes). Existem diversos tipos de aditivos que exercem funcionalidades específicas (1): a. Detergente-dispersante; b. Antioxidante; c. Anticorrosivo; d. Antiferrugem; e. Extrema pressão; f. Antidesgaste; g. Abaixador do ponto de fluidez; h. Aumentador do índice de viscosidade.

Estas características são verificadas por meio dos seguintes ensaios: A) Densidade; B) Viscosidade; C) Índice de viscosidade; D) Ponto de fulgor (ou de lampejo) e ponto de inflamação (ou de combustão); E) Pontos de fluidez e névoa; F) Água por destilação; G) Água e sedimentos; H) Demulsibilidade; I) Extrema pressão; J) Diluição; K) Cor; L) Cinzas oxidadas; M) Cinzas sulfatadas; N) Corrosão em lâmina de cobre; O) Consistência de graxas lubrificantes; P) Ponto de gota.

No mercado brasileiro existem vários tipos de óleos lubrificantes definidos pela Agência Nacional do Petróleo (ANP) por meio da da Portaria No 125 (2).

A portaria $\mathrm{N}^{\mathrm{o}} 129$ (3) da ANP descreve algumas características de qualidade para os óleos básicos, dentre elas: aparência, cor, viscosidade, índice de viscosidade, ponto de fulgor, ponto de fluidez, índice de acidez total, cinzas, resíduos de carbono Rambottom, corrosividade, estabilidade a oxidação, emulsão e perda por evaporação.

O análise de óleo é uma parte integrante das operações de rotina de setores, como: indústrias, marinha, aviação, refinarias de petróleo, de geração de energia elétrica, em operações de mineração, transportes públicos, automóveis, etc.

Basicamente, todos os tipos de motores, ao longo do tempo, apresentam desgaste que pode ser identificado com a presença de metais nos óleos lubrificantes. A identificação preventiva deste desgaste permite prolongar a vida útil dos motores.

O uso da análise de óleo como estratégica na avaliação de desgaste de motores começou a ser aplicada na década 50. Com a crise do petróleo, este tipo de análise 
intensificou de forma rotineira e passou a cumprir uma nova função na manutenção das máquinas, permitindo o monitoramento das condições do óleo lubrificante e identificando a necessidade de troca ou apenas reposição parcial, assim como, diagnosticar problemas nos equipamentos (1).

No Brasil, a Agência Nacional do Petróleo, Gás Natural e Biocombustível (ANP) (4) é a responsável pelo controle de qualidade dos óleos lubrificantes produzidos e utilizados no país e através do programa de monitoramento da qualidade dos lubrificantes (PMQL) utiliza o método da norma ABNT NBR 14066 (5) para a determinação de metais em óleos lubrificantes novos e quantificados por espectrometria de absorção atômica com forno de grafite(GF AAS). No método o óleo é diluido com querosene de aviação (que é tóxico, irritante e de difícil aquisição) e na calibração utilizam-se padrões lipossolúveis, que são caros e instáveis.

Diversas técnicas instrumentais têm sido utilizadas para determinação de metais em óleos lubrificantes, tais como, espectrometria de absorção atômica (AAS), (6), (7), espectrometria de emissão óptica acoplado ao plasma indutivo (ICPOES), (8), espectrometria de massa acoplada ao plasma indutivo (ICP-MS), (9) e de fluorescência de raios $\mathrm{X}$ (espectrometria de FRX), (10).

Cada técnica apresenta determinadas desvantagens: por exemplo, o AAS tem baixa frequencia anlítica e só permite a medição de um elemento de cada vez, tanto o AAS, como ICPOES e MS exigem amostras líquidas (ou a utilização de acessórios) e o XRFS tem dificuldades para determinar com precisão os elementos mais leves. A maioria das técnicas requerem preparação da amostra e serviços adicionais, tais como gases e de água de resfriamento (11). Além disso esta é uma análise complicada em função da viscosidade das amostras e dos efeitos do tamanho das particulas.

Com relação ao preparo de amostras, encontramos na literatura métodos como, digestão por microondas (12), diluição em meio ácido / diluição em solvente orgânico (13), emulsão/ microemulsão (14).

A técnica de Espectrometria de Emissão Óptica com Plasma Induzido por Laser, conhecida no inglês como Laser Induced Breakdown Spectroscopy (LIBS) (técnica utilizada neste trabaho), vem sendo difundida nos últimos anos como alternativa para análise de metais majoritários, em diferentes tipos de matrizes.

Diferente das demais técnicas utilizadas para este fim, o uso da técnica de LIBS não exige a preparação de amostras do modo tradicional (com utilização de solvente). 
O método aqui desenvolvido, utilizando a técnica de deposição em papel torna a preparação mais rápida, evitando o desgaste do equipamento (em função da introdução de solvente). Além disso, a geração de resíduo é praticamente nula seguindo, portanto, uma tendencia mundial no que diz respeito à preservação do meio ambiente.

Outrossim, a técnica do LIBS ainda não está muito disseminada no Brasil, além disso, a maioria dos laboratórios utilizam equipamentos híbridos. Nesse trabalho será utilizado um novo tipo de equipamento compacto com sistemas integrados, conhecido como J200 Tandem La-LIBS.

Os maiores desafios estão relacionados com o preparo da amostra em substrato de papel e na otimização dos parâmetros instrumentais. 


\section{OBJETIVOS}

O presente estudo teve como objetivo desenvolver um método analítico multielementar para a determinação de metais $(\mathrm{Cu}, \mathrm{Cr}, \mathrm{Fe}, \mathrm{Mg}, \mathrm{Mo}, \mathrm{Pb})$ em amostra de óleo lubrificante usado de automóveis, utilizando a técnica de LIBS e preparação de amostras com depósito em substrato de papel.

Os objetivos específicos foram:

-Avaliar as concentrações de metais nas amostras de óleo lubrificante usado de automóveis;

-Avaliar as concentrações desses metais e suas correlações com desgaste de partes do motor;

-Otimizar os parâmetros instrumentais;

- Validar a metodologia analítica. 


\section{REVISÃO DA LITERATURA}

Os óleos lubrificantes são normalmente formulados a partir do óleo básico mineral obtido em uma das frações de destilação do petróleo, entre 300 a $400^{\circ} \mathrm{C}$, sendo caracterizado por possuir compostos orgânicos de 16 a 20 átomos de carbonos. O petróleo para a produção dos lubrificantes é composto basicamente por: (1)

a. Naftênica (cicloalcanos): possuem como principais características: baixo ponto de fluidez e baixo índice de viscosidade. Essas características permitem a sua utilização na formulação de óleos para lubrificação em condições de baixas temperaturas como, por exemplo, óleos para compressores de refrigeração.

b. Parafínica (alcanos): possuem alto índice de viscosidade, alto ponto de fluidez e baixo poder de solvência, quando comparados com óleos naftênicos. Por sua vez, estes óleos são indicados principalmente para formulação dos lubrificantes para motores a combustão, óleos para sistemas hidráulicos e para engrenagens, ou seja, são óleos para trabalhos em condições severas (altas temperaturas e altas pressões) (11).

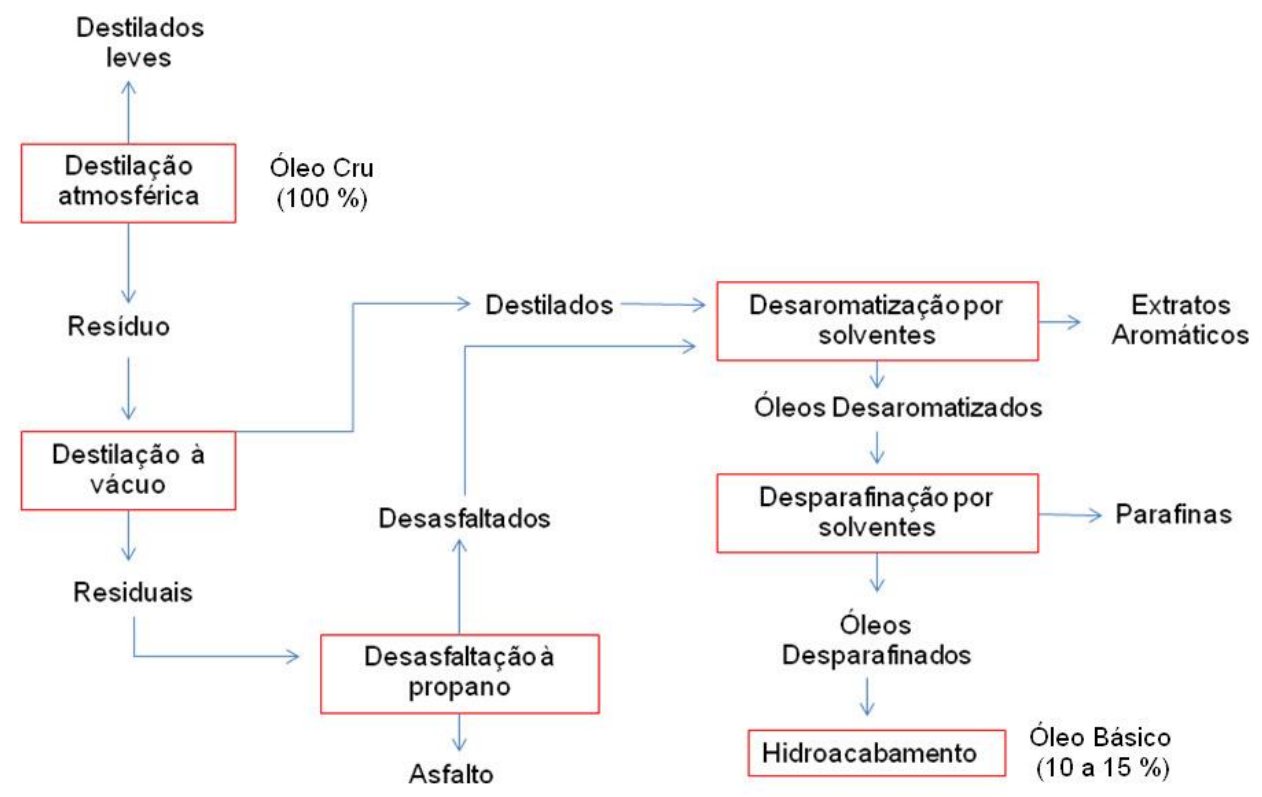

FIGURA 1: Esquema do processo de obtenção de óleos básicos a partir do petróleo. 


\subsection{Funções dos lubrificantes:}

As principais funções dos lubrificantes, nas suas diversas aplicações, são (15):

a. Controle do atrito: transformando o atrito sólido em atrito fluido, evitando assim a perda de energia;

b. Controle do desgaste: reduzindo ao mínimo o contato entre as superfícies, origem do desgaste;

c. Controle da temperatura: absorvendo o calor gerado pelo contato das superfícies (motores, operações de corte etc.);

d. Controle da corrosão: evitando que ação de ácidos destrua os metais; reduzindo a oxidação e impedindo a formação de ferrugem;

e. Transmissão de força: funcionando como meio hidráulico, transmitindo força com um mínimo de perda (sistemas hidráulicos, por exemplo);

f. Amortecimento de choques: transferindo energia mecânica para energia fluida (como nos amortecedores dos automóveis) e amortecendo o choque dos dentes de engrenagens;

g. Remoção de contaminantes: evitando a formação de borras, lacas e vernizes;

h. Vedação: impedindo a saída de lubrificantes e a entrada de partículas estranhas (função das graxas) e impedindo a entrada de outros fluidos ou gases (função dos óleos nos cilindros de motores ou compressores).

\subsection{Classificação}

Devido a diversidade de óleos lubrificantes no mercado brasileiro a Portaria $\mathrm{N}^{\mathrm{o}} 125$ (2) da Agência Nacional do Petróleo (ANP), definiu o óleo lubrificante em:

Óleo lubrificante básico: principal constituinte do óleo lubrificante acabado, podendo ser de origem mineral (derivado do petróleo) ou sintética (síntese química);

Óleo lubrificante acabado: produto formulado a partir de óleo lubrificante básico, podendo conter aditivos;

Óleo lubrificante usado ou contaminado: óleo lubrificante acabado que, em função do seu uso normal ou por motivo de contaminação, tenha se tornado inadequado à sua finalidade original; 
Óleo lubrificante rerrefinado: processo industrial para remoção de contaminantes, de produtos de degradação e de aditivos do óleo lubrificante usado ou contaminado, conferindo ao produto final as mesmas características de óleo lubrificante básico.

Além dos óleos básicos descritos pela ANP (2), existem também os óleos compostos que são óleos minerais com adição de 1 a 30\% de óleos graxos. A composição varia de acordo com a sua finalidade. Os óleos graxos conferem aos óleos minerais propriedades de emulsibilidade, oleosidade e extrema pressão. Os principais óleos graxos são:
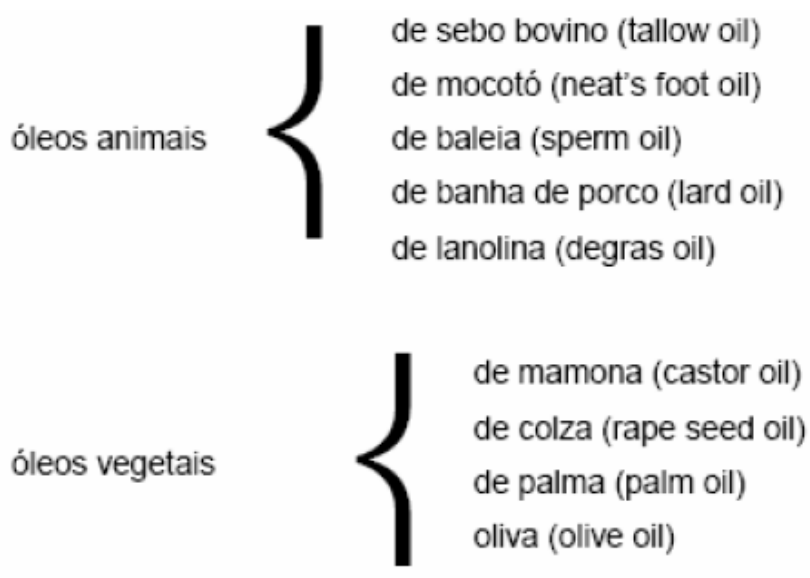

Os óleos graxos foram os primeiros lubrificantes a serem utilizados, sendo mais tarde substituídos pelos óleos minerais. Seu uso nas máquinas modernas é raro, devido à sua instabilidade química, principalmente em altas temperaturas, o que provoca a formação de ácidos e vernizes (14).

\subsection{Aditivos}

Para melhorar ou atribuir certas propriedades específicas aos óleos básicos é necessário realizar a adição de aditivos.

Existem diversos tipos de aditivos, os principais, são $(15,16,17)$ :

\section{a. Detergente-dispersante:}

Detergentes: são compostos utilizados para manter em suspensão e finamente dispersos os produtos de oxidação do óleo, retardando a formação de borra, evitando assim que esta se 
deposite nos componentes metálicos. Ex.: sulfonados, fosfonatos e/ou tiofosfonatos, fenatos, salicilatos alcoilsubstituídos.

Dispersantes: atuam junto com os detergentes dispersando compostos insolúveis para evitar a formação de borras. Ex.: copolímeros contendo éster carboxilato com funções polares adicionais, polímeros de hidrocarbonetos, alquenil succinimidas, amidas, poliamidas, ésteres, poliésteres, sais de aminas, ácidos orgânicos.

Aplicações: Motores de combustão interna.

Finalidades: Este aditivo tem a função de limpar as partes internas dos motores, e manter em suspensão, finamente dispersos, a fuligem formada na queima do combustível e os produtos de oxidação do óleo.

Quando o lubrificante não possui aditivo detergente-dispersante, os resíduos se agrupam e precipitam, formando depósitos.

Nos óleos que contêm detergente-dispersante, o aditivo envolve cada partícula de resíduo com uma camada protetora, que evita o agrupamento com outros resíduos e, consequentemente, a sua precipitação. Este fenômeno é observado com o rápido escurecimento do óleo, que ainda é mal entendido por alguns mecânicos e usuários, que acreditam que o lubrificante se deteriora rapidamente. No entanto, o escurecimento significa que as partículas que iriam formar borras, lacas e vernizes estão sendo mantidas em suspensão e serão drenadas junto com o óleo.

A quantidade de material disperso depende da quantidade e do tipo dos aditivos. Isto significa que, após determinados períodos de uso, os aditivos saturam-se e os óleos necessitam ser drenados, para não ocorrer a formação de depósitos.

b. Antioxidante: são substâncias que aumentam a resistência dos óleos básicos à oxidação, retardando o envelhecimento do óleo, aumentando o período de estocagem e a vida útil do mesmo, além de prevenir a formação de vernizes e borra. A oxidação de um óleo lubrificante ocorre em função da exposição do mesmo a alta temperatura, água contaminante, superfície metálica (catalisam a oxidação). Ex.: Sulfetos, dissulfetos, sulfóxidos, fosfitos, aminas, fenóis, celenatos e ditiofosfato de zinco.

Aplicações: Motores de combustão interna, turbinas, compressores, motores elétricos, fusos, sistemas hidráulicos, sistemas de circulação de óleo etc.

c. Anticorrosivo / Inibidores de Corrosão: Ex.: Diorgano-ditiofosfato de zinco, dicarbamatos de zinco, dipentano sulfurado, terpenos fosfo-sulfurados. Aplicações: 
Motores de combustão interna, turbinas, compressores, motores elétricos, fusos, sistemas hidráulicos, sistemas de circulação de óleo etc. Finalidades - São empregados para prevenir a corrosão de superfícies metálicas não ferrosas. Os agentes corrosivos podem ser produtos da própria oxidação do óleo, como também agentes externos contidos no ar atmosférico e no caso de motores de combustão interna, ácidos formados na combustão.

Os anticorrosivos têm por finalidade a neutralização dos ácidos orgânicos, formados pela oxidação do óleo, dos ácidos inorgânicos, no caso de lubrificantes de motores, e proteger as partes metálicas da corrosão. No funcionamento dos motores, são formados ácidos sulfúrico e nítrico, devido à presença de enxofre e nitrogênio nos combustíveis, que são altamente corrosivos.

d. Antiferrugem/ Inibidores de ferrugem: Ex.: Ácidos alquenil - succínicos, ácidos alcoil - tioacéticos, Imidazolinas substituídas, fosfatos de aminas.

Aplicações: Óleos protetivos, turbinas, sistemas hidráulicos, compressores, motores de combustão interna, sistemas de circulação de óleo etc.

Finalidades - Semelhante ao anticorrosivo, este aditivo tem a finalidade de evitar a corrosão dos metais ferrosos (atuação de proteção somente em peças de ferro) pela ação da água ou umidade. A presença de sais na água acelera consideravelmente a ferrugem. Envolvendo as partes metálicas com uma película protetora, o aditivo antiferrugem evita que a água entre em contato com as superfícies.

e. Antiespumante. Ex.: Silicones, copolímeros orgânicos.

Aplicações: Óleos para máquinas e motores em geral.

Finalidades - A formação da espuma é devido à agitação do óleo. Quando a bomba de óleo alimenta as partes a lubrificar com uma mistura óleo-ar, dá-se o rompimento da película de óleo, o contato metal com metal e o consequente desgaste. $\mathrm{O}$ aditivo antiespumante tem a função de agrupar as pequenas bolhas de ar, existentes no seio do óleo, formando bolhas maiores, que conseguem subir a superfície, onde se desfazem, logo evitando a aceleração do processo de oxidação do óleo lubrificante.

f. Extrema pressão: Quase todos os aditivos de extrema pressão são compostos químicos que contêm enxofre, fósforo, cloro e chumbo.

Aplicações: Óleos para transmissões automotivas, óleos para mancais ou engrenagens industriais que trabalham com excesso de carga e óleos de corte. Finalidades: Tanto os aditivos de extrema pressão, como os antidesgastes, lubrificam quando a película é mínima. 
g. Antidesgaste: Seus principais elementos são o zinco e o fósforo.

Aplicações: Motores de combustão interna, sistemas hidráulicos etc. Finalidades: Estes aditivos são semelhantes aos de extrema pressão, mas têm ação mais branda.

h. Abaixadores do ponto de fluidez: Ex.:Polimetacrilatos, poliacrilamidas, copolímeros de vinil caboxilato - dialcoil - fumaratos.

Aplicações: Podem ser empregados nos óleos de máquinas e motores que operem com o óleo em baixas temperaturas/ ambientes frios

Finalidades: Este aditivo tem a função de envolver os cristais de parafina que se formam a baixas temperaturas, evitando que eles aumentem e se agrupem, o que impediria a circulação do óleo. Portanto, permite que o lubrificante flua em baixas temperaturas.

i. Atuam no aumentam do índice de viscosidade. Ex.: Poliisobutenos, polimetacrilatos, copolímeros de vinil-acetato, poliacrilatos, poliestireno alcoilados.

Aplicações: Motores de combustão interna.

Finalidades: são empregados para diminuir a variação de viscosidade do óleo em função da temperatura, possibilitando a permanência da película lubrificante em uma faixa ampla de temperatura.

Devido à manutenção de uma viscosidade menor variável, o consumo de lubrificante é reduzido e as partidas do motor em climas frios tornam-se mais fáceis.

O mecanismo dos aditivos aumentadores do índice de viscosidade é o seguinte: - Em temperaturas menores, as moléculas do aditivo estão contraídas em seus invólucros; Em temperaturas elevadas, as moléculas distendem-se em seus invólucros, aumentando de volume. O escoamento do óleo é dificultado, apresentado uma maior viscosidade.

Além dos aditivos citados, existem outros, como os emulsificantes (óleos de corte solúveis, óleos para amaciamento de fibras têxteis, óleos para ferramentas pneumáticas etc.), os de adesividade (óleos para máquinas têxteis etc.), grafite (óleos de moldagem etc.).

Existem alguns aditivos que englobam diversas funções como dispersantes, antioxidantes, anticorrosivos e antidesgaste, são os chamados multifuncionais. 


\subsection{Características:}

As características contempladas pela portaria $N^{\circ} 129$ (3) da ANP são aquelas de maior importância para a caracterização do óleo básico:

a. Aparência: é uma indicação visual da pureza do óleo e permite verificar a presença de contaminantes visíveis.

b. Cor: é mais utilizada como um controle na produção do óleo lubrificante. As variações na cor determinada de um óleo lubrificante podem indicar uma possível contaminação ou indícios de oxidação.

c. Viscosidade: é a medida da sua resistência ao escoamento a uma determinada temperatura. É uma das caraterísticas de maior importância do óleo lubrificante.

d. Índice de viscosidade: é uma indicação da variação da viscosidade do óleo de acordo com a temperatura. Quanto maior o índice de viscosidade menor é a variação da viscosidade com a temperatura, característica esta desejável para os óleos que trabalham em aplicações sujeitas a variações de temperatura.

e. Ponto de fulgor: dá uma indicação da possível presença de compostos voláteis e inflamáveis no óleo. É definido como a menor temperatura, sob determinadas condições de teste, na qual o produto se vaporiza em quantidade suficiente para formar com o ar uma mistura capaz de inflamar-se momentaneamente quando se aplica uma chama sobre a mesma.

f. Ponto de fluidez: é a menor temperatura na qual o óleo lubrificante flui quando sujeito a resfriamento sob condições determinadas de teste. É principalmente controlado para avaliar o desempenho nas condições de uso em que o óleo é submetido a baixas temperaturas ou em climas frios.

g. Índice de acidez total: é uma medida da quantidade de substâncias ácidas presentes no óleo e indica a eficiência do processo de neutralização dos resíduos ácidos resultantes do tratamento do óleo.

h. Cinzas: a quantidade de cinzas presentes no óleo pode ser resultante da presença de compostos metálicos no óleo ou solúveis em água, bem como de outros materiais tais como poeira e ferrugem.

i. Resíduo de carbono Ramsbottom: indica a tendência do óleo à formação de depósitos de carbono, quando submetido a altas temperaturas.

j. Corrosividade ao cobre: dá uma indicação relativa do grau de corrosividade do óleo. 
k. Estabilidade à oxidação: indica a capacidade de resistência à oxidação do óleo quando submetido a longos períodos de estocagem ou sob condições dinâmicas de uso.

1. Emulsão: é um indicativo da capacidade de separação da água do óleo quando submetido a contaminação por água.

m. Perda por evaporação: avalia as perdas dos hidrocarbonetos mais leves do óleo quando submetido a temperaturas elevadas, o que levaria ao maior consumo do óleo e alteração de suas características.

\subsection{Análises:}

No caso do óleo novo, faz-se necessário o monitoramento dos contaminantes presentes nos óleos por meio de um controle de qualidade que assegure suas propriedades lubrificantes (16). Para tanto utiliza-se a norma padrão : ABNT NBR 14066 (5).

No caso do óleo lubrificante usado arrasta todo tipo de impurezas geradas pelo desgaste dos componentes internos dos motores. Desta forma faz-se necessário um acompanhamento das propriedades físico químicas e dos teores de metais para determinar o momento apropriado de trocá-los. Além disso pode-se monitorar o desgaste dos motores através da análise dos teores de metais presentes no óleo usado.

\subsubsection{Físico-químicas}

Para se atingirem as características desejadas em um óleo lubrificante, realizam-se análises físico-químicas, que permitem fazer uma pré-avaliação de seu desempenho.

Algumas destas análises não refletem as condições encontradas na prática, mas são métodos empíricos que fornecem resultados comparativos de grande valia quando associado aos métodos científicos desenvolvidos em laboratórios (15).

Algumas das análises realizadas com os lubrificantes:

a. Viscosidade: é a medida de resistência ao escoamento de um fluido, é a principal propriedade dos óleos lubrificantes. A medida é feita a $40^{\circ} \mathrm{C}$ ou $100^{\circ} \mathrm{C}$. A viscosidade diminui devido à contaminação por solvente ou óleos de menor viscosidade. A viscosidade aumenta devido à oxidação, presença de insolúveis, água e contaminação por óleos de maior viscosidade (18). 
b. Índice de viscosidade: é um número admensional que mede a intensidade de variação da viscosidade em relação à temperatura. Quanto maior o Índice de Viscosidade, menor é a variação da viscosidade em função da temperatura (18).

c. Pontos de fluidez: é a menor temperatura na qual o óleo lubrificante flui quando sujeito a resfriamento sob condições determinadas de teste. É principalmente controlado para avaliar o desempenho nas condições de uso em que o óleo é submetido a baixas temperaturas ou em climas frios (19).

d. Cinzas: a quantidade de cinzas presentes no óleo pode ser resultante da presença de compostos metálicos no óleo ou solúveis em água, bem como de outros materiais, tais como poeira e ferrugem (19).

e. Corrosão em lâmina de cobre: Este valor define as características de proteção corrosiva do óleo lubrificante. Este ensaio determina o comportamento do óleo em relação ao cobre e as suas ligas (19)

f. Ponto de fulgor (ou de lampejo) e ponto de inflamação (ou de combustão): $O$ Ponto de Fulgor representa a temperatura que o óleo deve atingir para que uma chama passada sobre a superfície inflame os vapores.

O Ponto de Inflamação representa a temperatura que o óleo deve atingir para que uma chama passada sobre a superfície inflame os vapores formados e sustente a combustão (18).

\subsubsection{Químicas}

\subsubsection{Relações dos metais com aditivos:}

A concentração destes metais é determinada com objetivo de controlar a qualidade dos óleos lubrificantes. Encontra-se descrita na TAB.1. 
TABELA 1 - Relação dos metais com aditivos (20).

\begin{tabular}{|c|c|}
\hline $\begin{array}{c}\mathrm{Ca}, \mathrm{Mg} \\
\text { ou } \\
\mathrm{Ca}+\mathrm{Mg}\end{array}$ & $\begin{array}{l}\text { Indica a presença de aditivos detergentes/dispersantes, utilizados } \\
\text { para manter as superfícies limpas e os materiais insolúveis em } \\
\text { suspensão, além de inibir a formação de ácidos. }\end{array}$ \\
\hline $\mathbf{Z n}$ & $\begin{array}{l}\text { Os ditiofosfatos de zinco (ZDDPs) são aditivos que funcionam } \\
\text { como antioxidantes inibidores de corrosão e, principalmente, } \\
\text { antidesgastes. O zinco que é o principal deles, ele vai sendo } \\
\text { depositado nas peças promovendo, assim, uma proteção } \\
\text { adicional ao sistema. O zinco é essencial nos Motores e } \\
\text { Sistemas Hidráulicos. }\end{array}$ \\
\hline $\mathbf{P}$ & $\begin{array}{l}\text { Indica a presença de um aditivo antioxidante, inibidor de } \\
\text { corrosão, antidesgaste e de extrema-pressão, que suporta } \\
\text { elevadas cargas de engrenamento sem partir o filme de óleo. }\end{array}$ \\
\hline Mo & $\begin{array}{l}\text { Indica a presença de aditivos modificadores de atrito, que } \\
\text { facilita o deslizamento entre as peças. }\end{array}$ \\
\hline $\mathbf{S i}$ & $\begin{array}{l}\text { Indica a presença de um aditivo antiespumante, que é utilizado } \\
\text { em praticamente todos os óleos. Isto justifica a presença de } \\
\text { silício até mesmo nas amostras de óleo novo. O valor médio } \\
\text { encontrado é próximo a } 10 \mathrm{ppm} \text {, mas não gera desgaste por ser } \\
\text { uma molécula orgânica não abrasiva. Todos os valores } \\
\text { encontrados a partir de } 20 \mathrm{ppm} \text { podem indicar uma } \\
\text { contaminação externa por poeira, que é altamente abrasiva. }\end{array}$ \\
\hline
\end{tabular}

\subsubsection{Elementos determinados em óleo usado e suas relações com o desgaste do motor: (TAB.2)}


TABELA 2 - Metais de desgaste encontrados em análises de óleos lubrificantes usados e áreas de possíveis falhas de componentes de motor. (21)

\begin{tabular}{|c|l|}
\hline $\begin{array}{l}\text { Metais } \\
\text { presentes }\end{array}$ & Indicação por desgaste \\
\hline $\mathbf{A l}$ & Pistões, rolamentos, bombas, rotores, tuchos de bombas. \\
\hline $\mathbf{B}, \mathbf{N a}$ & Furos no sistema de resfriamento \\
\hline $\mathbf{F e}$ & $\begin{array}{l}\text { Cilindros, engrenagens, anéis, eixo, virabrequim, rolamentos, } \\
\text { bomba de óleo, compressor de ar, eixo de comando de válvulas, } \\
\text { impurezas, corrosão, bomba de óleo. }\end{array}$ \\
\hline $\mathbf{C r}$ & $\begin{array}{l}\text { Anéis, rolamentos, cubos de freio, cilindros e partes de sistemas } \\
\text { hidráulicos. }\end{array}$ \\
\hline $\mathbf{C d}$ & Rolamentos \\
\hline $\mathbf{C u}$ & $\begin{array}{l}\text { Buchas, rolamentos, discos de transmissão, Arruelas de } \\
\text { encosto, mancais. }\end{array}$ \\
\hline $\mathbf{S i}$ & Contaminação pelo ar \\
\hline $\mathbf{N i}$ & Rolamento e válvulas \\
\hline $\mathbf{S n}$ & Rolamentos \\
\hline $\mathbf{P b}$ & Rolamentos \\
\hline
\end{tabular}

\subsection{Técnicas:}

Das técnicas mais utilizadas para análise de óleos lubrificantes, podemos destacar: AAS, ICPOES, ICP-MS, FRX.

\subsubsection{Espectrometria de absorção atômica (AAS)}

Os elementos a serem determinados são atomizados (ou seja, vaporização e quebra de ligações moleculares). Os atomizadores de chama (FAAS) e eletro-térmico, por exemplo, forno de grafite (GFAAS) são os mais comumente utilizados. Cada elemento atomizado absorve um comprimento de onda característico durante a excitação com a luz, que é utilizado para identificação do elemento (ou seja, a determinação qualitativa). A concentração do elemento (ou seja, quantitativa determinação) é determinada pelo grau de absorção de comprimento de onda esta característica (22).

Mesmo apresentando baixa sensibilidade em relação a outras técnicas espectroanalíticas e característica mono-elementar, a F AAS se mantém como uma 
importante técnica para determinação de metais em óleos lubrificantes. Isto se deve, ao seu baixo custo e robustez em relação á tolerância das chamas utilizadas á maioria dos solventes orgânicos, além disso é considerada uma técnica simples e de alta velocidade analítica (7).

Comparada com a FAAS a técnica de GFAAS é mais sensivel, possibilita a inserção de amostras sólidas sem a necessidade de preparo, uso de menores quantidades de amostra e menor interferências físicas, porém sua velocidade analítica é muito menor (23).

\subsubsection{Espectrometria de Emissão Óptica ( ICPOES)}

Nesta técnica os elementos a serem determinados são atomizados / ionizados e exitados com plasma indutivamente acoplado(ICP).

Ao contrário da AAS, cada elemento emite um ou vários comprimentos de onda característicos após a excitação. Mais uma vez, estes comprimentos de onda são usados para identificação do elemento (ou seja, a determinação qualitativa). A concentração do elemento (ou seja, a determinação quantitativa) é determinada pela intensidade da luz emitida nos comprimentos de onda característicos (22).

É a técnica mais utilizada na determinação de metais em óleos lubrificantes, provavelmente devido à determinação multielementar e baixo limite de detecção (7). Apesar destas vantagens, é também conhecida a dificuldade que o ICP apresenta na presença de óleos (em função da viscosidade) e introdução de solventes orgânicos ( ocasionam o ressecamento do sistema e instabilidade do plasma), tornando difícil a análise direta de amostras de óleo diluído em solvente orgânico. Além disso, esta técnica apresenta um custo relativamente alto para análise de rotina.

\subsubsection{Espectrometria de massa acoplada ao plasma indutivo (ICP-MS)}

Uma das técnicas mais sensíveis, é a combinação da excitação do ICP com a espectrometria de massa. Os elementos a serem determinados são atomizados / ionizado e excitado por um plasma indutivamente acoplado (ICP). Um analisador de massa (por exemplo, filtro de massa de quadrupolo) separa os íons de acordo com a sua razão massacarga pela aplicação de campos electromagnéticos (22).

\subsubsection{Fluorecência de Raios- X}

A técnica XRF baseia-se no fato de que, quando uma amostra é bombardeado com raios-X, elétrons são ejetados dos vários níveis de energia dos átomos-alvo. Raios-X com 
energias discretas são emitidos. Cada elemento tem uma distribuição de eletron único; assim, cada elemento produz um espectro de raios X secundário único cuja intensidade é proporcional à concentração elementar na amostra (22).

\subsubsection{Vantagens e desvantagens das técnicas}

Conforme mencionado anteriormente, cada uma das técnicas fornece vantagens e desvantagens, dentre elas (22):

\section{$>\quad$ Principais vantagens:}

- ICPOES e ICP-MS: Análise multielementar e baixo limite de detecção.

- FAAS e GFAAS: Baixo custo e tolerância a solventes orgânicos.

- FRX: baixo custo de análise, geralmente requer baixo consumo de reagentes e vidraria, gera pouco ou nenhum resíduo, determinações múltiplas e simultâneas, não destrutiva, sensibilidade nível ppm e excelente precisão e exatidão.

\section{Principais desvantagens:}

- ICPOES e ICP-MS: Dificuldade na presença de solventes orgânicos, alto custo.

- FAAS : Baixa sensibilidade.

- FAAS e GFAAS: Mono-elementar.

- ICPOES, ICP-MS e FAAS: Efeito matriz, interferência de transporte, alteração na temperatura da chama.

- FRX: Dificuldade em fazer análises quantitativas precisas em amostras sem qualquer preparação, pois este método sofre de efeito matriz. Alto custo da instrumentação, várias interferências e problema para encontrar padrões correspondentes as amostras.

\subsection{Métodos de preparo}

Estão descritas na literatura diversas estratégias para de preparo de amostras para análise de óleos lubrificantes, a maioria exige processos demorados e/ou com a geração de rejeitos. Dentre os métodos mais comumente utilizados podemos destacar: 


\subsubsection{Diluição em solvente orgânico}

Devido a praticidade e rapidez a análise direta da amostra diluida em solvente orgânico é bastante utilizada. Padrões orgânicos são requeridos para a construção da curva de calibração para análise de óleos, porém, são caros e difíceis de preparar. Além disso, a presença de espécies inorgânicas insolúveis em óleo lubrificante usado gera problemas na repetitividade e falsos resultados. Quando utilizado com as técnicas de ICPOES e ICP-MS, a presença de vapores orgânicos no plasma ocasiona sua instabilidade e extinção (24).

\subsubsection{Digestão ácida}

A amostra é digerida com ácidos inorgânicos sob aquecimento em blocos digestores ou microondas, até a completa decomposição da matéria orgânica, com isso há a possibilidade de calibração utilizando padrões inorgânicos aquosos. É um processo demorado, com alto consumo de reagentes, possibilidade de contaminação, baixa reprodutibilidade e perda de analítos (12).

\subsubsection{Pastilhas prensadas / fundidas}

No processo de preparação de pastilhas prensadas, para análise via FRX, a amostra seca e pulverizada, com o auxilio de uma prensa é submetida a ação de uma força onde ocorre a eliminação do ar entre as partículas.

No processo de preparação de amostras fundidas, a amostra devidamente seca e pulverizada é submetida à fusão com um material fundente, tais como o tetraborato de lítio, metaborato de lítio ou uma mistura de ambos. Ao fundir o material temos a formação de uma pérola vítrea, homogênea (22).

\subsubsection{Depósito em substrato de papel}

Este é o método de preparo de amostras utilizado neste trabalho. As amostras foram depositadas de modo uniforme em papel de filtro e para tanto se realizou um estudo do processo de deposição das amostras (vide capítulo 8, subcapitulo 8.2). 


\section{ESPECTROMETRIA DE EMISSÃO ÓPTICA COM PLASMA INDUZIDO POR LASER (LIBS)}

\subsection{Um pouco de história}

Em meados de 1960 ocorreu a construção do primeiro laser de rubi.

Em 1962, nascimento do LIBS com o experimento realizado por Brech (25) que utilizou laser de rubi para produzir vapores na superfície de materiais metálicos e não metálicos.

Em 1964, LIBS torna-se uma técnica espectrométrica para a análise direta de amostras, com o experimento realizado por Runge et al (26) onde foram construídas curvas analíticas baseadas nas emissões de linhas atômicas e/ou iônicas de crômio e níquel, detectadas diretamente no plasma induzido na superfície de amostras de aço.

Na década de 1970 as empresas empresas Jarrell-Ash Corporation e VEB Carl Zeiss, disponibilizaram no mercado alguns equipamentos comerciais (LIBS), porém, o interesse pela técnica LIBS entrou em declínio devido ao alto custo da instrumentação e baixo desempenho, quando comparada com GFAAS e ICPOES (27).

Nos anos 80, após o desenvolvimento de lasers pulsados com maior energia por pulso - alta potência (e.g. > $50 \mathrm{~mJ})$ e mais rápidos (e.g. < $10 \mathrm{~ns})$, acarretaram o renascimento pelo interesse em LIBS.

A partir de 1995, com o desenvolvimento dos detectores de estado sólido ICCD (intensified charge-coupled device), que possibilitam melhor resolução temporal nas medidas espectroscópicas e melhor discriminação entre o espectro de emissão dos analitos e o espectro de fundo devido à emissão do continuum do plasma e o crescimento do número de trabalhos publicados sobre LIBS (maior nos últimos 10 anos), impulsionaram o renascimento da técnica.

Apesar de esta técnica ser utilizada desde 1960, a grande maioria dos equipamentos são originários de pesquisas universitárias, isso quer dizer que cada centro de pesquisa monta o seu próprio LIBS, de bancada, manualmente. $\mathrm{O}$ equipamento utilizado neste trabalho é de origem comercial, isso quer dizer que é um sistema compacto com todos os sistemas integrados e totalmente automatizado e com todas as funções administradas eletronicamente pelo seu software.

Em consulta realizada na página do web of science (28) com o termo laser induced breakdown spectroscopy, é possível observar na FIG.2 o crescimento significativo do número de trabalhos sobre LIBS nos últimos 10 anos. 


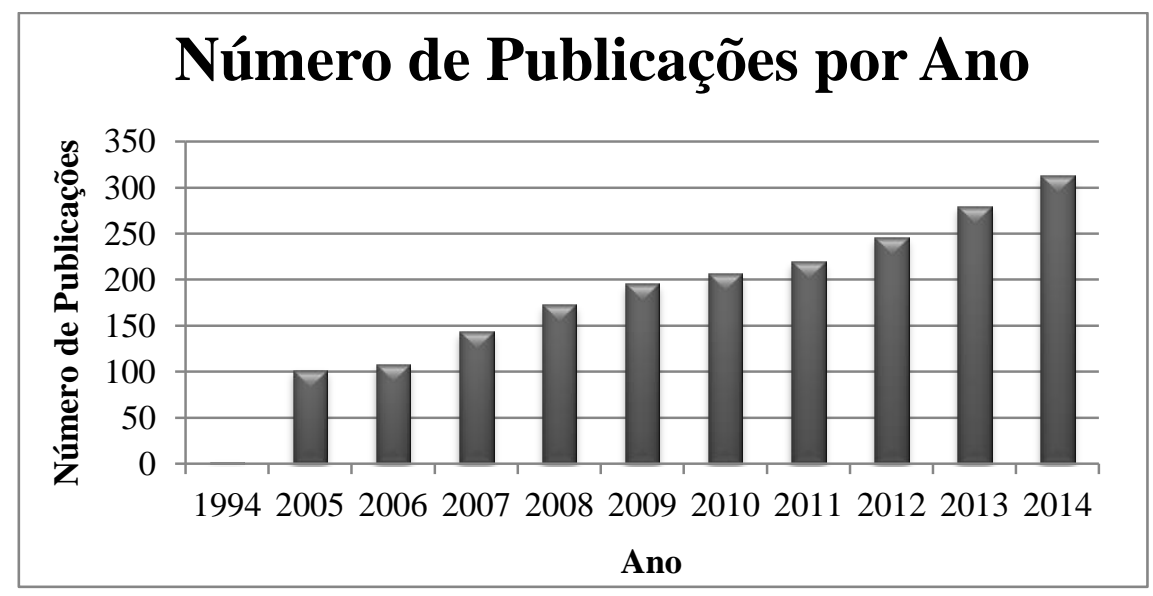

FIGURA 2 - Número de trabalhos sobre espectrometria de emissão óptica com plasma induzido por lasers entre 1994 e 2014

\subsection{Técnica anaítica LIBS}

LIBS é uma técnica espectroanalítica rápida, que emprega a microamostragem por ablação com laser e subsequente excitação dos átomos, íons e fragmentos moleculares presentes no microplasma induzido durante a ablação. Em geral, LIBS utiliza um laser pulsado de 1 a $10 \mathrm{~ns}$, com taxa de repetição entre 1 e $10 \mathrm{~Hz}$ e energia por pulso entre $10 \mathrm{e}$ $200 \mathrm{~mJ}$. O laser é focalizado por uma lente convergente, resultando em irradiâncias da ordem de GW cm-2 para pulsos com duração de ns, provocando a formação de um plasma de alta temperatura (e.g.8000 a $20000 \mathrm{~K}$ ) que vaporiza uma certa quantidade de material (29).

Esta é uma técnica analítica bastante versátil e oferece muitas vantagens em relação às técnicas de análise elementar. Dentre elas:

a. Permite tempo de análises extremamente rápidas $(0,5 \mathrm{~min})$ e in situ;

b. Análise multielementar;

c. Massas amostradas entre 1 e $250 \mu \mathrm{g}$;

d. Pode dispensar totalmente o preparo da amostra;

e. Permite análise de gases, líquidos e sólidos;

f. Possibilita a análise de materiais de difícil dissolução.

g. Rápida varredura na superfície da amostra e diferentes níveis de profundidade;

h. Análise de amostras finas (thin-sample), sem preocupação com a interferência no substrato. 
Um típico limite de detecção de LIBS para elementos metálicos pesados está na faixa abaixo de mg/l. LIBS é aplicável a uma ampla variedade de matrizes de amostra que incluem metais, semicondutores, vidros, tecidos biológicos, isoladores, plásticos, solos, plantas, pintura fina de revestimento e materiais eletrônicos (30).

Um esquema típico de um sistema LIBS é mostrado na FIG.3. O sistema é composto por uma fonte de energia, um laser, uma lente (focalizadora) plano-convexa para focalização do pulso do laser na superfície da amostra, um suporte para fixar a amostra em uma câmara de ablação, unidade de detecção (espectrômetro) e um microcomputador para controle e processamento dos dados.

Quando a lente convergente focaliza o pulso de laser na superfície da amostra, as moléculas componentes do material são dissociadas tanto em átomos, devido à ruptura das ligações moleculares, quanto em íons e elétrons, devido à ruptura das ligações eletrônicas. Essa ruptura (breakdown) é promovida pelo gradiente de campo elétrico intenso do laser que acompanha a focalização (31).

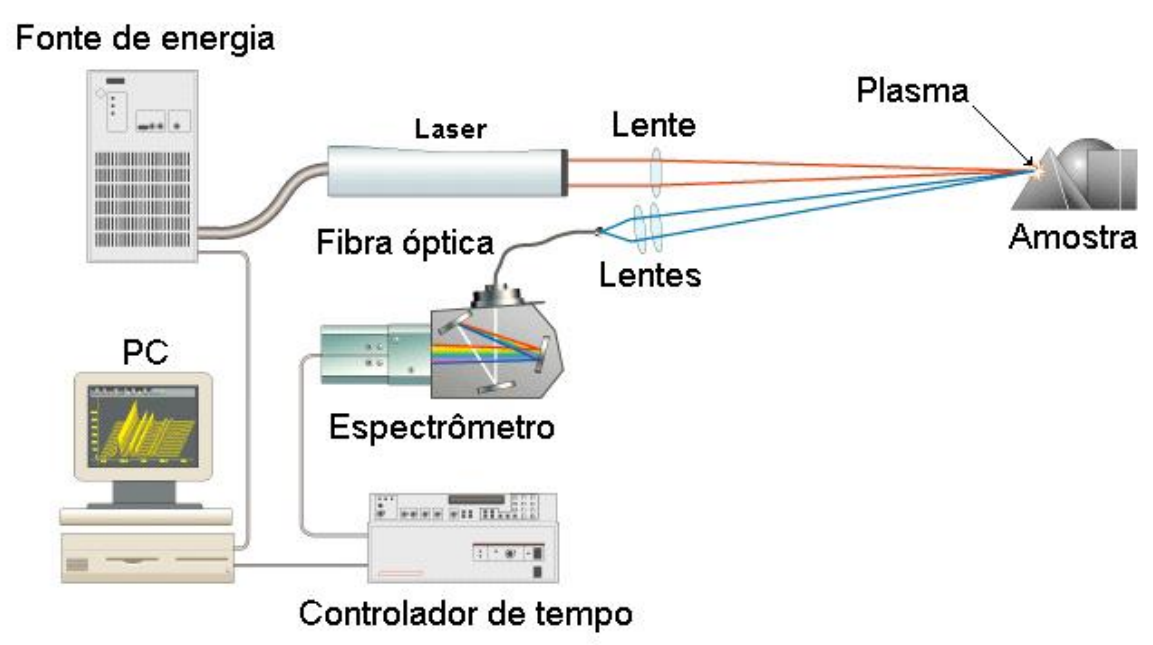

FIGURA 3 - Sistema de LIBS (32).

O principal processo físico, que constitui a essência da tecnologia LIBS é a formação de plasma de alta temperatura, induzida por um curto pulso de laser.

Quando o curto empulso do feixe de laser é focalizado sobre a superfície da amostra, este promove uma microamostragem por ablação de massa (a amostra é removida pelos mecanismos térmicos e não térmicos) - por um processo conhecido como a ablação a laser (33). 
Durante a ablação a laser ocorre à indução da formação de um micro plasma altamente energético que contém elétrons livres, átomos excitados e ions.

Muitos projetos de investigação fundamental têm mostrado que a temperatura do plasma pode exceder $30.000 \mathrm{~K}$ na sua fase de tempo de vida precoce (34).

Quando o empulso de laser termina, o plasma começa a esfriar. Durante o processo de resfriamento do plasma, os elétrons dos átomos e íons dos estados eletrônicos excitados voltam a seus estados fundamentais, fazendo com que o plasma emita luz com discretos picos espectrais - comprimentos de onda característicos - o que possibilita a descrição qualitativa dos componentes da amostra. Parte da luz emitida pelo plasma é capturada por um sistema óptico e transferida para um espectrômetro que dispersa as radiações emitidas pelas espécies atômicas e iônicas excitadas no plasma. Um detector registra os sinais de emissão que são convertidos em espectros . O espectro emitido é usado para determinar os elementos constituintes da amostra (35).

Ao identificar os diferentes espectros podemos determinar rapidamente a composição química das amostras analisadas. Muitas vezes, as informações sobre as intensidades de pico, podem ser utilizadas para quantificar a concentração de traços e de elementos majoritários na amostra.

A FIG.4 demostra o funcionamento do LIBS.
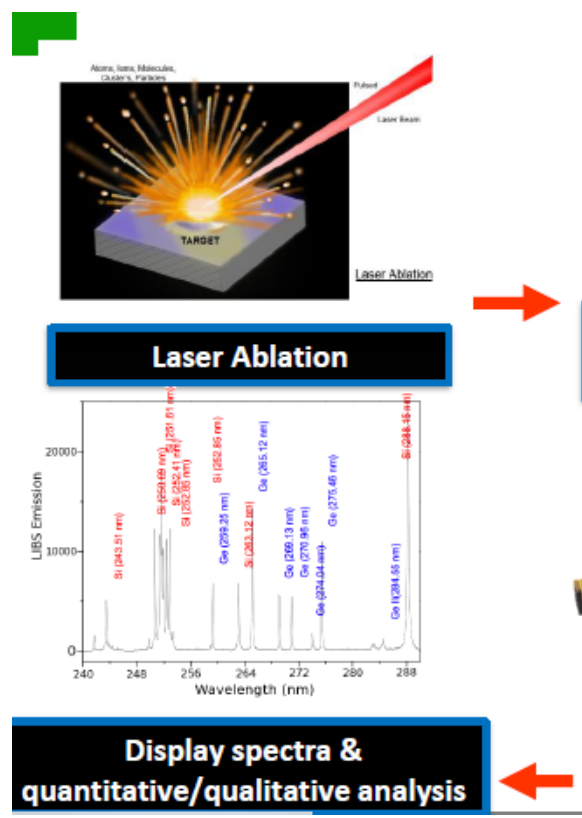
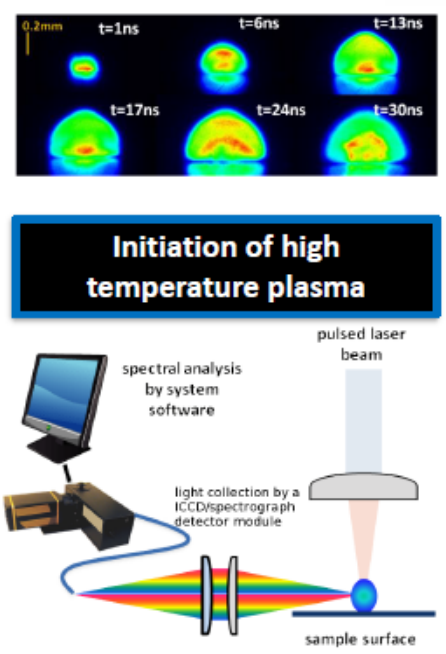

Light Collection

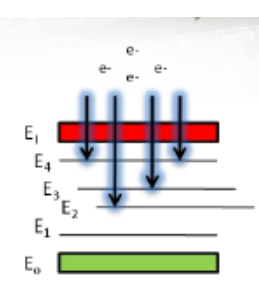

Continuum emission (< $200 \sim 300$ nsec)

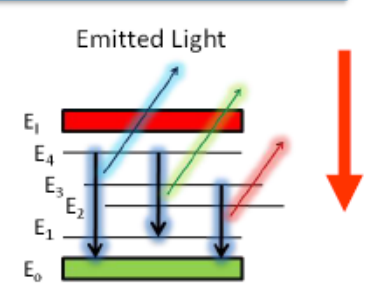

Emission of discrete atomic lines (> 300 nsec)

FIGURA 4- Funcionamento do LIBS (36).

A inicialização, formação e decaimento do plasma são processos complexos. 
A absorção da radiação incidente do laser ocorre por mecanismos de bremsstrahlung inverso e envolve colisões entre fótons, elétrons e átomos ou moléculas. A excitação eletrônica para níveis específicos de energia depende de fatores como o equilíbrio termodinâmico e interações com outros átomos e moléculas, geralmente influenciados pelas características da matriz. Após o término do pulso do laser (tipicamente em $10 \mathrm{~ns}$ ), o plasma decai em um intervalo compreendido por alguns microssegundos, dependendo da energia depositada e pressão da atmosfera de ablação. (37)

O espectro de emissão altera-se em função da evolução temporal do plasma. Nos primeiros instantes, o espectro é caracterizado pela emissão de radiação do continuum e de espécies iônicas excitadas. O continuum é a -luz brancall emitida pelo plasma, proveniente, principalmente, de reações de recombinação dos elétrons livres com os íons e de fenômenos bremsstrahlung. Ao longo do decaimento do plasma, o espectro começa a ser caracterizado por radiação emitida por átomos neutros e, eventualmente, por moléculas simples, formadas pela recombinação de espécies atômicas. $\mathrm{Na}$ prática, durante o decaimento, observa-se uma diminuição da intensidade de emissão de radiação de fundo devida ao continuum (37).

O termo "breakdown" refere-se a um fenômeno coletivo relacionado à ruptura dielétrica das ligações moleculares do material que ocorre anteriormente à formação do plasma e envolve propriedades da amostra, tais como elasticidade e compressibilidade. As propriedades da amostra também determinam os mecanismos de deposição e dissipação de energia em que ocorre o processo de ablação, formação do plasma, excitação, emissão atômica e/ou molecular (38).

Os principais fatores que afetam as determinações feitas por LIBS são as propriedades intrínsecas do laser (e.g. comprimento de onda, duração do pulso, número de pulsos, taxa de repetição, configuração do conjunto óptico de focalização e respectiva fluência), as propriedades da amostra (e.g. distribuição do tamanho das partículas, densidade e porosidade das pastilhas de material vegetal moído), a atmosfera de ablação (e.g.tipo de gás e pressão) e as condições das medidas de emissão óptica (e.g. coleta da radiação emitida pelo plasma, seleção de linhas atômicas e iônicas, tempo de atraso e tempo de integração das medidas) (39).

Esses fatores devem ser estudados e cuidadosamente selecionados para cada aplicação analítica (40).

Os processos físicos envolvidos na interação entre o laser e a amostra, na expansão dinâmica do plasma e em outros fenômenos envolvidos na ablação com laser, são 
dependentes da matriz e, principalmente, da fluência do laser.58, 62, 63 Neste sentido, para cada aplicação, selecionam-se a energia por pulso e o diâmetro de focalização do laser que resultem na fluência que proporcionará as melhores características analíticas como, por exemplo, a melhor razão sinal-ruído (SNR) e os menores coeficientes de variações (CVs). A escolha da fluência deve considerar o tipo de material a ser ablado, os níveis de energia de excitação das linhas de emissão dos analitos e o arranjo óptico do sistema LIBS (41).

Desvantagens da técnica: limites de detecção, sensibilidade para alguns elementos, análise de amostras sólidas, preferencialmente, ausência de padrões sólidos cerfiticados.

Dificuldades encontradas: estudo da melhor maneira de realizar o depósito em substrato de papel, seleção do comprimento de onda adequado, otimização dos parâmetros instrumentais. 


\section{VALIDAÇÃO DA METODOLOGIA}

Uma vez estabelecida às condições do equipamento é necessário avaliar a exatidão da metodologia analítica. A validação do método é realizada para garantir que a metodologia analítica é exata, reprodutível sobre uma faixa específica que uma substância será analisada.

A metodologia analítica desenvolvida foi validada por meio da análise do material de referência certificado NIST em 1084a. Foi utilizado como guia o documento “Orientação sobre validação de métodos analíticos”, doq-cgcre-008 do Inmetro (42).

\subsection{Linearidade}

A quantificação requer que se conheça a dependência entre a resposta medida e a concentração do analito. A equação da reta que relaciona as duas variáveis é: (42)

$y=\mathbf{a}+\mathbf{b} x$

Sendo:

$y=$ resposta medida (absorbância, altura ou área do pico, etc.);

$x=$ concentração;

$a=$ interseção com o eixo y, quando $x=0$;

$b=$ inclinação da curva analítica $=$ sensibilidade.

Para construção da curva analítica neste trabalho foi utilizado o padrão de óleo S-21 multielementar da Conostan de 500ppm (SCP Science, Champlain, NY) (43), este padrão foi diluído com branco em óleo para diluições (vide certificado de análise do branco anexo) para obter todos os pontos da curva (12,5ppm; 25ppm; 50ppm; 75ppm; 100ppm; 300ppm).

Calcular o modelo através da regressão linear, os resíduos e o coeficiente de correlação linear $(r)$. Este é frequentemente utilizado para indicar o quanto a reta pode ser considerada adequada como modelo matemático para o estudo de caso. Uma alternativa para avaliar a linearidade seria a realização da análise de variância (ANOVA) na regressão (42).

O coeficiente de determinação, também chamado de $\mathbf{R}^{2}$, é uma medida de ajustamento de um modelo estatístico linear generalizado. $\mathrm{O} \mathrm{R}^{2}$ varia entre 0 e 1 , 
indicando, em percentagem, o quanto o modelo consegue explicar os valores observados. Quanto maior o $\mathrm{R}^{2}$, mais explicativo é o modelo, melhor ele se ajusta à amostra.

\subsection{Tendência/ Recuperação}

A tendência pode ser expressa como recuperação analítica, definida como (42) :

$$
\frac{\text { valorobservado }}{\text { valoresperado }} \times 100 \%
$$

Nota: A exatidão é avaliada numericamente por meio da tendência

\subsection{Limite de Detecção e de Quantificação}

O limite de detecção é a menor quantidade de analito que pode ser detectada com certo nível de segurança (44). É calculado pela seguinte equação (42):

$\mathrm{LD}=3 * \sigma_{\text {branco }} / \mathrm{S}$

Onde: $\sigma_{\text {branco }}=$ é o desvio padrão das dez leituras (cps) do branco $(\mathrm{n}=10)$. $\mathrm{S}=$ é o coeficiente angular ou inclinação da curva de calibração.

O limite de quantificação (LQ) é a menor concentração do analito que pode ser quantificado com um nível de precisão e exatidão aceitável. Na pratica, corresponde normalmente ao padrão de calibração de menor concentração (excluindo o branco) (42). É calculado pela seguinte equação:

$$
\mathrm{LQ}=10 * \sigma_{\text {branco }} / \mathrm{S}
$$

\subsection{Precisão / Repetitividade}

O termo precisão é utilizado em circunstancias especificas de medição. Ela pode ser expressa por meio da repetitividade de uma medida, considerando-se as mesmas condições de metodologia, instrumentação, observador e local. A repetitividade pode ser quantificada por meio do desvio padrão relativo.

O coeficiente de variação ( $\mathrm{CV}$, usualmente expresso em \%), também conhecido como desvio padrão relativo (DPR), é calculado da seguinte forma: 
$C . V=D P R=D P / C M D \times 100$

Sendo:

$\mathrm{DP}=$ desvio-padrão;

$\mathrm{CMD}=$ concentração média determinada.

\subsection{Erro Relativo}

Uma forma de avaliar a exatidão do método é por meio do cálculo do erro relativo (ER), expresso em percentagem por meio da expressão: (42)

$$
E R=\frac{X_{l a b}-X_{v}}{X_{v}} .100
$$

Sendo:

$X l a b=$ valor obtido experimentalmente ou média aritmética de valores obtidos;

$X v=$ valor aceito como verdadeiro (valor certificado do MRC). 


\section{INCERTEZA DA MEDIÇÃO}

Toda a incerteza está sujeita a algum grau de variabilidade. Esta variabilidade pode vir de diferentes fontes, como: o instrumento de medição, o item medido, o ambiente, etc e representam a incerteza analítica da medida. A estimativa da incerteza considera todas as fontes de erros do procedimento analítico. Portanto, ao ser associada com uma medida analítica, permite um melhor entendimento do processo de medição. E torna-se uma parte essencial deste processo, pois facilita a inter-comparação de resultados obtidos por diferentes laboratórios e metodologias (45).

As fontes de incerteza consideradas neste trabalho foram: as pesagens da amostra e do Material de referência certifcado (MRC) e balança utilizada; o MRC e a curva de calibração; também entram nos cálculos os números de replicatas das amostras, o número de vezes que cada padrão de calibração é analisado, o desvio padrão obtido no MRC e a concentração obtida da análise do MRC para cada elemento.

\section{Identificação das fontes de incerteza}

Fontes de incerteza na espinha de peixe para determinação da incerteza padrão combinada na concentração do elemento (FIG.5):

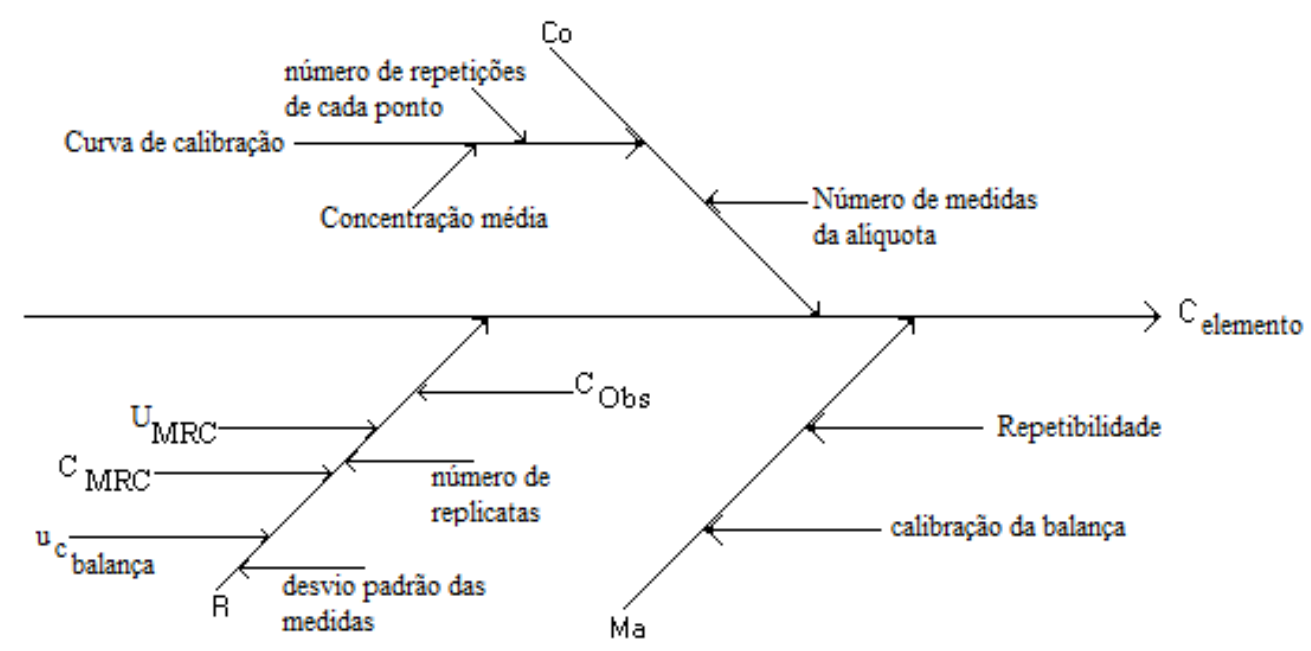

FIGURA 5 - Diagrama de causa-efeito das fontes de incerteza associada à medição. 
Onde:

$\mathbf{C}_{\mathbf{0}}=$ concentração na alíquota da amostra analisada $=$ As influências dessa fonte são a curva de calibração e o número de medidas da alíquota - para obter o valor médio de concentração dessa alíquota. A curva de calibração, por sua vez, é influenciada pelo número de repetições de cada ponto da curva e o valor da concentração média dessa curva. $\mathbf{R}=$ recuperação $=$ As influências dessa fonte são a incerteza combinada $\left(\mathrm{u}_{\mathrm{c}}\right)$ da balança utilizada na preparação do MRC (combinada por calibração da balança e sua repetibilidade); concentração do $\mathrm{MRC}\left(\mathrm{C}_{\mathrm{MRC}}\right)$; incerteza expandida do $\mathrm{MRC}\left(\mathrm{U}_{\mathrm{MRC}}\right)$; concentração observada na leitura da solução do $\mathrm{MRC}\left(\mathrm{C}_{\mathrm{obs}}\right)$; número de replicatas da solução do MRC e desvio padrão obtido da leitura das replicatas.

$\mathbf{M a}=$ massa de amostra $=\mathrm{A}$ influência nessa fonte é incerteza combinada $\left(\mathrm{u}_{\mathrm{c}}\right)$ da balança utilizada na preparação da amostra (combinada por calibração da balança e sua repetibilidade.

\section{$>$ Cálculo da Incerteza:}

A estimativa de incerteza é comumente baseada no ISO GUM (45). Nela estão contempladas as incertezas de todas as componentes de padrão das medições, que são combinadas quadraticamente de forma a se obter a incerteza combinada $\left(\mu_{c}\right)$ (eq.7).

$$
u_{c}=\sqrt{\sum_{i=1}^{n} u\left(x_{i}\right)^{2}}
$$

Onde:

$\mathrm{u}_{\mathrm{c}}=$ incerteza combinada;

$\mathrm{u}(\mathrm{xi})=$ incerteza padrão.

A incerteza padrão u(xi) para cada entrada é avaliado pelos seguintes critérios: tipo A, que considera o desvio padrão da média de uma serie de observações; tipo B. que considera todas as informações disponíveis, tais como as fontes externas, certificados de calibração, incerteza do fabricante e o julgamento baseado na experiência do especialista.

O resultado final de uma medição é expresso de forma a permitir um fator de abrangência associado ao nível de confiança escolhido, que é determinado a partir do 
calculo de grau de liberdade efetivo ( eq. 8) e seu correspondente fator de abrangência dado pela distribuição t-Student. Isso se faz necessário para garantir que a distribuição de uma pequena população amostral seja Gaussiana.

$$
v_{e f f}=\frac{u_{c}^{4}}{\sum_{i=1} \frac{u_{i}^{4}}{v_{i}}}
$$

Onde:

$\mathrm{V}_{\text {eff }}=$ grau de liberdade efetivo;

$\mathrm{u}_{\mathrm{c}}=$ incerteza combinada;

$\mathrm{u}_{\mathrm{i}}=$ incerteza padrão;

$\mathrm{v}_{\mathrm{i}}=$ grau de liberdade de cada incerteza padrão.

Um nível de confiança de $95.45 \%$ corresponde a um fator de abrangência de $\mathrm{k}=2,00$ e um nível de confiança de 99,73\% a um $\mathrm{k}=3,00$. Portanto, a incerteza expandida (U) é calculada pela seguinte equação:

$\boldsymbol{U}=\boldsymbol{u}_{\boldsymbol{c}} \boldsymbol{k}$

Onde:

$\mathrm{U}=$ incerteza expandida;

$\mathrm{u}_{\mathrm{c}}=$ incerteza combinada;

$\mathrm{k}=$ fator de abrangência.

Os resultados das medições foram expressos como a média das medidas seguidos pelos valores de suas incertezas expandidas, na forma: $\bar{y} \pm U$ (45). 


\section{FERRAMENTAS ESTATISTICAS UTILIZADAS NA AVALIAÇÃO DOS RESULTADOS: QUIMIOMETRIA}

Uma vez conclusa a validação do método, a parte final deste trabalho dedicou-se a avaliar a qualidade da metodologia proposta em amostras reais de óleos usados.

Fez-se uso de ferramentas estatisticas sequenciais, como a equação Estatísticas Stuarges e o teste de Kruskal-Wallis, com o intuito de avaliar e interpretar o grande número de amostras com múltiplas variáveis.

\subsection{Equação de Sturges}

No cálculo do número de classes, na maioria dos casos, é necessário definir arbitrariamente o número de CLASSES, ou categorias, que integram observações individuais da mesma ordem de grandeza, com que vamos elaborar a tabela de frequências (46).

Quando estamos a trabalhando com variáveis contínuas, um modo de resolver esta questão é recorrer à seguinte equação (fórmula de Sturges) para calcular o número de classes $\mathrm{k}$ :

$k=I\left(\log _{2} n\right)+1$

Em que $\log _{2}$ é o logaritmo de base 2, n é o tamanho da amostra e I indica que o resultado deve ser arredondado ao número inteiro mais próximo.

Pode-se obter o número de classes $\mathrm{k}$ através de outra equação, talvez mais simples:

$$
k=I\left(\frac{\log n}{\log 2}\right)+1
$$

Neste caso, utilizam-se logarítmos de base 10 . Se $n \geq 25$ é possível obter $k$ através de $\mathrm{k}=\sqrt{\mathrm{n}}(46)$. 


\subsection{Teste não paramétrico de Kruskal Wallis}

O Teste de KruskalWallis é utilizado quando se deseja testar a hipótese de que várias amostras têm a mesma distribuição (47).

O mesmo se baseia nos postos (ranks) das observações em cada grupo.

O teste de KruskalWallis é calculado pela equação:

$$
H=\left[\frac{12}{(N .(N+1)}\right] \cdot\left[\frac{\sum R_{1}^{2}}{n_{1}}+\frac{\sum R_{2}{ }^{2}}{n_{2}}+\frac{\sum R_{3}{ }^{2}}{n_{3}}\right]-3 \cdot(N+1)
$$

Onde: $\mathrm{N}$ é o número dados em todos os grupos, $\mathrm{n}$ é o número de sujeitos em cada grupo e $\Sigma$ Ré a somatória dos postos em cada grupo.

\subsection{Teste a posteriori de comparações múltiplas de médias (48)}

Frequentemente, uma informação é apresentada na forma de probabilidade condicional.

Probabilidade de um evento $B$, sabendo qual será o resultado de um evento $A$.

Esse tipo de problema é tratado usando o Teorema de Bayes.

A estatística Bayesiana utiliza a experiência do pesquisador para atribuir probabilidades a um evento. Todas as informações que se sabe sobre um parâmetro a ser estimado são expressas através da distribuição a priori. Realizada uma amostragem, obtém-se a obtém-se a distribuição a posteriori.

O Teorema de Bayes relaciona as probabilidades de $A$ e $B$ com suas respectivas probabilidades condicionadas

$$
P(A \mid B)=\frac{P(A) P(B \mid A)}{P(B)}, \operatorname{para} P(B)>0
$$

Onde:

$P(A)$ e $P(B)$ : probabilidades a priori de $A$ e $B$;

$P(B \mid A)$ e $P(A \mid B)$ : probabilidades a posteriori de $B$ condicional a $A$ e de $A$ condicional a $B$ respectivamente. 
$>\quad$ Probabilidade a priori:

Probabilidade dada sem conhecimento de qualquer outro evento.

Probabilidade de tirar um número par num dado: $1 / 2$.

$>\quad$ Probabilidade a posteriori:

É a probabilidade condicional que é atribuída quando um evento relevante é considerado.

Ao lançarmos um dado $N$ vezes, teremos a posteriori que a distribuição dos valores tendem ao previsto a priori. 


\section{PROCEDIMENTO EXPERIMENTAL}

A parte experimental foi desenvolvida no Instituto de Química - IQUSP (com a colaboração da Professora Cassiana Seimi Nomura) em conjunto com o plano de trabalho desenvolvido no Laboratório de Caracterização Química e Isotópica - IPEN.

Etapa1: Foram coletadas de 55 amostras em oficina de troca de óleo.

Etapa2: As amostras foram depositadas em papel de filtro (34 mm de diâmetro e 1,5 mm de largura) depois de realizado estudo de adsorção e avaliação da intensidade de sinal do equipamento em função do tipo de deposição.

Etapa3: Sequêntemente realizou-se otimização dos parâmetros instrumentais, considerando o tipo de interação do laser, a energia do laser, tempo de atraso e diâmetro da área de interação do laser.

Etapa4: Validação da metodologia com a análise do material de referência certificado (MRC) de metais de desgaste, em óleo lubrificante (SRM 1084a) obtidos junto ao Instituto Nacional de Padrões e Tecnologia (NIST, Gaithersburg, MD) (44) (vide certificados de análise dos padróes utilizados em anexo).

Etapa5: Cálculo da incerteza da medição da análise baseada no ISO GUM (45).

Etapa6: Uso de estatística multivariada para interpretação dos dados.

\subsection{Instrumentação}

O equipamento utilizado neste trabalho foi o J200 Tandem LA-LIBS da Applied Spectra (SP - Basil).

A FIG. 6 exibe o equipamento utilizado neste trabalho.

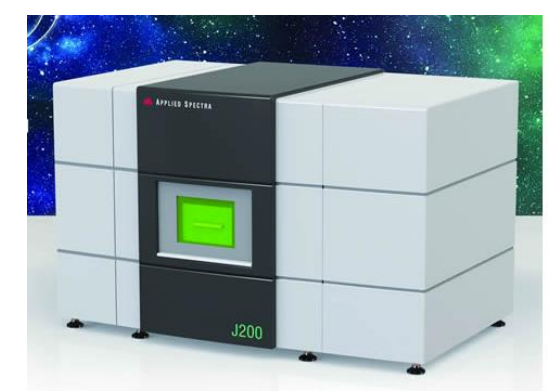

FIGURA 6- LIBS modelo J200 Tandem (36) 


\subsubsection{Parâmetros de Performance (30):}

a. Laser: Q-switched, Nd: YAG.

b. Taxa de repetição: 5 ns (FWHM) e uma variável de 1 a $20 \mathrm{~Hz}$.

c. Controle de Energia: monitoramento integrado de energia do laser.

d. Pulso de energia do Laser: de 4,5 a $100 \mathrm{~mJ} /$ pulso

e. Controle do diâmetro de laser (Laser Spot Size Control): 5 a 250 microns.

f. Detector: Espectrometro CCD de seis canais sincronizados cobrindo a faixa espectral de 190 a 1040nm. Gerador de atraso de pulso (pulse delay) eletronicamente integrado para ajuste do portão de atraso (gate delay) de 50 nanossegundos a $1 \mathrm{~ms}$ com 25 nanossegundos na etapa de resolução.

g. Densidade de Energia: $>20 \mathrm{~J} / \mathrm{cm}^{2}$, fluência baseada no diâmetro do laser na faixa de $3-150$ microns.

h. Ablação no ponto alvo: o laser vermelho funciona como sensor de ajuste automático da altura da amostra que reconhece alterações morfológicas na superfície da mesma. Este recurso permite manter um foco preciso do laser, proporcionando fluência constante do laser e alcançando ablação consistente em todos os locais amostrados, independentemente de superfícies irregulares (FIG.7).

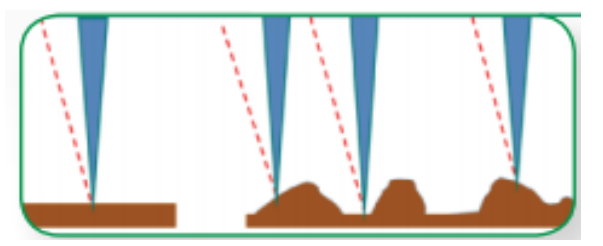

FIGURA 7 - Sensor de ajuste de altura do laser.

\subsection{Amostragem}

Amostras de óleo usadas foram coletadas (55 amostras) em oficina de troca de óleo, variando-se a quilometragem, a marca do carro e a marca do óleo, com o preenchimento de formulários contendo as informações necessárias à pesquisa.

As amostras foram etiquetadas com suas respectivas identificações em tubo Falcon de $15 \mathrm{ml}$. 


\subsection{Preparação das amostras: Estudo do processo de deposição:}

Foram utilizados papéis de filtro (34 $\mathrm{mm}$ de diâmetro e $1,5 \mathrm{~mm}$ de largura) comercialmente, disponíveis. Os papéis de filtro foram cortados e dispostos em suportes de tudo de ensaio de isopor para que o óleo não fosse depositado em nenhuma superfície abaixo do papel, como apresentado na FIG. 8 abaixo:.

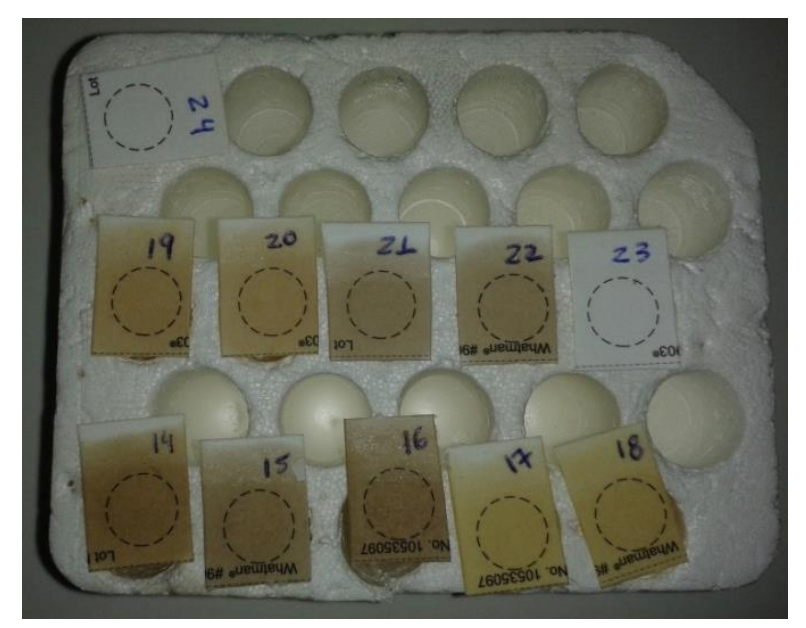

FIGURA 8 - Deposição das no papel utilizando suporte para tubos de ensaio de isopor.

\subsubsection{Avaliação da adsorção:}

Adsorção ativa: deposição do óleo no papel com a utilização da micropipeta.

Adsorção Passiva: com a pipeta de Pasteur, tocar levemente o papel de filtro.

O objetivo deste estudo foi à obtenção de uma deposição centrada e distribuição homogênea das amostras.

Foi avaliada a deposição de amostras em função do aglomerado de partículas, da heterogeneidade na superfície (com a utilização do microscópio) e peso constante (com a utilização da balança analítica de 5 casas).

O método de deposição ativa mostrou-se mais indicado para os objetivos desse trabalho. 


\section{RESULTADOS E DISCUSSÁO}

\subsubsection{Avaliação do melhor tipo de deposição}

Após a avaliação física, na qual se optou pela deposição ativa, foi avaliado o melhor sinal em função no número de gotas e condição da mesma (in natuta / depois de seca). $\mathrm{Na}$ FIG. 9 podemos avaliar a intensidade de sinal em função de diferentes tipos de deposições:

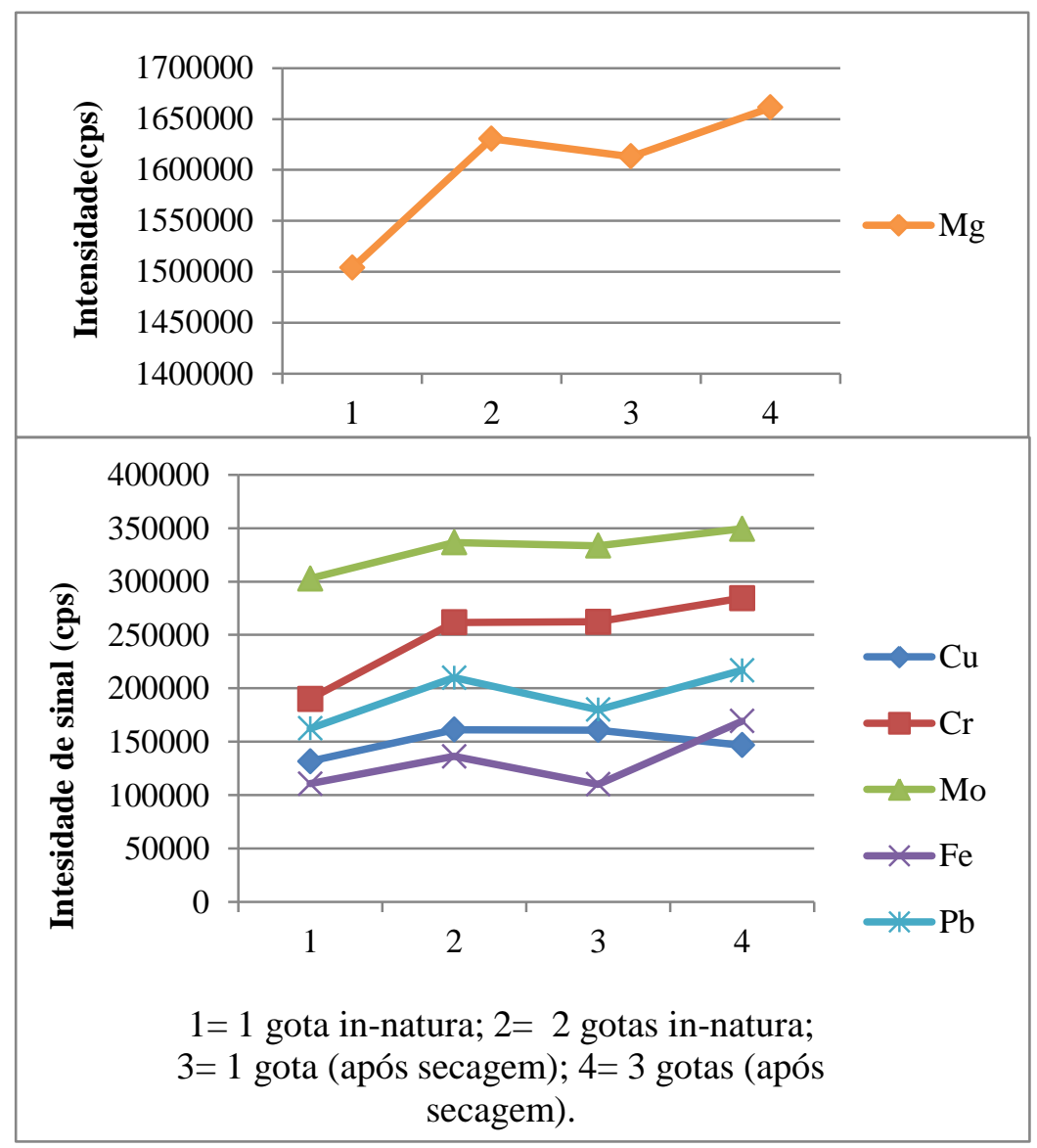

FIGURA 9 - Intensidade de sinal(cps) em função de diferentes tipos de deposições.

Conforme observado na Figura 9 a melhor intensidade de sinal foi alcançada depositando-se 3 gotas de amostra secas ( a secagem das amostras aumentou o fator de adsorção das mesmas), desta maneira, os óleos foram depositadas em substrato de papel gota a gota (total de 3 gotas), de modo que aproximadamente 0,02 g de óleo se espalhassem uniformemente sobre a superfície. As amostras foram colocadas para secar em estufa a uma temperatura de 30 graus por 30 minutos. 
Podemos notar que não ocorre um aumento de sinal proporcional ao depósido de gotas, isso porque o LIBS interage até certa profundidade (pré-determinada), portanto uma maior quantidade de amostras não resulta em maior intensidade de sinal.

\subsection{Comprimento de onda adequado}

Faz-se necessário determinar o melhor comprimento de onda, aquele que possui maior intensidade de sinal para cada elemento, pois para o $\mathrm{Cu}$ por exemplo, para a técnica LIBS encontramos por volta de 25000, já para AAS de 3 a 4 comprimentos de onda, e para ICPOES aproximadamente 1000.

O software do equipamento utilizado neste trabalho tem catalogado na biblioteca, os comprimentos de onda mais sensíveis para cada elemento, cabe ao analista decidir qual o melhor comprimento de onda de acordo com a biblioteca do software ou pesquisa bibliográfica levando em consideração a matriz da amostra. As FIG. 10 - 15 mostram diferentes intensidades de sinal para o mesmo elemento em diferentes comprimentos de onda.

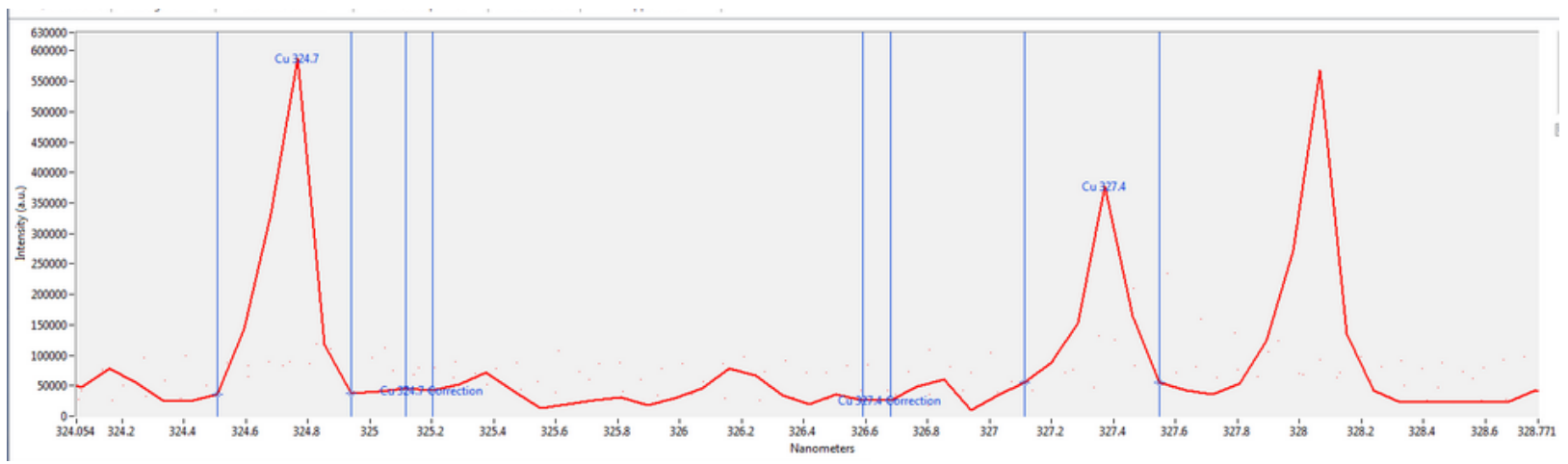

FIGURA 10 - Picos de $\mathrm{Cu}-324,8 \mathrm{~nm}$ e $327,4 \mathrm{~nm}$.

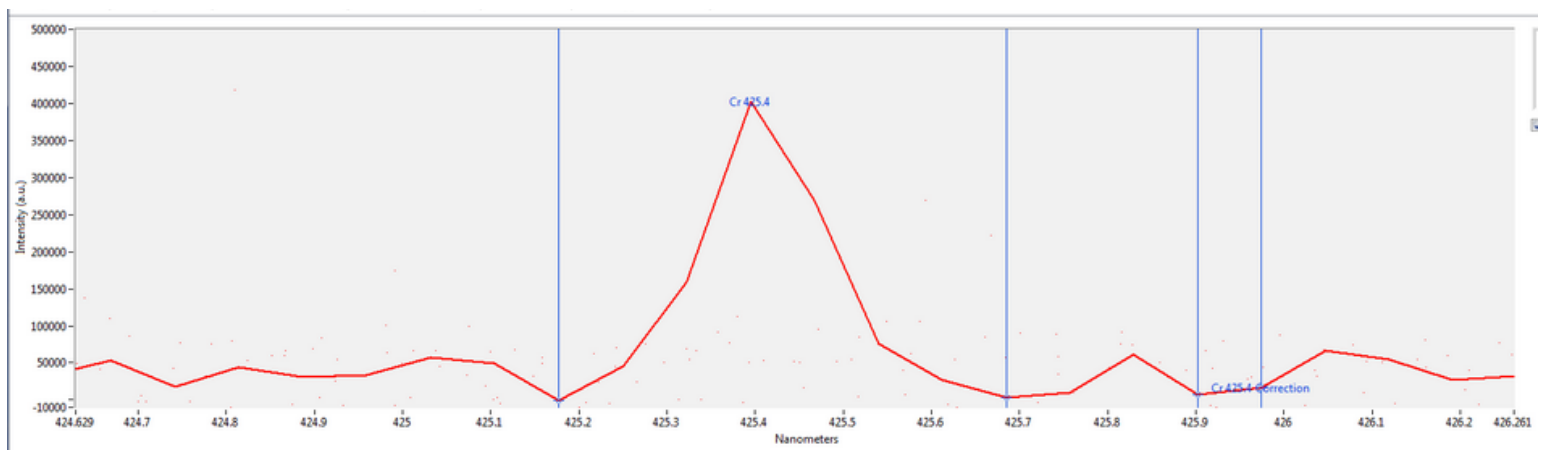

FIGURA 11 - Pico de $\mathrm{Cr}-425,4 \mathrm{~nm}$. 


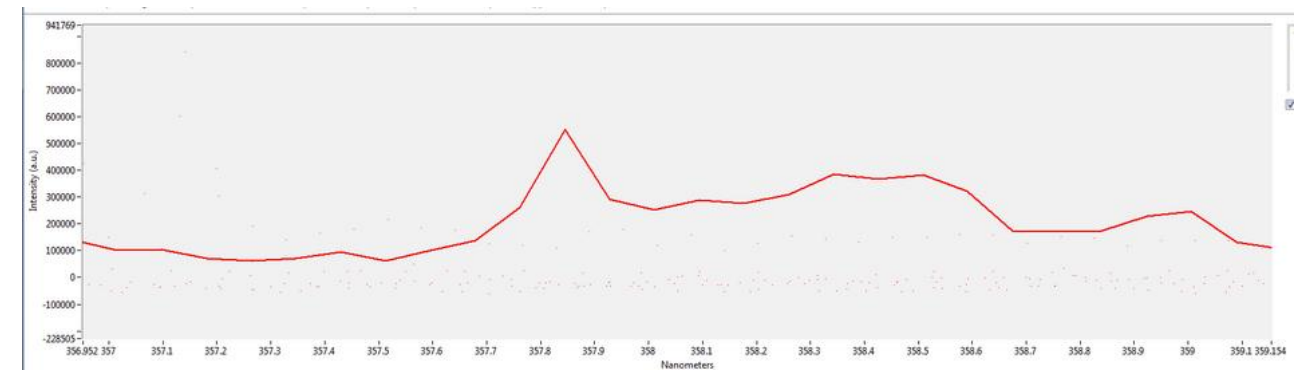

FIGURA 12- $\mathrm{Pico}$ de $\mathrm{Cr}-357,8 \mathrm{~nm}$.

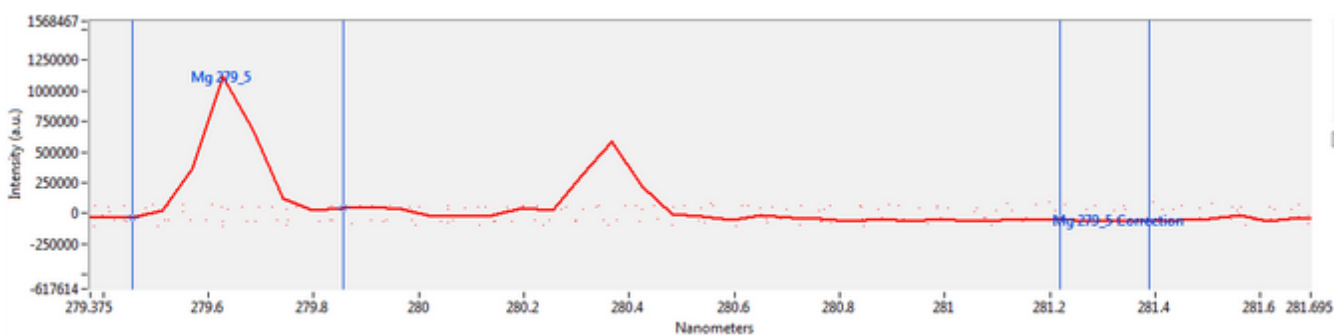

FIGURA 13 - Pico de Mg 279,5nm.

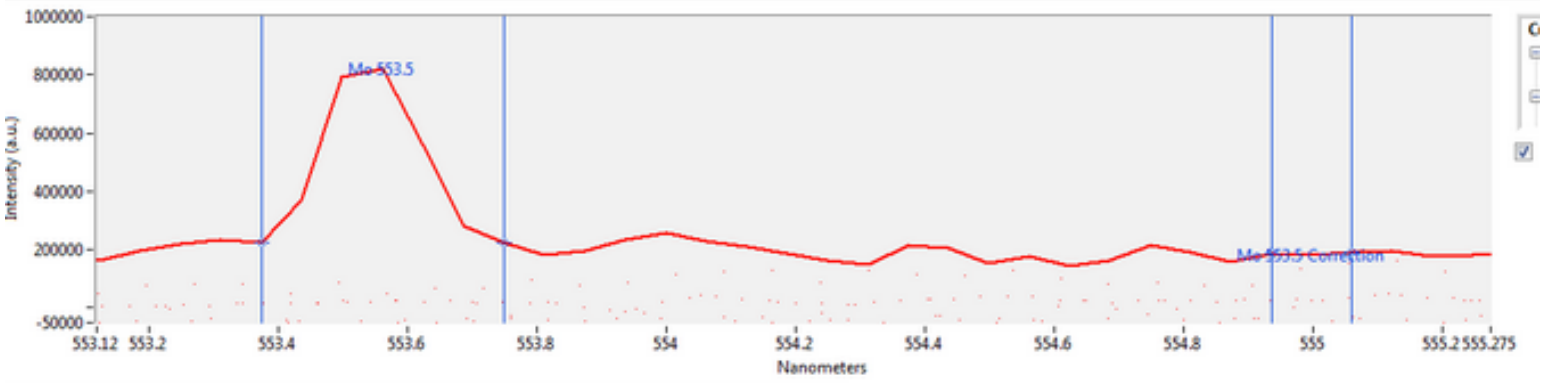

FIGURA 14 - Pico de Mo 553,5nm.

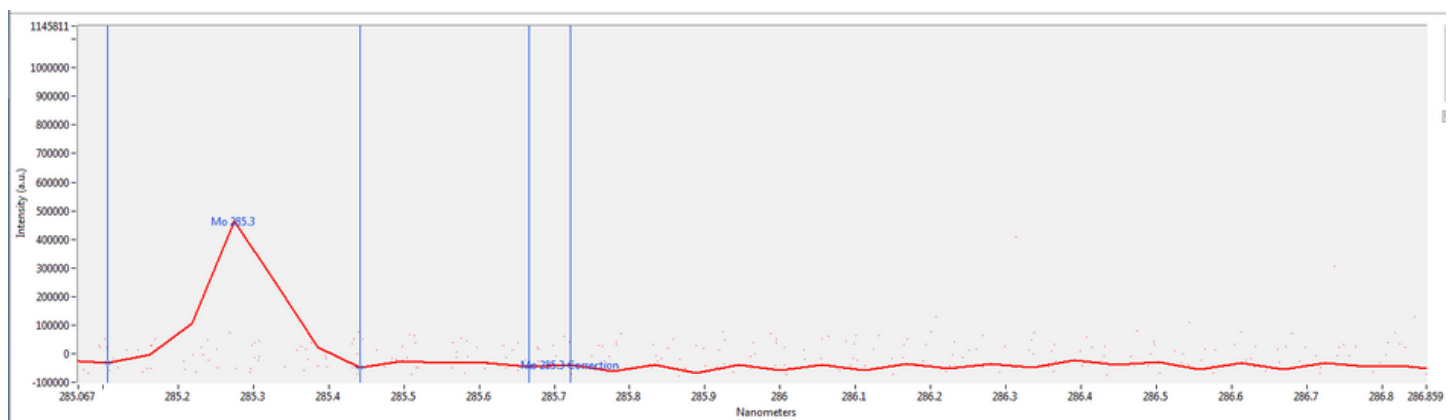

FIGURA 15 - Pico de Mo 285,3nm. 


\subsection{Otimização dos parâmetros instrumentais}

O desenvolvimento de um método multi elementar para análises via LIBS envolve a otimização de parâmetros, tais como, tempo de atraso e tempo de integração do detector, energia de pulso e número acumulado de pulsos de laser, melhor distância entre a lente e a amostra (esta afeta a fluencia do laser, o tamanho da interação com o laser, o volume do plasma, a massa ablada, intensidades de emissão de linha, o sinal de background e a relação sinal-ruído) (49).

\subsubsection{Estudo do sinal em função do tipo de ablação:}

Analisamos os tipos de interação:

$>$ Varredura (Raster): em que o laser realiza ablação em um caminho prédeterminado, observado na FIG.16.

> Point-to-point: laser realiza a ablação ponto a ponto, observado na FIG.17.

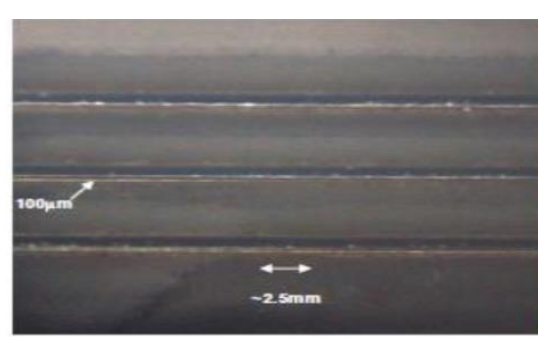

FIGURA 16 - Interação varredura

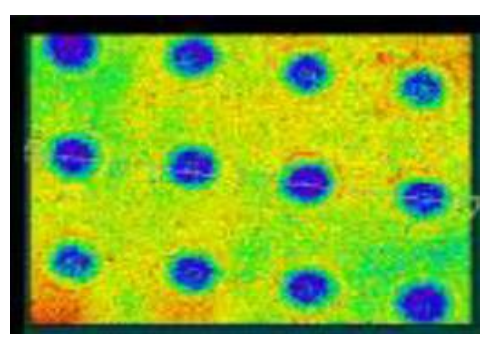

FIGURA 17 - Interação ponto-a-ponto

No caso das nossas amostras com a interação ponto-a-ponto a intensidade de sinal foi muito inferior comparada com a interação tipo varredura. Portanto para o experimento realizamos apenas interações do tipo varredura, alterando o número de pulsos para alcançar um equilíbrio entre a maior intensidade de sinal e menor ruido possível. 
Realizou-se o estudo da intensidade do sinal em função do número de de pulsos com interação do tipo varredura (FIG.18).

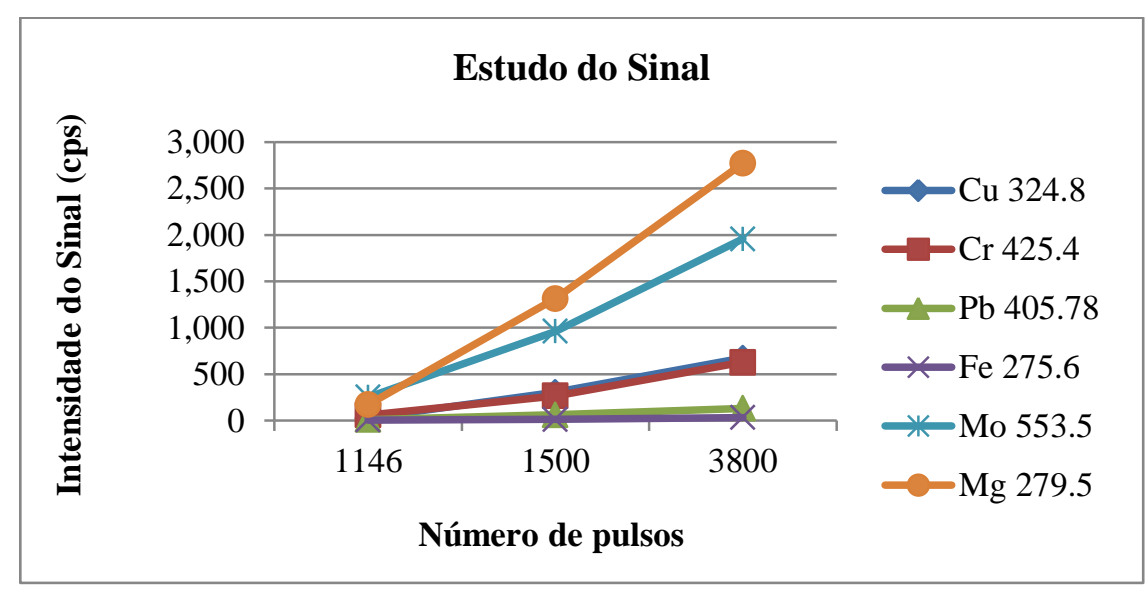

FIGURA 18 - Estudo da variação da intensidade do sinal (cps) em função do número de pulsos.

Na FIG.18 podemos observar que para todos os elementos analisados a intensidade de sinal aumenta com o aumento do número de pulsos para as mesmas condições (energia do laser: $40 \mathrm{~mJ}$; diâmetro da área de interação do laser: $35 \mu \mathrm{m}$ e tempo de atraso: $0,25 \mu \mathrm{s}$ ).

\subsubsection{Otimização da Energia do Laser}

Dentre os fatores mais importantes que influenciam a luz emitida pelo plasma podemos destacar: temperatura, densidade das espécies emissoras e densidade eletrónica. A densidade das espécies emissoras de luz (por exemplo, átomos, molécula, ions, etc) dependem da massa total ablada pelo laser, da temperatura do plasma e do grau de excitação e / ou ionização do plasma. A quantidade vaporizada a partir da superfície, por sua vez, depende da absorção da radiação do laser incidente na superfície, que depende da fluência do laser incidente (energia) (50).

Fluência:

$$
\mathbf{F}=\mathbf{e} / \boldsymbol{\pi} \mathbf{r}^{2}
$$

Onde: $\mathrm{e}=$ energia

Foi investigada a energia do laser em função da intensidade do sinal emitido em busca da melhor intensidade e precisão.

Foi regsutrado na região de 390-650 nm a energias de laser de 20, 30, 40 e $50 \mathrm{~mJ}$ por energias de impulso. A variação de intensidade da linha com as energias do laser para o os elementos analisados é apresentado nas FIG. 19 e 20. 


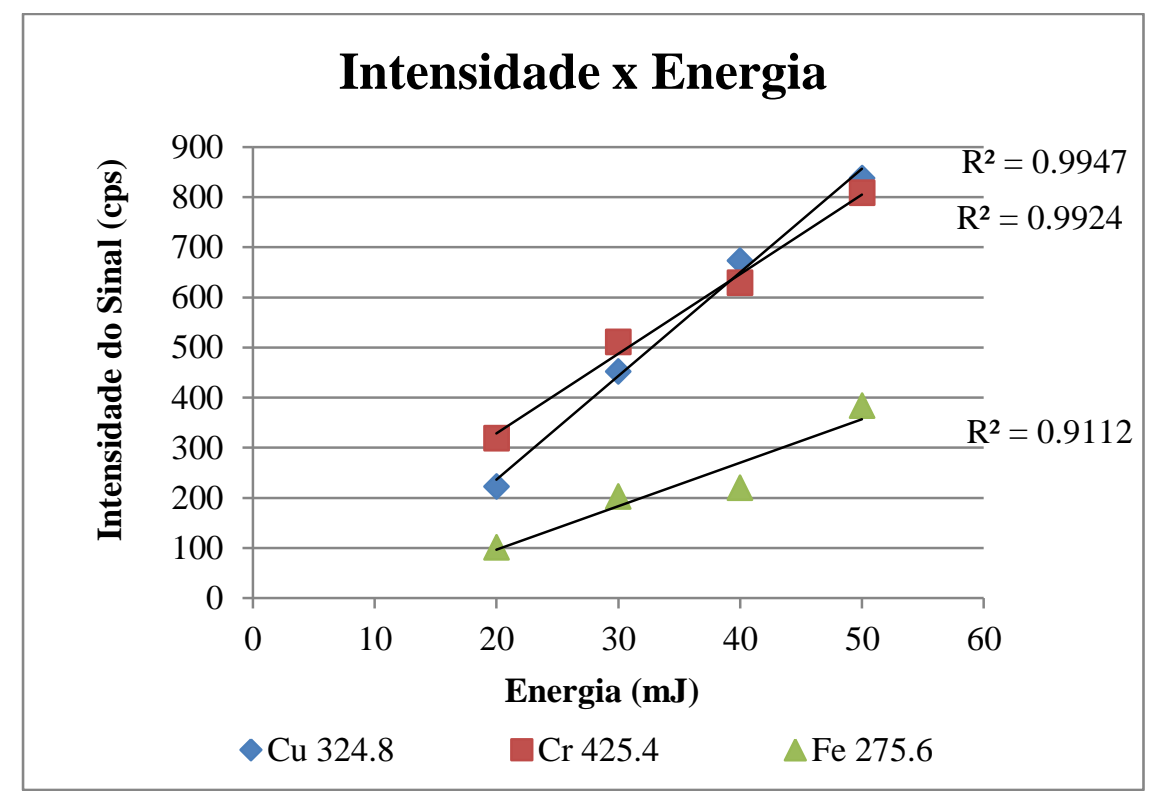

FIGURA 19 - Estudo da variação da intensidade de sinal (cps) em função da energia do laser(mJ) para os elememtos $\mathrm{Cu}, \mathrm{Cr}$ e $\mathrm{Fe}$. Parâmetros fixos: Interação: raster - 3800 tiros;

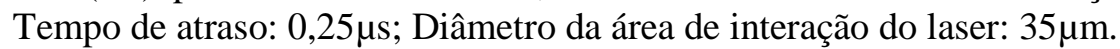

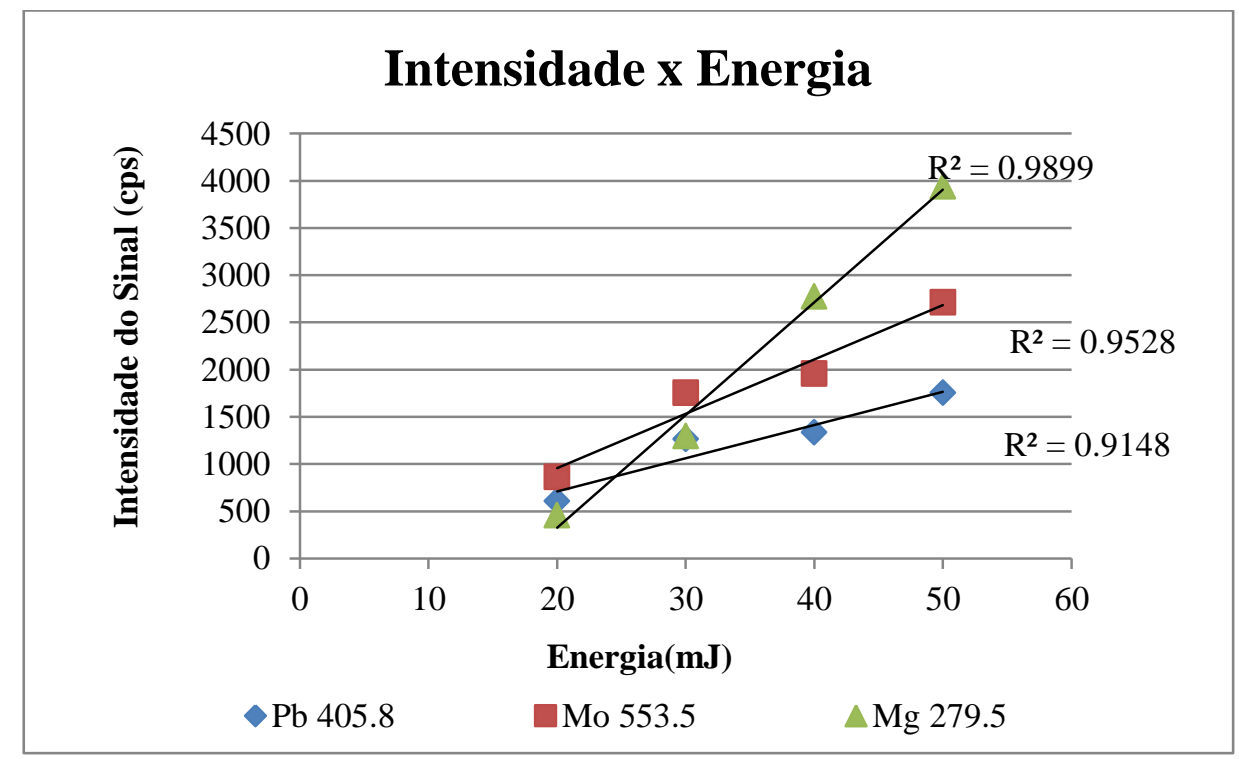

FIGURA 20 - Estudo da variação da intensidade de sinal (cps) em função da Energia do Laser(mJ) para os elememtos Pb,Mo e Mg. Parâmetros fixos: Interação: raster - 3800 tiros;

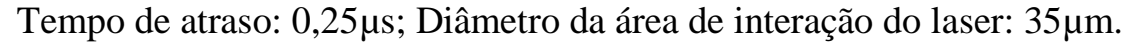

Foi observado que ocorre um aumento da intensidade da energia do laser de $20 \mathrm{~mJ}$ a $50 \mathrm{~mJ}$ por impulso e o sinal LIBS mostra forte dependência linear com a energia do laser, o que é indicado pelo ajuste de mínimos quadrados $>0,9$, indicando que a resposta do equipamento é linear. 
Com as energias de laser mais elevadas, a taxa de aumento torna-se menor. A energia do laser superior gera plasma opticamente espesso e forte contínuo fundo. Isto mostra que pode haver uma região de saturação em maiores energias de impulso de laser. Notou-se durante o estudo que um pulso de $45 \mathrm{~mJ}$ foi suficiente para obter uma intensidade de sinal elevada comparada as demais variações de energia, atendendo a todos os elementos investigados.

\subsubsection{Otimização do Tempo de Atraso (Gate delay)}

Quando um pulso de laser é focado em uma pequena área da amostra, com a alta temperatura o micro plasma é formado. A temperatura deste plasma é tão alta que parte da amostra é vaporizada e ionizada. Nos estágios iniciais de termalização do plasma, como os elétrons interagem e se recombinam com íons, a energia será lançada em uma ampla faixa espectral, a partir do UV visível até próximo ao IR. Os estágios iniciais de plasma resultam em brilho e intensa emissão molecular que é levada ao sistema de detecção. Depois de um intervalo de tempo adequado, o plasma resfria ao ponto em que as emissões atômicas e iônicas podem ser observadas. Assim, o estudo sobre o tempo de atraso entre o pulso de laser e o início do sistema de aquisição é essencial (50).

Foi realizada uma série de medidas com a finalidade de determinar o melhor tempo de atraso, o pulso de laser e o início da aquisição de espectros de LIBS. Conforme esperado, os espectros de LIBS mostram uma dependência dramática ao tempo de atraso, como mostram as FIG. 21 e 22 abaixo.

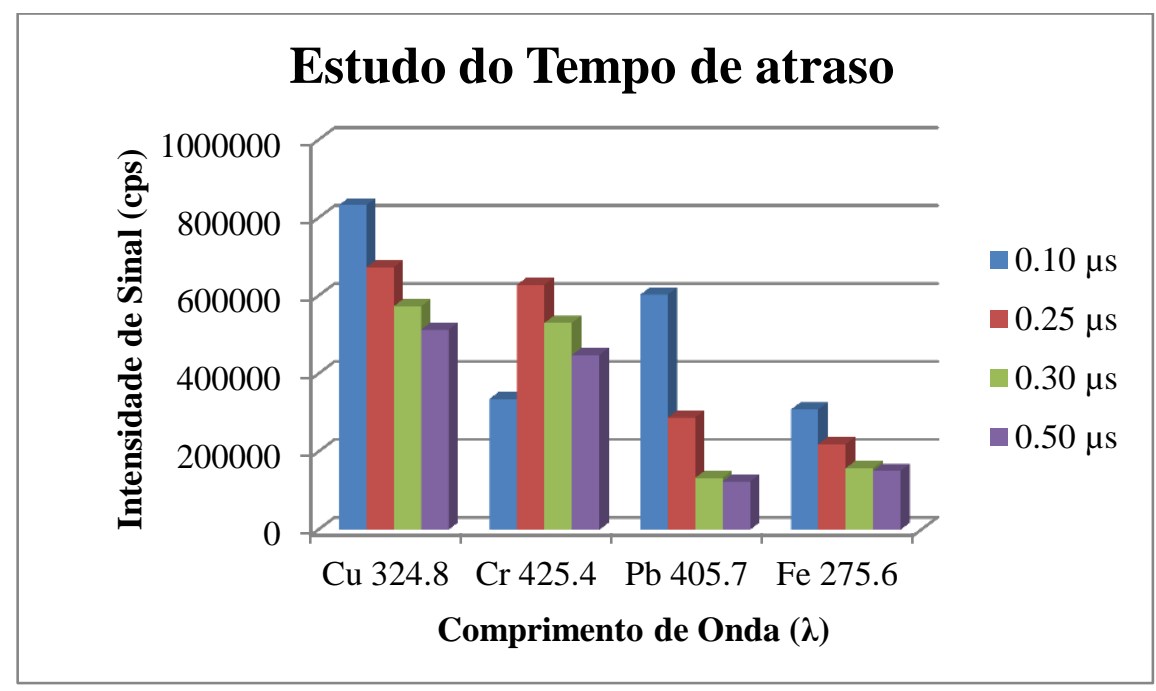

FIGURA 21 - Estudo da variação do tempo de atraso ( $\mu$ s), para os elementos $\mathrm{Cu}, \mathrm{Cr}, \mathrm{Pb}$ e Fe. Parâmetros fixos: Interação: raster - 3800 tiros; Diâmetro da área de interação do laser: $35 \mu \mathrm{m}$; energia do laser: $45 \mathrm{~mJ}$. 


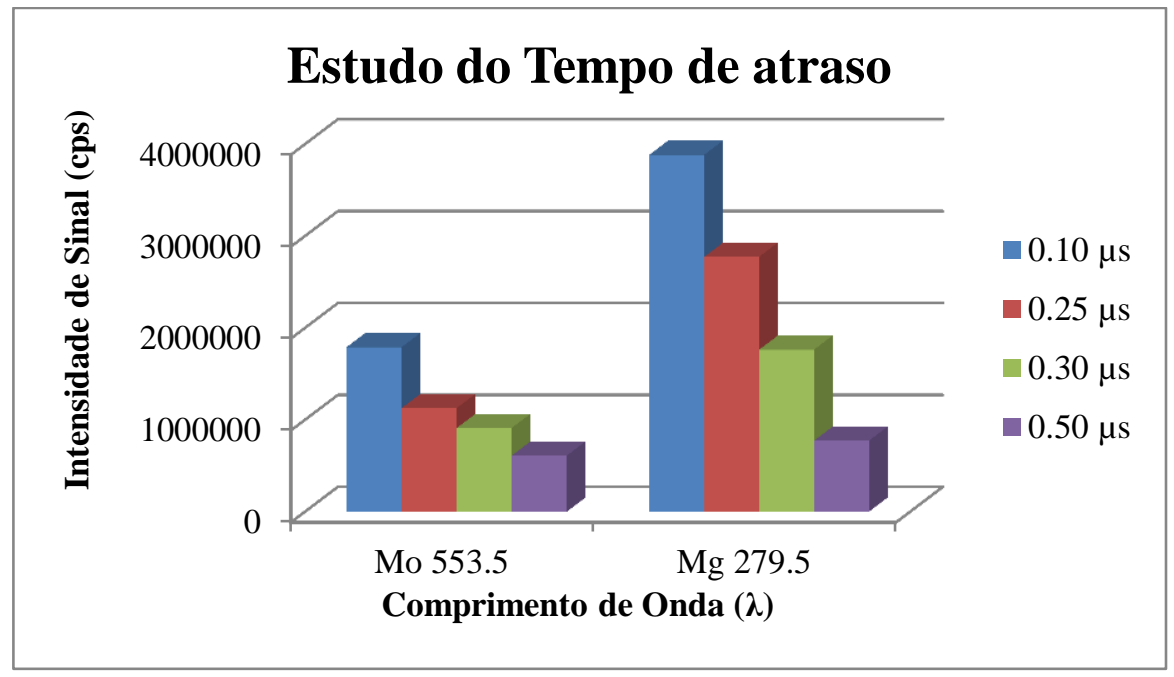

FIGURA 22 - Estudo da variação do tempo de atraso ( $\mu \mathrm{s})$, para os elementos Mo e $\mathrm{Mg}$. Parâmetros fixos: Interação: raster - 3800 tiros; Diâmetro da área de interação do laser: $35 \mu$ m; energia do laser: $45 \mathrm{~mJ}$.

Podemos observar que para todos os elementos a função intensidade de sinal versus tempo de atraso é inversamente proporcional, portanto quanto menor o tempo de atraso, maior a intensidade. Porém a utilização de tempo de atraso muito baixo gera muito ruido, o que gera perturbações nas linhas espectrais.

Foi determinado durante a experiencia que um tempo de atraso de $0,25 \mu$ s foi o suficiente para obter uma intensidade suficiente para atender aos elementos analizados.

\subsubsection{Otimização do diâmetro da área de interação do laser (Spot Size)}

A escolha das dimensões da área de interação do laser com o substrato é um fator preponderante na qualidade do ensaio uma vez que esta diretamente relacionada com a quantidade de material ablado. É importante notar que essa relação não pode ser alterada de forma aleatória, mas sim em conjunto com os fatores anteriormente estudados de forma a garantir simultaneamente o aumento da intensidade do sinal e a manutenção da qualidade do mesmo. Na FIG.23 podemos observar a variação da intensidade de sinal em função do diâmetro da área de interação do laser.

No equipamento utilizado neste trabalho a variação do diâmetro da cratera pode ser realizada na faixa de 35 até $140 \mu \mathrm{m}$. 


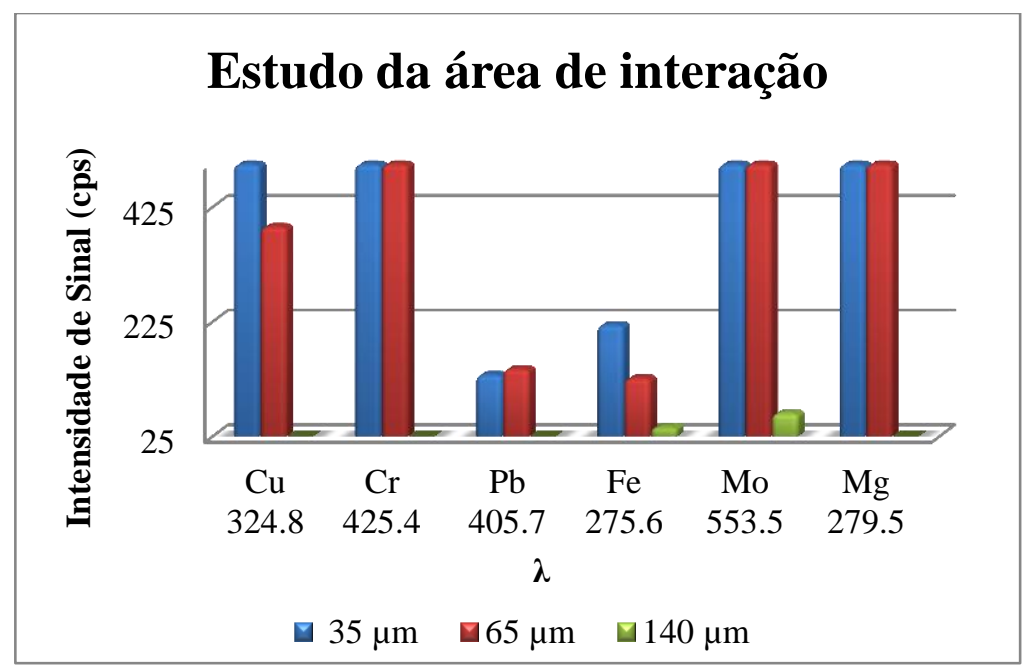

FIGURA 23 - Estudo da variação da intensidade de sinal(cps) em função do diâmetro da cratera $(\mu \mathrm{m})$. Parâmetros fixos: Interação: raster - 3800 tiros; Tempo de atraso: 0,25 $\mu$ s; energia do laser: $45 \mathrm{~mJ}$.

Podemos observar que para todos os elementos investigados a intensidade de sinal diminui com o aumento do diâmetro da cratera, isso porque o quanto menor a área de interação mais denso será o laser e portanto maior o sinal, por outro lado quanto maior a área de interação mais dissipada será a energia do laser e menos será a intensidade de sinal.

Determinou-se durante a experiencia que um diâmetro da cratera de $35 \mathrm{um}$ foi o suficiente para obter uma intensidade suficiente para todos os elementos analisados.

\subsubsection{Resumo dos parâmetros otimizados}

A TAB. 3 Apresenta o resumo dos parâmetros otimizados e utilizados nas análises.

TABELA 3 - Resumo dos parâmetros otimizados.

\begin{tabular}{cc}
\hline Parâmetros & Optimização \\
\hline Tipo de Interação & Raster -3800 tiros \\
Energia do Laser & $45 \mathrm{~mJ}$ \\
Tempo de Atraso & $0,25 \mu \mathrm{s}$ \\
Tamanho da cratera & $35 \quad \mathrm{~m}$ \\
\hline
\end{tabular}




\subsection{Validação do método}

\subsubsection{Linearidade}

No caso dos $\mathrm{R}^{2}$ apresentados nas figuras 24 a 29 todos os valores estão acima de 0,99 , isto significa que $99 \%$ da variável dependente consegue ser explicada pelos regressores presentes no modelo 


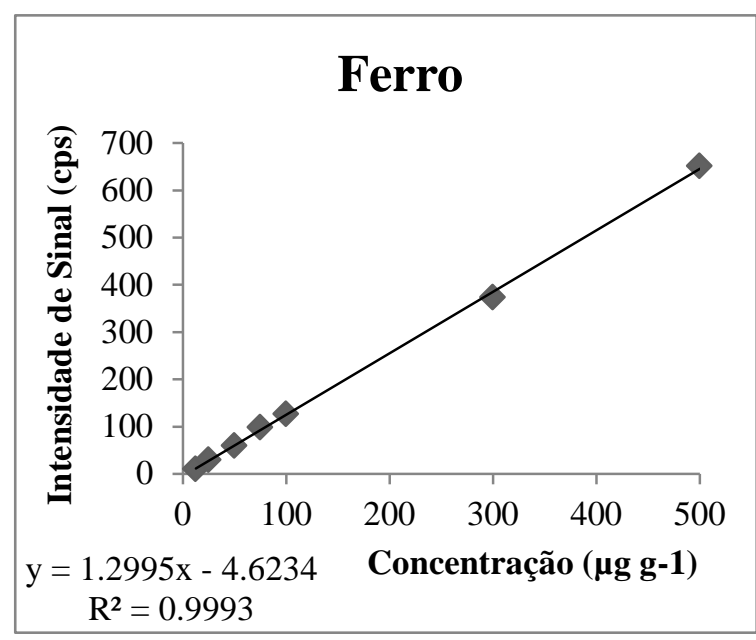

FIGURA 24 - Curva analítica para Fe.

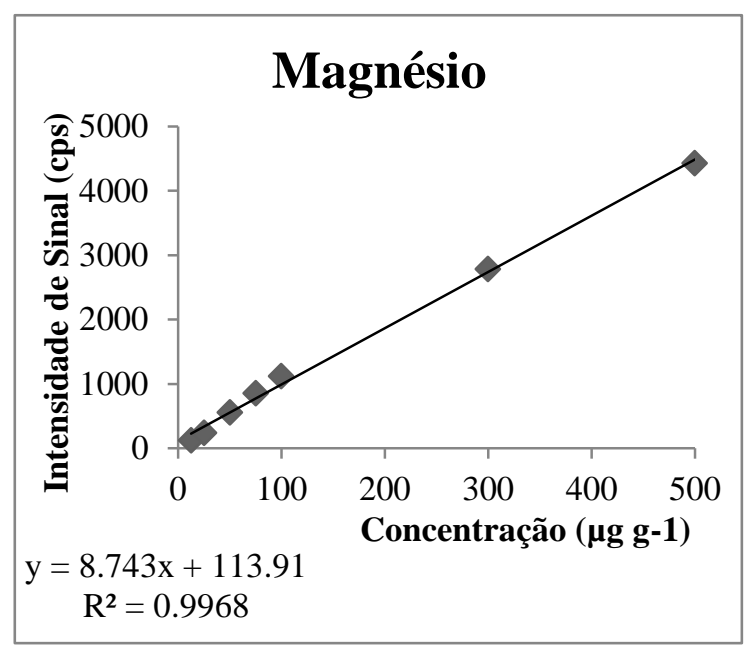

FIGURA 26 - Curva analítica para Mg.

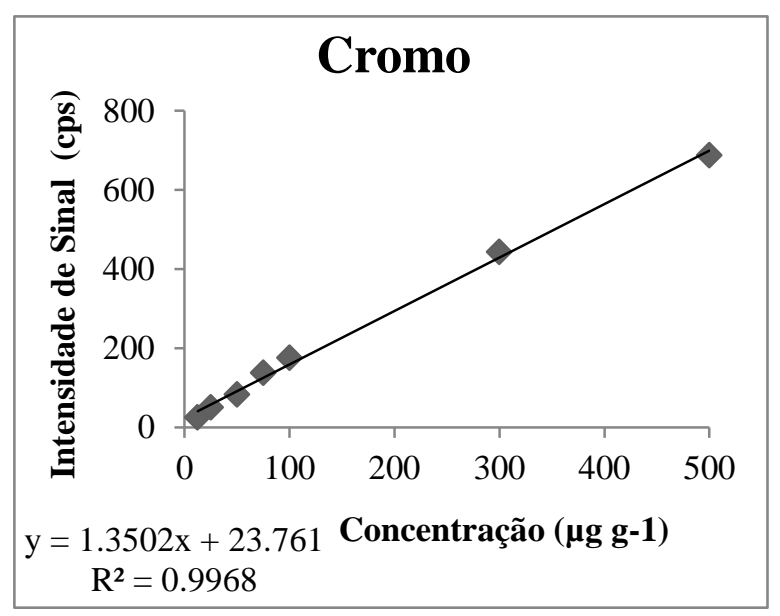

FIGURA 28 - Curva analítica para Cr.

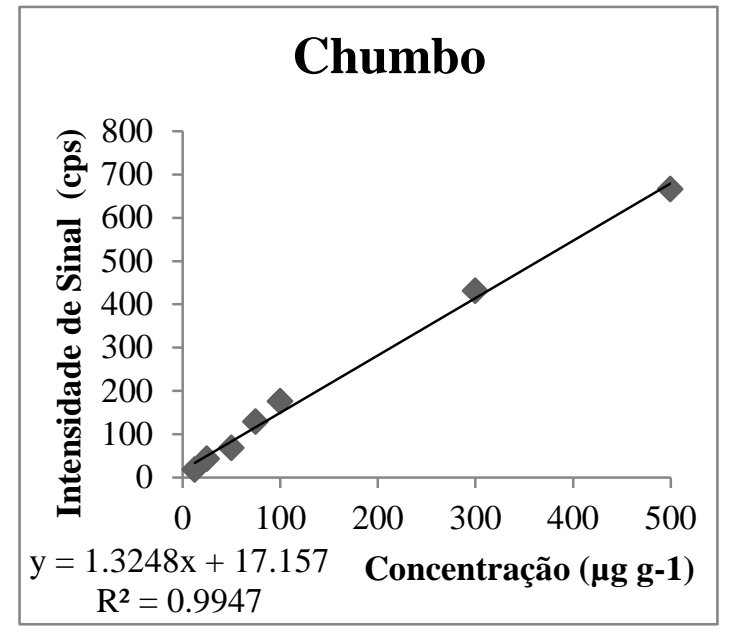

FIGURA 25 - Curva analítica para $\mathrm{Pb}$.

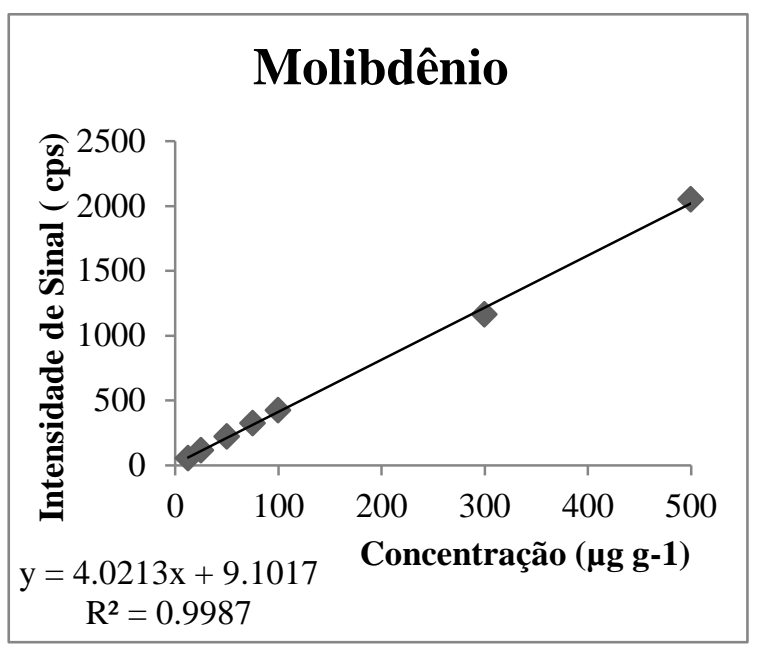

FIGURA 27 - Curva analítica para Mo.

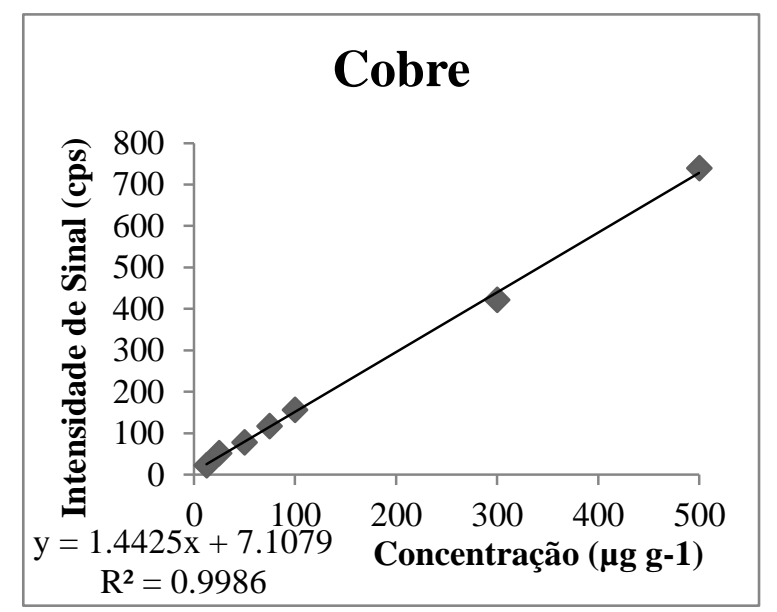

FIGURA 29 - Curva analítica para $\mathrm{Cu}$. 


\subsubsection{Tendência/ Recuperação}

A tendência pode ser expressa como recuperação analítica, apresentada na TAB.4:

TABELA 4 - Recuperação do padrão NIST SRM 1084a.

\begin{tabular}{|c|c|c|c|}
\hline Elemento & $\begin{array}{c}\text { Valor } \\
\text { Observado } \\
\left(\mu \mathrm{g} \mathrm{g}^{-1}\right)\end{array}$ & $\begin{array}{c}\text { Valor } \\
\text { Esperado* }^{*} \\
\left(\mu \mathrm{g} \mathrm{g}^{-1}\right)\end{array}$ & $\begin{array}{c}\text { Recuperação } \\
(\%)\end{array}$ \\
\hline $\mathrm{Cu}$ & 102,5 & 100,0 & 102,5 \\
\hline $\mathrm{Cr}$ & 99,3 & 98,3 & 101,0 \\
\hline $\mathrm{Fe}$ & 93,8 & 98,9 & 94,8 \\
\hline $\mathbf{P b}$ & 99,8 & 101,1 & 98,7 \\
\hline Mo & 102,3 & 100,3 & 101,9 \\
\hline Mg & 101,5 & 99,5 & 102,0 \\
\hline
\end{tabular}

* Valor certificado do MRC (NIST SRM 1084a).

\subsubsection{Limite de Detecção e de Quantificação}

No cálculo do LD e LQ, apresentado na TAB.5, utilizou-se a solução padrão de branco da Conostan (Anexo2: certificados de análises dos padrões utilizados).

TABELA 5 - Limite de detecção e de quantificação.

\begin{tabular}{cccccc}
\hline Elemento & $\begin{array}{c}\text { Comprimento } \\
\text { de Onda } \\
(\mathbf{n m})\end{array}$ & $\begin{array}{c}\text { Média da } \\
\text { leitura dos } \\
\text { Brancos } \\
(\mathbf{c p s})\end{array}$ & Equação da Reta & $\begin{array}{c}\text { LD } \\
\left(\boldsymbol{\mu g} \mathbf{g}^{-1}\right)\end{array}$ & $\begin{array}{c}\text { LQ } \\
\left(\boldsymbol{\mu g} \mathbf{g}^{-\mathbf{1}}\right)\end{array}$ \\
\hline $\mathbf{C r}$ & 425.4 & 2,17 & $\mathrm{y}=1,3502 \mathrm{x}+23,761$ & 4,82 & 16,1 \\
$\mathbf{C u}$ & 324.8 & 3,22 & $\mathrm{y}=1,4425 \mathrm{x}+7,1079$ & 9,69 & 22.3 \\
$\mathbf{P b}$ & 405.7 & 2,85 & $\mathrm{y}=1,3248 \mathrm{x}+17,157$ & 9,45 & 21.5 \\
$\mathbf{F e}$ & 373.7 & 2,56 & $\mathrm{y}=1,2995 \mathrm{x}-4,6234$ & 5,9 & 19,7 \\
$\mathbf{M o}$ & 553.5 & 3,94 & $\mathrm{y}=4,0213 \mathrm{x}+9,1017$ & 2,93 & 9,8 \\
$\mathbf{M g}$ & 279.5 & 7,92 & $\mathrm{y}=8,743 \mathrm{x}+113,91$ & 2,72 & 9,05 \\
\hline
\end{tabular}




\subsubsection{Precisão / Repetitividade}

As condições de repetitividade podem ser caracterizadas utilizando: mesmo procedimento de medição; mesmo observador; mesmo instrumento usado sob mesmas condições; mesmo local, e repetições no menor espaço de tempo possível (45). Apresentado na TAB.6.

TABELA 6 - Estudo do CV ou DPR, 10 repetições.

\begin{tabular}{|c|c|c|c|c|c|c|}
\hline Elemento & $\begin{array}{c}\mathrm{Cr} \\
425.4 \mathrm{~nm}\end{array}$ & $\begin{array}{c}\mathrm{Cu} \\
324.8 \mathrm{~nm}\end{array}$ & $\begin{array}{c}\mathrm{Pb} \\
405.7 \mathrm{~nm}\end{array}$ & $\begin{array}{c}\text { Fe } \\
373.7 \mathrm{~nm}\end{array}$ & $\begin{array}{c}\text { Mo } \\
553.5 \mathrm{~nm}\end{array}$ & $\begin{array}{c}\text { Mg } \\
279.5 \mathrm{~nm}\end{array}$ \\
\hline \multirow{10}{*}{$\begin{array}{c}\text { Leituras } \\
\text { ( cps) }\end{array}$} & 660886 & 711167 & 132556 & 191829 & 2371528 & 3135299 \\
\hline & 634411 & 678837 & 124203 & 206666 & 2483089 & 3577127 \\
\hline & 715660 & 693144 & 135185 & 201511 & 2118923 & 3319312 \\
\hline & 636318 & 772114 & 149730 & 211887 & 2660632 & 3929424 \\
\hline & 629274 & 738573 & 147556 & 217757 & 2423140 & 3195473 \\
\hline & 710349 & 628923 & 131289 & 215888 & 2221625 & 4063703 \\
\hline & 706710 & 628066 & 148157 & 209063 & 2377011 & 4083020 \\
\hline & 592601 & 785716 & 137334 & 226082 & 2589731 & 3641711 \\
\hline & 683977 & 785716 & 125432 & 217354 & 2531582 & 4083020 \\
\hline & 668311 & 768327 & 148299 & 224399 & 2436857 & 3986422 \\
\hline Média & 663850 & 719058 & 137974 & 212244 & 2421412 & 3701451 \\
\hline $\begin{array}{l}\text { Desvio } \\
\text { Padrão }\end{array}$ & 40844 & 60796 & 9829 & 10447 & 162486 & 379648 \\
\hline DPR (\%) & 6 & 8 & 7 & 5 & 7 & 10 \\
\hline
\end{tabular}




\subsubsection{Erro Relativo}

A TAB. 7 apresenta o erro relativo do método.

TABELA 7 - Erro relativo da análise.

\begin{tabular}{|c|c|c|c|}
\hline Elemento & $\begin{array}{c}\text { Valor Obtido } \\
\qquad\left(\mu \mathrm{g} \mathrm{g}^{-1}\right)\end{array}$ & $\begin{array}{c}\text { Valor } \\
\text { Esperado* }^{*} \\
\left(\mu \mathrm{g} \mathrm{g}^{-1}\right)\end{array}$ & $\begin{array}{c}\text { Erro Relativo } \\
(\%)\end{array}$ \\
\hline $\mathbf{C u}$ & 102,5 & 100,0 & 2,50 \\
\hline $\mathrm{Cr}$ & 99,3 & 98,3 & 1,02 \\
\hline $\mathbf{F e}$ & 93,8 & 98,9 & 5,15 \\
\hline $\mathbf{P b}$ & 99,8 & 101,1 & 1,28 \\
\hline Mo & 102,3 & 100,3 & 1,99 \\
\hline Mg & 101,5 & 99,5 & 2,01 \\
\hline
\end{tabular}

Com relação à validação da metodologia de amostras, no teste de linearidade todos os valores dos coeficientes de determinação variaram de 0,9947 até 0,9993 . No teste de repetitividade todos os resultados obtidos apresentaram desvios padrões relativos abaixo de $10 \%$. No teste de recuperação do padrão valores entre 94.8 e $102.5 \%$ e no teste de erro relativo entre 1.02 e $5.5 \%$. A qualidade está compatível com outras técnicas consolidadas $(10,52,53)$.

\subsubsection{Comparação de analise se amostras LIBS x ICPOES}

Para melhor validação da metodologia, realizamos a comparação da analise do padrão MRC (NIST SRM 1084a) pela técnica estabelecida de ICPOES, apresentada na TAB.8. A curva de calibração e o padrão foram preparados com diluição em solvente orgânico (querosene de aviação). 
TABELA 8 - Comparação LIBS x ICPOES.

\begin{tabular}{|c|c|c|c|}
\hline Elemento & $\begin{array}{c}\text { Valor } \\
\text { observado } \\
\text { no LIBS } \\
\left(\mu \mathrm{g} \mathrm{g}^{-1}\right)\end{array}$ & $\begin{array}{c}\text { Valor } \\
\text { observado no } \\
\text { ICPOES } \\
\left(\mu \mathrm{g} \mathrm{g}^{-1}\right)\end{array}$ & $\begin{array}{c}\text { Valor } \\
\text { Esperado* }^{*} \\
\left(\mu \mathrm{g} \mathrm{g}^{-1}\right)\end{array}$ \\
\hline $\mathbf{C u}$ & $102,5 \pm 7,2$ & $100,5 \pm 1,5$ & $100,0 \pm 1,9$ \\
\hline $\mathrm{Cr}$ & $99,3 \pm 6,1$ & $98,2 \pm 1.2$ & $98,3 \pm 0,8$ \\
\hline $\mathrm{Fe}$ & $93,8 \pm 6,7$ & $99,0 \pm 1,8$ & $98,9 \pm 1,4$ \\
\hline $\mathbf{P b}$ & $99,8 \pm 5,3$ & $101,3 \pm 0,8$ & $101,1 \pm 1,3$ \\
\hline Mo & $102,3 \pm 8,8$ & $100,1 \pm 1,3$ & $100,3 \pm 1,4$ \\
\hline Mg & $101,5 \pm 9,1$ & $99,6 \pm 1,5$ & $99,5 \pm 1,7$ \\
\hline
\end{tabular}

*Valor certificado do MRC (NIST SRM 1084a).

\section{INCERTEZA DO MÉTODO (incerteza na medição)}

Na TAB.9 podemos verificar a concentração das amostras analisadas.

Tabela 9 - Concentração dos metais em $\mu \mathrm{g} \mathrm{g}^{-1}$ (mediana) em função do ano de fabricação.

\begin{tabular}{ccccccc}
\hline Ano & Cu & Cr & Pb & Fe & Mo & Mg \\
\hline $\mathbf{2 0 1 3}$ & $10.9 \pm 0.6$ & $<$ LD & $14.6 \pm 3.5$ & $22.4 \pm 5.1$ & $21.65 \pm 0.7$ & $12.6 \pm 0.3$ \\
$\mathbf{2 0 1 2}$ & $10.5 \pm 0.4$ & $<$ LD & $32.1 \pm 26.7$ & $39.7 \pm 15.7$ & $20.5 \pm 1.29$ & $11.4 \pm 0.7$ \\
$\mathbf{2 0 1 1}$ & $11.3 \pm 1.2$ & $<$ LD & $51.3 \pm 30.7$ & $58.3 \pm 23.2$ & $17.7 \pm 3.9$ & $10.3 \pm 1.76$ \\
$\mathbf{2 0 1 0}$ & $13.4 \pm 0.8$ & $<$ LD & $94.9 \pm 25.5$ & $107.7 \pm 23.2$ & $12.1 \pm 3.2$ & $9.6 \pm 0.48$ \\
$\mathbf{2 0 0 7}$ & $13.8 \pm 0.7$ & $6.6 \pm 0.7$ & $74.5 \pm 17.7$ & $96.7 \pm 29.5$ & $10.1 \pm 3.6$ & $9.9 \pm 0.89$ \\
$\mathbf{2 0 0 5}$ & $13.7 \pm 1.2$ & $8.5 \pm 0.5$ & $82.3 \pm 17.9$ & $123.5 \pm 24.1$ & $11.3 \pm 3.6$ & $9.8 \pm 0.7$ \\
$\mathbf{2 0 0 3}$ & $16.7 \pm 2.0$ & $9.1 \pm 0.7$ & $104.7 \pm 5.9$ & $143.9 \pm 33.1$ & $10.3 \pm 1.8$ & $8.7 \pm 0.6$ \\
$\mathbf{2 0 0 1}$ & $25.4 \pm 6.8$ & $20.7 \pm 8.7$ & $134.0 \pm 35.9$ & $144.3 \pm 29.1$ & $6.0 \pm 3.0$ & $7.2 \pm 1.2$ \\
$\mathbf{1 9 9 9}$ & $22.8 \pm 2.9$ & $17.7 \pm 5.6$ & $140.7 \pm 25.8$ & $135.7 \pm 28.4$ & $9.3 \pm 3.9$ & $6.6 \pm 0.4$ \\
$\mathbf{1 9 9 7}$ & $24.7 \pm 9.5$ & $19.9 \pm 7.0$ & $156.9 \pm 47.7$ & $163.4 \pm 18.9$ & $5.9 \pm 2.2$ & $6.0 \pm 2.3$ \\
$\mathbf{1 9 9 5}$ & $22.4 \pm 10.4$ & $23.6 \pm 14.9$ & $149.4 \pm 23.7$ & $163.9 \pm 25.7$ & $7.9 \pm 0.9$ & $6.3 \pm 0.6$ \\
$\mathbf{1 9 9 1}$ & $46.4 \pm 13.0$ & $51.1 \pm 21.0$ & $162.1 \pm 30.3$ & $231.4 \pm 103.9$ & $6.7 \pm 1.2$ & $7.1 \pm 1.3$ \\
$\mathbf{1 9 9 0}$ & $56.9 \pm 38.5$ & $126.4 \pm 102.9$ & $176.2 \pm 20.8$ & $305.9 \pm 55.1$ & $6.4 \pm 2.5$ & $2.72 \pm 2.1$ \\
\hline
\end{tabular}

OBS: Os dados foram transformado em $\mathrm{LOG}(\mathrm{X}+10)$ para analise estatística. 


\subsection{Calculos das incertezas}

\subsubsection{Incerteza associada}

\subsubsection{Curva analitica}

O cálculo da incerteza associada da curva analítica foi calculada como se segue:

$$
u\left(c_{o}\right)=\frac{S}{B_{1}} \sqrt{\frac{1}{p}+\frac{1}{n}+\frac{\left(c_{o}-\bar{c}\right)^{2}}{Q_{x x}}}
$$

Onde:

$\mathrm{S}=$ desvio padrão;

B1 = inclinação da curva;

$\mathrm{p}=$ número de medidas para determinar $\mathrm{C}_{0}$;

$\mathrm{n}=$ número de medidas para calibração;

$\mathrm{C}_{\mathrm{o}}=$ concentração do analito;

Média $\mathrm{C}=$ media das concentrações da curva;

Qxx = soma das concentrações

Os valores da incerteza associada da curva analitica são:

$\mathbf{u}\left(\mathbf{C}_{\mathbf{0}}\right) \mathbf{M o}=\mathbf{1 , 5 3 8 4 0 8}$ - para Mo com 12,5 ppm em nova curva (sem o ponto de $500 \mu \mathrm{g} \mathrm{g}^{-1}$ )

$\mathbf{u}\left(\mathbf{C}_{\mathbf{0}}\right) \mathbf{P b}=\mathbf{5 , 3 5 3 5 9}$ - para $\mathrm{Pb}$ com 41 ppm em nova curva (sem o ponto de $500 \mu \mathrm{g} \mathrm{g}^{-1}$ ) 


\subsubsection{Balança}

A incerteza associada com o peso inicial do papel de filtro (sem amostra) e final (com amostra) foi associada com o certificado de calibração da balança e sua repetibilidade demonstrada medindo o desvio padrão da balança obtido através de sucessivas medidas de verificação diária, o saldo resulta da soma destas duas variáveis que foram utilizadas como a incerteza das massas dada pela equação:

$$
u(m)=\sqrt{\left(u_{1}\right)^{2}+\left(u_{2}\right)^{2}}
$$

$u(\mathbf{m})=0,00001$

\subsubsection{Recuperação do material de referencia certificado (mrc)}

A incerteza associada à recuperação do método foi obtida com a leitura do material de referência combinado com sua incerteza informada no certificado do padrão.

Todos os cálculos do molibdênio são referentes à concentração igual a $12,5 \mu \mathrm{g} \mathrm{g}^{-1} \mathrm{em}$ nova curva e os cálculos de chubo são referentes a concentração igual a $41 \mu \mathrm{g} \mathrm{g}^{-1}$ em nova curva.

\section{A. Cálculo da incerteza da solução do MRC}

$$
u_{\text {sol }}=C_{\text {sol }} \times \sqrt{\left(\frac{u_{M R C}}{C_{M R C}}\right)^{2}+\left(\frac{u_{M_{M R C}}}{M_{M R C}}\right)^{2}}
$$

Obs.: $\mathrm{u}_{\mathrm{MRC}}$ e $\mathrm{C}_{\mathrm{MRC}}$ são referentes ao elemento analisado

$\mathrm{u}_{\mathrm{M} \_ \text {MRC }}$ e $\mathrm{u}_{\mathrm{MRC}}=0,00001$

$$
\begin{aligned}
& \mathbf{u}_{\text {sol }}(\mathrm{Mo})=1,397 \\
& \mathbf{u}_{\text {sol }}(\mathrm{Pb})=1,287
\end{aligned}
$$




\section{B. Incerteza na recuperação}

\section{b.1. Calculando $\boldsymbol{R}_{m}$}

Apresentado na TAB. 9.

$R_{m}=\frac{C_{o b s}}{C_{M R C}}$

Tabela 10 - Cálculo do Rm para Mo e Pb.

\begin{tabular}{|c|c|c|}
\hline & Mo & Pb \\
\hline $\mathrm{C}_{\mathrm{obs}}=$ & $102,300 \mu \mathrm{g} \mathrm{g}^{-1}$ & $99,800 \mu \mathrm{g} \mathrm{g}^{-1}$ \\
\hline $\mathrm{C}_{\mathrm{MRC}}=$ & $100,300 \mu \mathrm{g} \mathrm{g}^{-1}$ & $101,100 \mu \mathrm{g} \mathrm{g}^{-1}$ \\
\hline $\mathrm{R}_{\mathrm{m}}=$ & $1,02 \mu \mathrm{g} \mathrm{g}^{-1}$ & $0,99 \mu \mathrm{g} \mathrm{g}^{-1}$ \\
\hline
\end{tabular}

\section{b.2. Incerteza na recuperação (TAB.10)}

$\mathrm{u}_{\mathrm{Rm}}=\mathrm{R}_{\mathrm{m}} \times \sqrt{\left(\frac{\mathrm{u}_{\mathrm{sol}}}{\mathrm{C}_{\mathrm{sol}}}\right)^{2}+\frac{\mathrm{S}_{\mathrm{obs}}^{2}}{\mathrm{n} \times \mathrm{C}_{\mathrm{obs}}^{2}}}$

Onde:

$\mathrm{S}_{\mathrm{obs}}=$ desvio padrão dos resultados das análises replicatas do MRC

$\mathrm{C}_{\mathrm{obs}}=$ concentração obtida da análise do MRC

$\mathrm{n}=$ número de replicatas 
TABELA 11 - Incerteza da recuperação.

\begin{tabular}{|c|c|c|}
\hline & Mo & Pb \\
\hline $\mathrm{S}_{\mathrm{obs}}=$ & 0,07 & 0,07 \\
\hline $\mathrm{C}_{\mathrm{obs}}=$ & 102,3 & 99,8 \\
\hline $\mathrm{n}=$ & 10 & 10 \\
\hline $\mathrm{u}_{\mathrm{Rm}}=$ & 0,0142809 & 0,0128347 \\
\hline
\end{tabular}

\subsubsection{Incerteza expandida}

Cálculo da incerteza expandida:

$\mathbf{U}=\mathbf{u}(\mathbf{a m o s t r a}) \mathbf{x} 2$

Onde:

$\mathrm{u}($ amostra $)=$ incerteza padrão combinada da amostra

$\mathrm{U}(\mathrm{Mo})=12,5 \pm 3,1 \mu \mathrm{g} \mathrm{g}^{-1}$

$\mathrm{U}(\mathrm{Pb})=\mathbf{4 1 , 0} \pm \mathbf{1 0 , 8} \mu \mathrm{g} \mathrm{g}^{-1}$

\subsubsection{Cálculo das incertezas expandidas e relativas}

Primeiramente foi calculada a incerteza com a curva completa -7 pontos com concetração de 12,5 a $500 \mu \mathrm{g} \mathrm{g}^{-1}$. Para estes primeiros cálculos foram observados que, para todos esses elementos, conforme cresce a concentração - a incerteza diminui consideravelmente. Incertezas expandidas apresentado nas TAB. 12 e 15. Incertezas relativas apresentados nas tabelas 13-17 e seus respectivos gráficos nas FIG. 30-33.

TABELA 12 - Incerteza expandida com todos os pontos da curva.

\begin{tabular}{|c|c|c|}
\hline Elemento & Concentração $\left(\boldsymbol{\mu g} \mathbf{g}^{-1}\right)$ & Incerteza expandida (\%) \\
\hline $\mathrm{Pb}$ & 15 a 176 & 92 a 8 \\
\hline $\mathrm{Mo}$ & 6 a 21,5 & 130 a 36 \\
\hline
\end{tabular}




\section{Para o Mo:}

TABELA 13 - Incertezas relativas para Mo com todos os pontos da curva.

\begin{tabular}{|c|c|}
\hline \multicolumn{2}{|c|}{ Incertezas relativas } \\
\hline $\mathrm{u}(\mathrm{Co}) / \mathrm{Co}$ & 0.309863126 \\
\hline $\mathrm{u}(\mathrm{Rec}) / \mathrm{Rec}$ & 0.014001672 \\
\hline $\mathrm{u}(\mathrm{ma}) / \mathrm{ma}$ & 0.000647573 \\
\hline
\end{tabular}

Onde:

$\mathbf{u}(\mathbf{C o}) / \mathbf{C o}=$ incerteza relativa da alíquota analisada - relação com a curva de calibração. $\mathbf{u}(\operatorname{Rec}) / \mathbf{R e c}=$ incerteza relativa da recuperação da análise do material de referência certificado.

$\mathbf{u}(\mathbf{m a}) / \mathbf{m a}=$ incerteza relativa da massa de amostra pesada - relação com a balança utilizada.

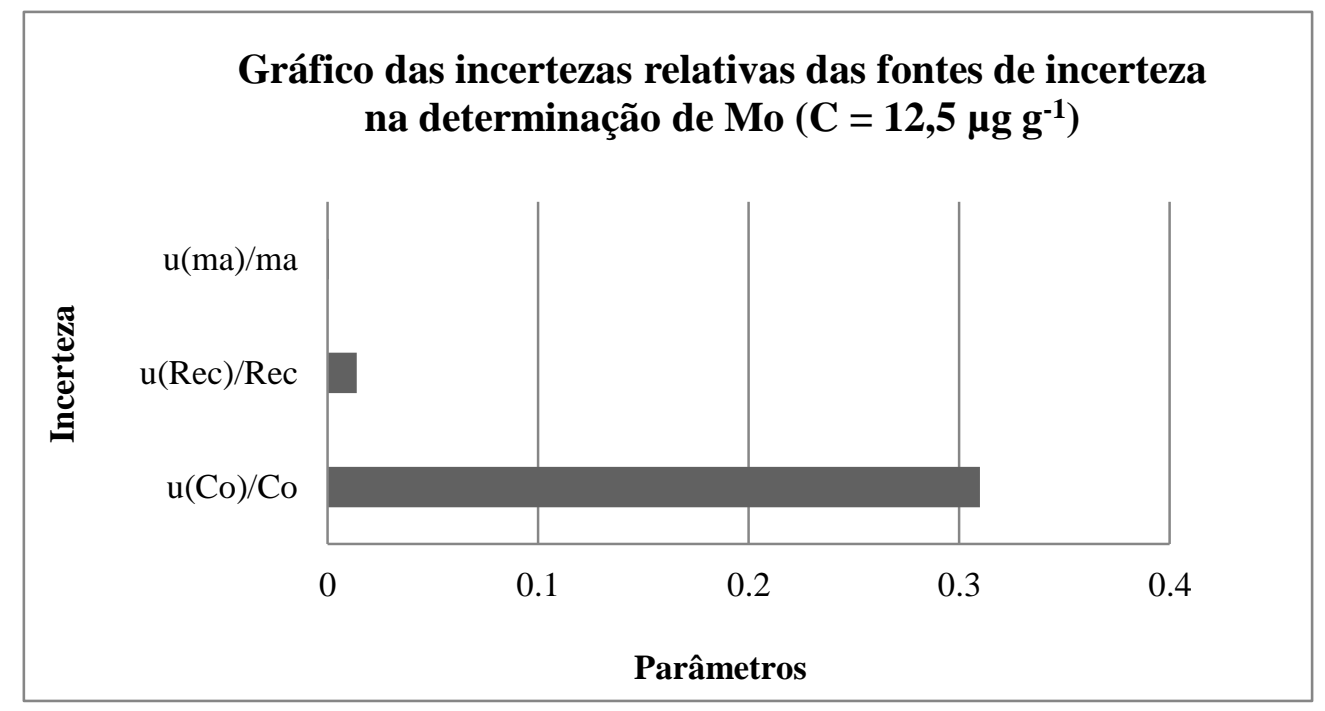

FIGURA 30 - Incertezas relativas para Mo com todos os pontos da curva. 


\section{Para o Pb:}

TABELA 14 - Incertezas relativas para $\mathrm{Pb}$ com todos os pontos da curva.

\begin{tabular}{|c|c|}
\hline \multicolumn{2}{|c|}{ Incertezas relativas } \\
\hline $\mathrm{u}(\mathrm{Co}) / \mathrm{Co}$ & 0.164842548 \\
\hline $\mathrm{u}(\mathrm{Rec}) / \mathrm{Rec}$ & 0.013001892 \\
\hline $\mathrm{u}(\mathrm{ma}) / \mathrm{ma}$ & 0.000647573 \\
\hline
\end{tabular}

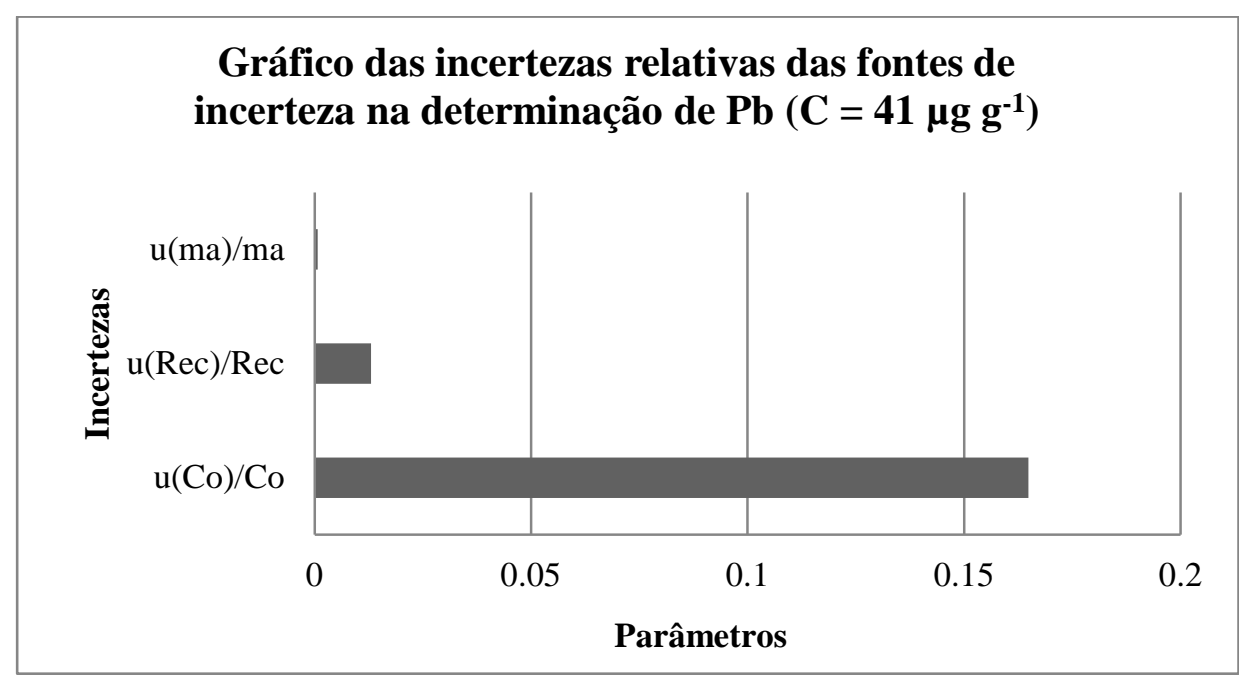

FIGURA 31 - Incertezas relativas para $\mathrm{Pb}$ com todos os pontos da curva.

Em seguida, a estensão da curva foi reduzida para $100 \mu \mathrm{g} \mathrm{g}^{-1}$, com o objetivo de ajustar os pontos da análise, ou seja, foram retirados os dois últimos pontos ( 300 e $500 \mu \mathrm{g}$ $\mathrm{g}^{-1}$ ). Então, obtivemos melhores incertezas totais. Mas manteve-se a mesma conclusão que ao aumentar a concentração diminui a incerteza.

TABELA 15 - Incerteza expandida após ajuste da curva.

\begin{tabular}{|c|c|c|}
\hline Elemento & Concentração $\left(\boldsymbol{\mu g} \mathbf{g}^{-1}\right)$ & Incerteza expandida (\%) \\
\hline $\mathrm{Pb}$ & 15 a 176 & 82 a 7 \\
\hline $\mathrm{Mo}$ & 6 a 21,5 & 54 a 14 \\
\hline
\end{tabular}

Para a concentração de $\mathrm{Pb}=176$, os cálculos foram realizados com a curva até 300 $\mu \mathrm{g} \mathrm{g}^{-1}$, ou seja foram retirados para esta concentração somente o último ponto de $500 \mu \mathrm{g} \mathrm{g}^{-1}$. 


\section{Nova curva para Mo:}

TABELA 16 - Incertezas relativas para Mo com a nova curva.

\begin{tabular}{|c|c|}
\hline \multicolumn{2}{|c|}{ Incertezas relativas } \\
\hline $\mathrm{u}(\mathrm{Co}) / \mathrm{Co}$ & 0.123073 \\
\hline $\mathrm{u}(\mathrm{Rec}) / \mathrm{Rec}$ & 0.014002 \\
\hline $\mathrm{u}(\mathrm{ma}) / \mathrm{ma}$ & 0.000648 \\
\hline
\end{tabular}

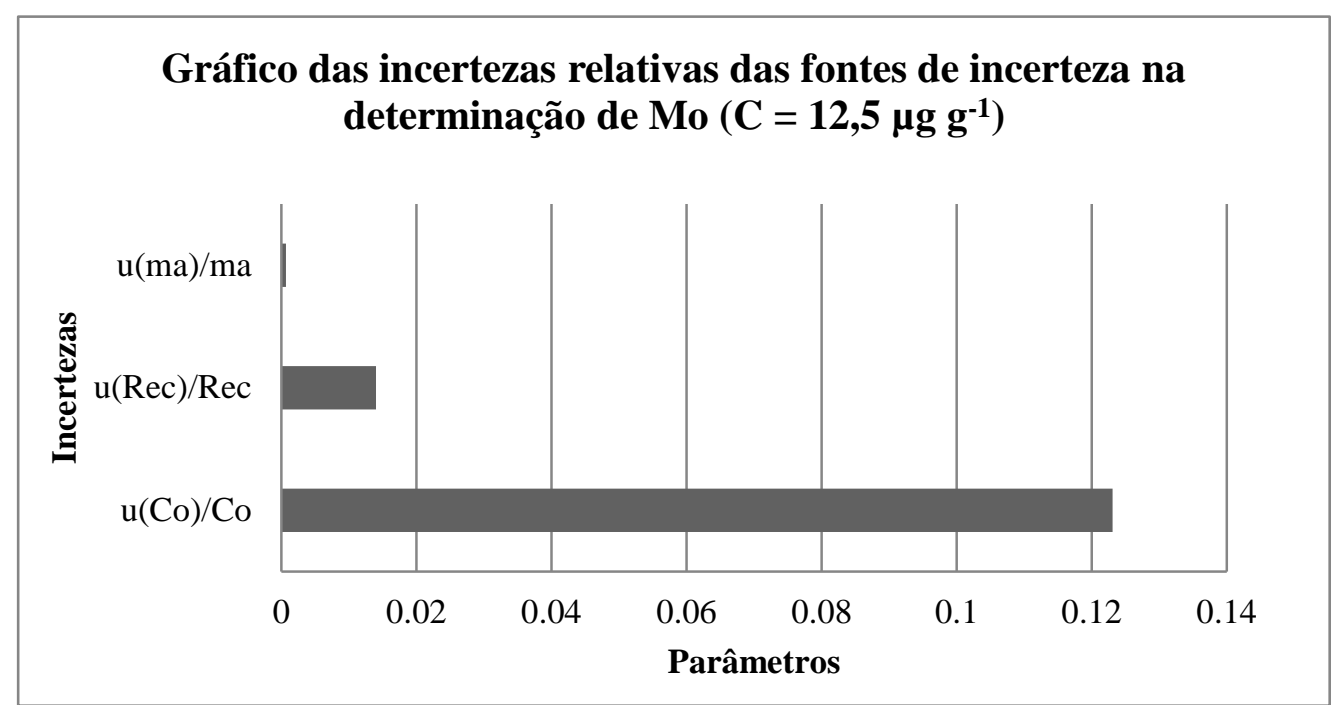

FIGURA 32 - Incertezas relativas para Mo com a nova curva.

\section{Nova curva para o $\mathbf{P b}$ :}

TABELA 17 - Incertezas relativas para $\mathrm{Pb}$ com a nova curva.

\begin{tabular}{|c|c|}
\hline \multicolumn{2}{|c|}{ Incertezas relativas } \\
\hline $\mathrm{u}(\mathrm{Co}) / \mathrm{Co}$ & 0.164842548 \\
\hline $\mathrm{u}(\mathrm{Rec}) / \mathrm{Rec}$ & 0.013001892 \\
\hline $\mathrm{u}(\mathrm{ma}) / \mathrm{ma}$ & 0.000647573 \\
\hline
\end{tabular}




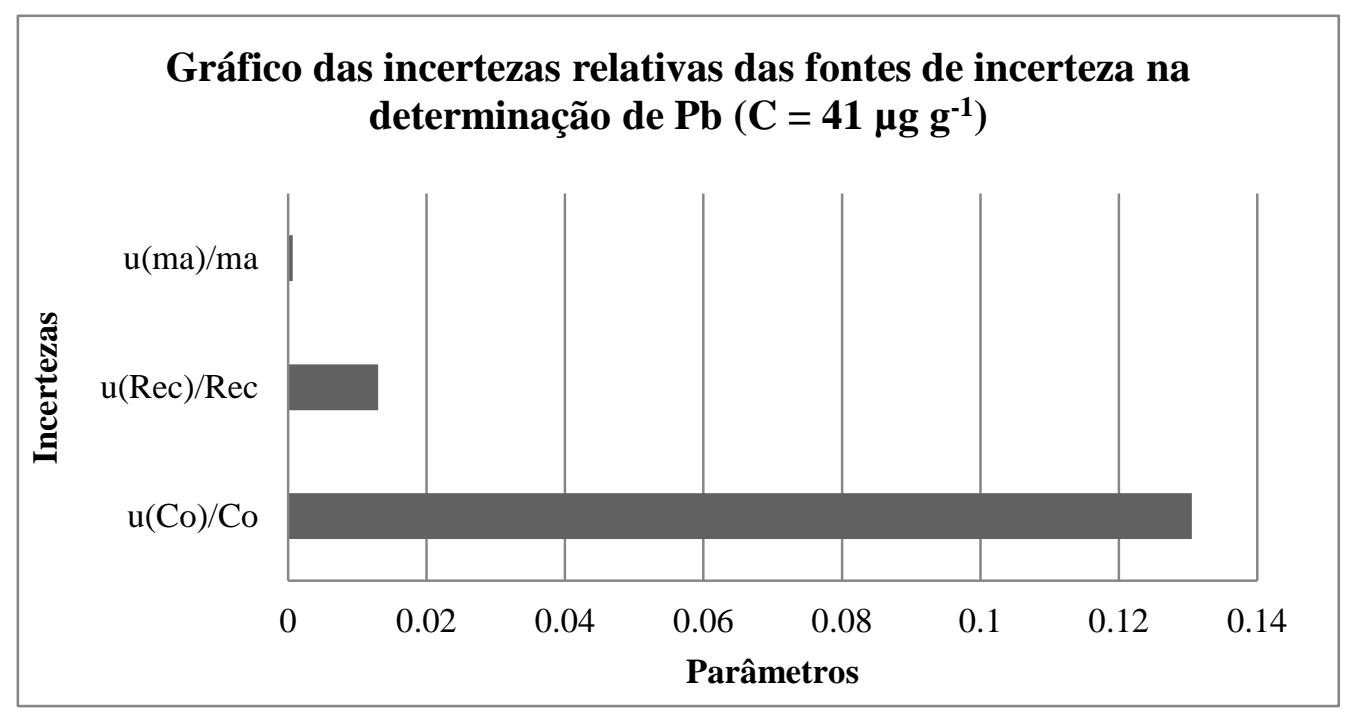

FIGURA 33 - Incertezas relativas para $\mathrm{Pb}$ com a nova curva.

Com relação às incertezas relativas. Em todas as amostras analisadas, verificou-se que a maior contribuição foi sempre da alíquota analisada - ou seja, em relação à curva de calibração. As outras fontes contribuiram muito pouco para a incerteza expandida (final).

\section{Calculo com as incertezas expandidas para todos os elementos analisados:}

TABELA 18 - Incerteza expandida calculada com todos os pontos da curva - 7 pontos de 12,5 a $500 \mu \mathrm{g} \mathrm{g}^{-1}$.

\begin{tabular}{|l|c|c|}
\hline Elemento & $\begin{array}{c}\text { Concentração } \\
\left(\mu \mathrm{g} \mathrm{g}^{-1}\right)\end{array}$ & $\begin{array}{l}\text { Incerteza } \\
\text { expandida }(\%)\end{array}$ \\
\hline $\mathrm{Cr}$ & $6,6-126,4$ & $227-7,5$ \\
\hline $\mathrm{Mg}$ & $3,9-12,4$ & $279-87$ \\
\hline $\mathrm{Fe}$ & $23-305$ & $24-4$ \\
\hline $\mathrm{Cu}$ & $10,9-56,9$ & $103-21$ \\
\hline $\mathrm{Pb}$ & $15-176,2$ & $92-8$ \\
\hline $\mathrm{Mo}$ & $6-21,5$ & $130-36$ \\
\hline
\end{tabular}

Podemos notar que para estes primeiros cálculos, para todos esses elementos, conforme cresce a concentração - a incerteza diminui consideravelmente. 
TABELA 19 - Incerteza expandida calculada reduzindo a curva para $100 \mu \mathrm{g} \mathrm{g}^{-1}$.

\begin{tabular}{|l|l|l|}
\hline Elemento & $\begin{array}{l}\text { Concentração } \\
\left(\mu \mathrm{g} \mathrm{g}^{-1}\right)\end{array}$ & $\begin{array}{l}\text { Incerteza } \\
\text { expandida }(\%)\end{array}$ \\
\hline $\mathrm{Cr}$ & $6,6-126,4$ & $87-5,0$ \\
\hline $\mathrm{Mg}$ & $3,9-12,4$ & $108-33$ \\
\hline $\mathrm{Fe}$ & $23-305$ & $17-9$ \\
\hline $\mathrm{Cu}$ & $10,9-56,9$ & $74-13$ \\
\hline $\mathrm{Pb}$ & $15-176,2$ & $82-7$ \\
\hline $\mathrm{Mo}$ & $6-21,5$ & $54-14$ \\
\hline
\end{tabular}

TABELA 20 - Incerteza expandida calculada para a concentração de $\mathrm{Fe}=120 \mathrm{e}$ $241 \mu \mathrm{gg}^{-1}$ - com a curva até $300 \mu \mathrm{g} \mathrm{g}^{-1}$.

\begin{tabular}{|l|l|l|}
\hline Elemento & $\begin{array}{l}\text { Concentração } \\
\left(\mu \mathrm{g} \mathrm{g}^{-1}\right)\end{array}$ & $\begin{array}{l}\text { Incerteza } \\
\text { expandida (\%) }\end{array}$ \\
\hline $\mathrm{Fe}$ & $120 ; 241 ;$ & 5,$0 ; 3,4$ \\
\hline
\end{tabular}

Mesmo ajustando-se a curva manteve-se a mesma conclusão que ao aumentar a concentração diminui a incerteza. O cálculo da incerteza de medição nos permitiu ver os pontos a serem melhorados no procedimento analitico, no caso deste trabalho, com a melhor adequação da curva analitica, conseguimos um decréssimo no valor da incerteza expandida e isso pode vir a alterar a interpretação dos resultados finais. 


\section{ANÁLISE DE METAIS EM ÓLEOS LUBRIFICANTES USADOS}

O método usado para múltiplas comparações está contido no teste não paramétrico de Kruskal-wallis. O Programa estatístico utilizado foi o Estatística 10.

\subsection{Equação de Stuarges}

A equação de Stuarges é uma ferramenta estatistica que foi utilizada com a finalidade de cientificar a decisão da divisão da quilometragem em classes.

Foram analisadas um total de 55 amostras de óleo lubrificante usado de automóveis.

Os dados foram divididos em classes seguindo a equação de Sturges, que sugeriu classes com base nos valores de Km. Todavia, porque as duas últimas possuíam um $\mathrm{n}$ muito pequeno, juntou-se as duas, formando 6 classes, como observado na tabela 21 .

TABELA 21 - Divisão das classes de acordo com a equação de Sturges.

\begin{tabular}{llllll}
\hline & $\begin{array}{c}\text { Min. } \\
\text { Km }\end{array}$ & $\begin{array}{l}\text { Máx. } \\
\text { Km }\end{array}$ & & \\
\hline $\mathbf{1}$ & $\mathbf{2}$ & $\mathbf{1}$ & $\mathbf{2}$ & $\mathbf{n}$ & classes \\
\hline$>=$ & $<$ & 5540 & 36084 & 14 & $\mathbf{A}$ \\
\hline & 36084 & 66628 & 9 & $\mathbf{B}$ \\
\hline & 66628 & 97172 & 7 & $\mathbf{C}$ \\
\hline & 97172 & 127716 & 7 & $\mathbf{D}$ \\
\hline & 127716 & 158260 & 9 & $\mathbf{E}$ \\
\hline & 158260 & 305498 & 9 & $\mathbf{F}$ \\
\hline
\end{tabular}

\subsection{Teste não paramétrico de Kruskal-wallis}

Após a divisão das classes os dados foram submetidos ao teste não paramétrico de Kruskal Wallis onde as diferenças significativas entre as classes foram detectadas por meio do teste a posteriori de comparações múltiplas de médias (com p < 0.05) representando diferenças significativas entre as classes (podendo ser observado com os dados destacados em vermelho nas tabelas disponíveis em Apendice A). As figuras 34 - 39 são a representação gráfica em boxplot geradas á partir do teste não paramétrico de Kruskalwallis. 


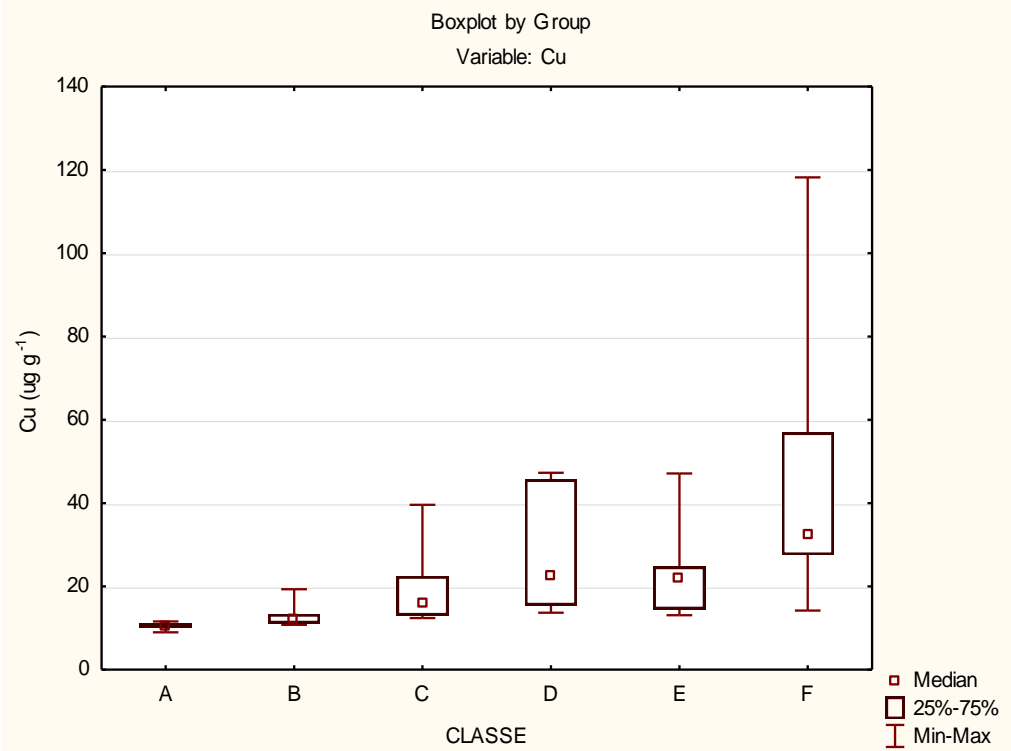

FIGURA 34 - Comparação múltipla entre as classes para $\mathrm{Cu}$.

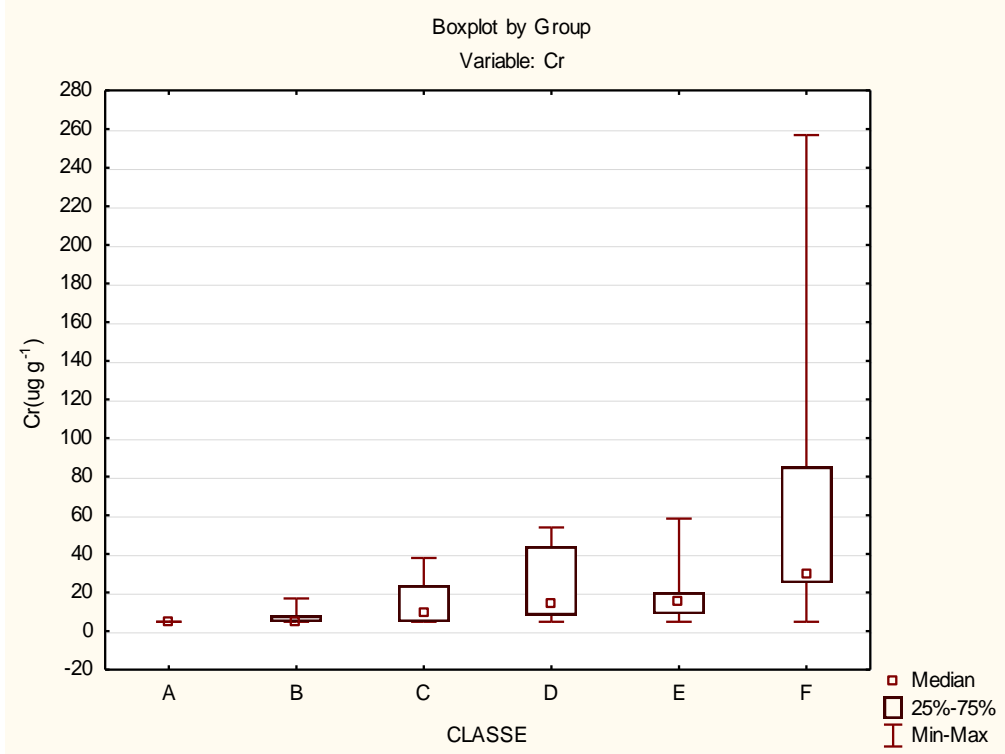

FIGURA 35 - Comparação múltipla entre as classes para Cr. 


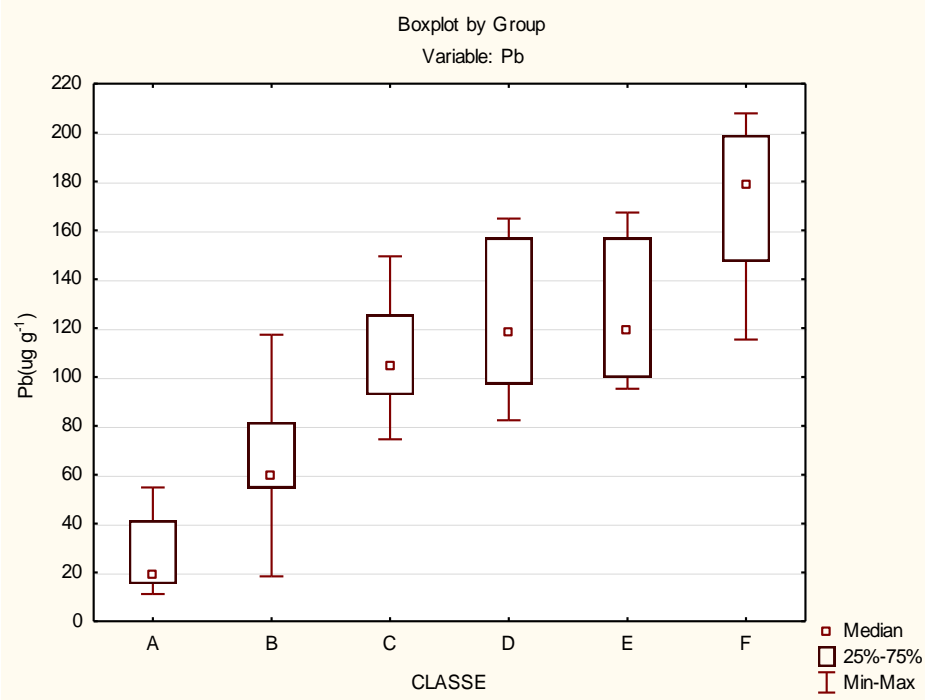

FIGURA 36 - Comparação múltipla entre as classes para Pb.

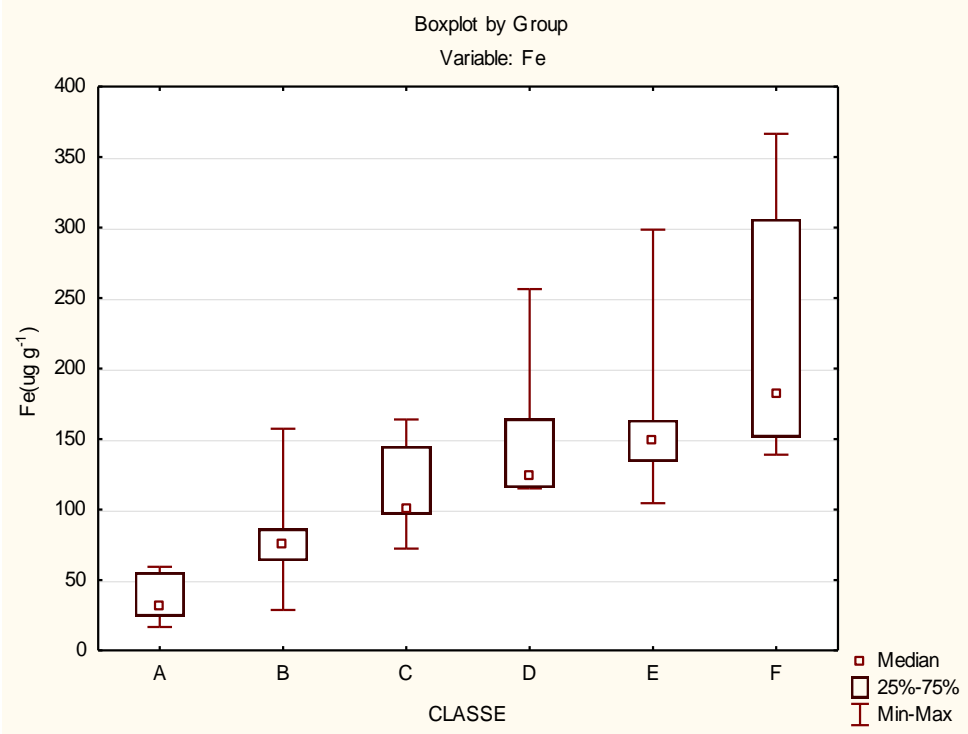

FIGURA 37 - Comparação múltipla entre as classes para Fe. 


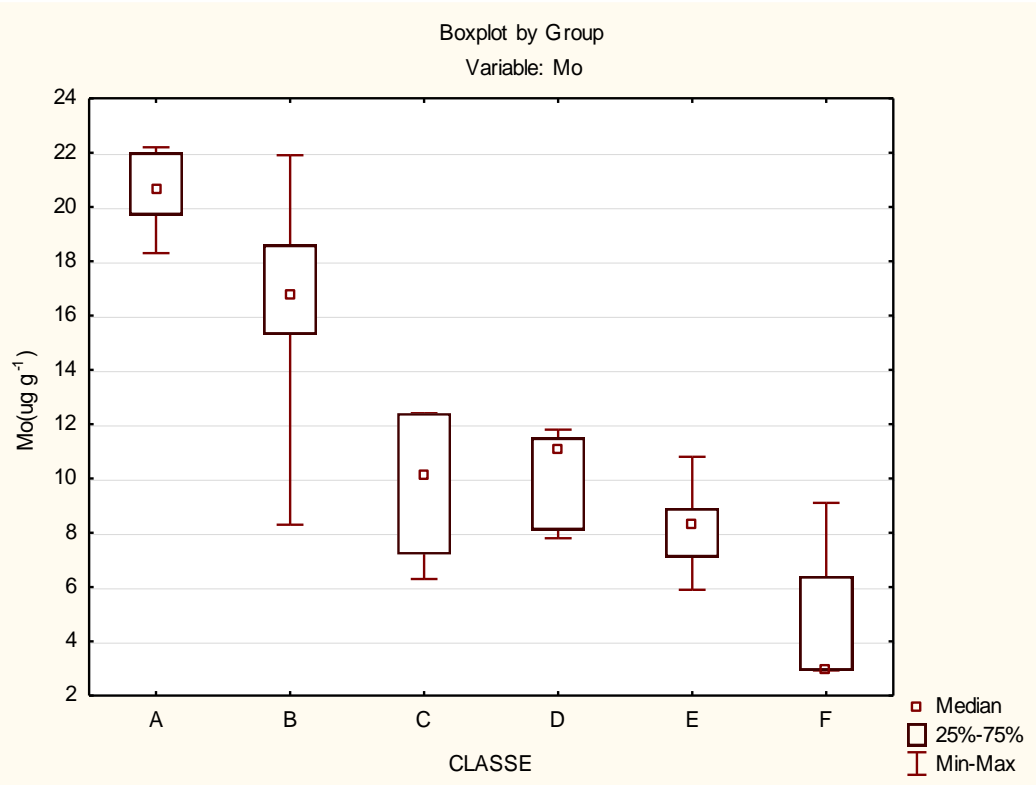

FIGURA 38 - Comparação múltipla entre as classes para Mo.

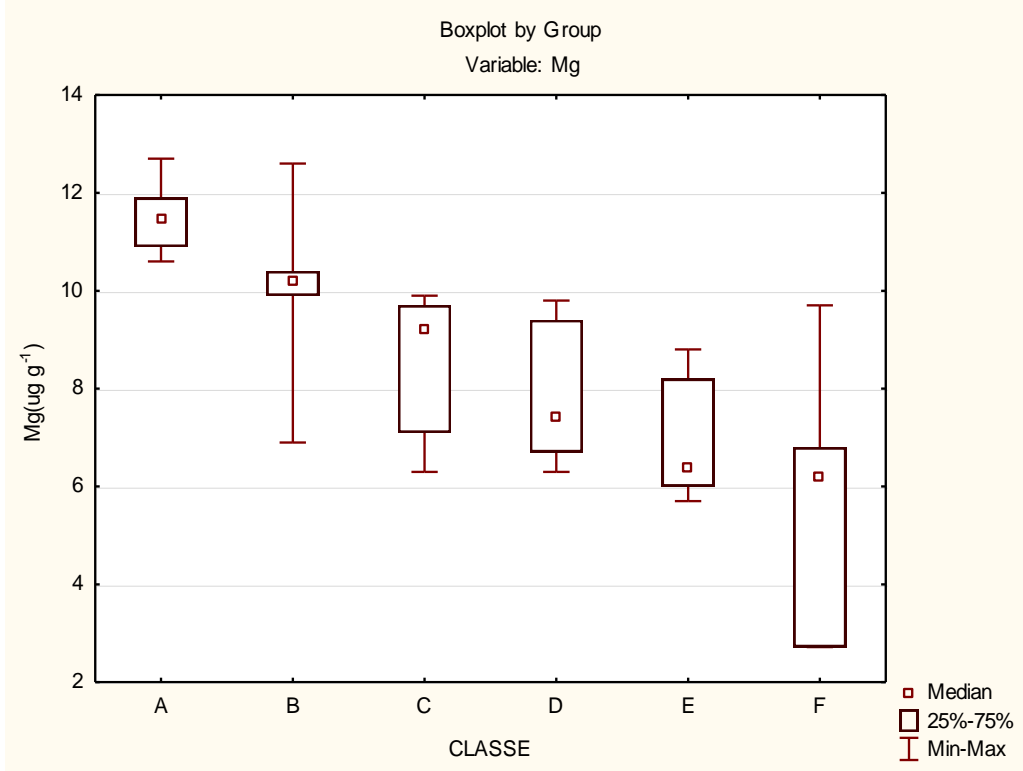

FIGURA 39 - Comparação múltipla entre as classes para Mg.

Podemos observar uma tendência de aumento na concentração dos metais $\mathrm{Cu}, \mathrm{Cr}$, $\mathrm{Pb}, \mathrm{Fe}$ bem como o declínio na concentração dos metais Mo e Mg. E em geral maior dispersão dos resultados na classe F.

As amostras de óleo usado apresentaram uma tendência de aumento na concentração dos metais $\mathrm{Cu}, \mathrm{Cr}, \mathrm{Pb}, \mathrm{Fe}$.

$\mathrm{O}$ aumento da concentração destes metais $(\mathrm{Cu}, \mathrm{Cr}, \mathrm{Pb}, \mathrm{Fe})$ estão diretamente relacionado com a qualidade e o desgaste das peças que constituem os motores, tais como, 
cilindros, pistões, engrenagens, anéis, eixos, bomba de óleo, virabrequim, pontos de apoio, etc. Dessa forma, tais concentrações tendem a aumentar com o uso do óleo (53).

Alguns fatores contribuem para o aumento desse desgaste como, por exemplo, o tipo do percurso realizado pelo veículo, o modo como o motorista conduz o veículo, a presença de contaminantes (fuligem, poeira, água, ácidos, etc) presentes no lubrificante. A presença destes metais é influenciada pelos fatores: ano de fabricação e distância percorrida.

O declínio na concentração dos metais molibdênio e magnésio advêm do fato de estes elementos serem adicionados aos óleos lubrificantes na forma de aditivos. Os aditivos sofrem degradação (que é o processo que reduz a capacidade do óleo cumprir suas funções) devido as diferentes condições que são submetidos dentro do motor, como, altas temperaturas, grandes velocidades, corrosão, contaminações, envelhecimento etc (53).

A quantidade de aditivos recomendada pelos fornecedores varia, em média, de 0,5 a $28 \%$ em volume (31).

Portanto durante o trabalho do motor, os aditivos (compostos por $\mathrm{Mo}$ e $\mathrm{Mg}$ ) perderam suas características iniciais, e, em contrapartida, os metais $\mathrm{Fe}, \mathrm{Cu}, \mathrm{Cr}, \mathrm{Pb}$ apareceram no óleo, originados do desgaste das ligas metálicas que compõem as peças do motor. 


\section{CONCLUSÕES}

Podemos verificar a importância do cálculo de incerteza de medição, pois uma incerteza expandida final que descresce de $82 \%$ para $7 \%$ altera a interpretação dos dados finais - então fica demonstrada a importância desse parâmetro na validação do método e o operador tem que estar atento. Em casos de rotina ou amostras desconhecidas é impossível o analista antever o que será medido, mas uma vez feita à medição, o compromisso com a qualidade, exige a criação de novos pontos. A seleção das faixas da curva reduzem substancialmente as incertezas do resultado.

Com relação ao uso do equipamento compacto x híbrido (montado em bancada) observamos as seguintes vantagens: mais barato, mais fácil de operar, todos os ajustes são automáticos, facilitando assim seu uso em análises de rotina. A qualidade das análises está compatível com outras técnicas consolidadas, podendo ser utilizado em ensaios que exijam maior precisão.

Trabalhos recentes $(54,55)$ realizaram análise de metais em óleos via LIBS, porém o procedimento utilizado neste trabalho além de simples, rápido, com pouca geração de residuos é uma boa alternativa para realização de monitoramento de óleos lubrificantes, podendo ser utilizada por indústrias de diversos segmentos. Com o programa de monitoramento ao invés de realizar a troca do oleo depois de um tempo ou distância específica, o oleo pode ser testado através da metodologia proposta e assim utilizado por mais tempo, ficando a vida extra e poupando dinheiro. Podendo tambem ser utilizado como manutenção preventiva uma vez que podemos identificar quais peças precisam ser substituidas, evitando assim a quebra de maquinas.

Outrossim, a utilização da técnica de deposição em papel, também traz uma inovação tornando a preparação mais rápida, evitando o desgaste do equipamento (em função da introdução de solvente). Além disso, a geração de resíduo é praticamente nula seguindo, portanto, uma tendencia mundial no que diz respeito à preservação do meio ambiente. 


\section{REFERENCIAS BIBLIOGRAFICAS}

1. PETROBRAS. Disponível em: www.petrobras.com.br. Acessado em junho de 2013.

2. Resolução ANP No 125, de 30.7.1999 - DOU 2.8.1999 - REPUBLICADA DO BRASIL 30.9.1999 E 28.4.2000.

3. Resolução ANP No 129, DE 30.7.1999 - DOU 02.08.1999 - REPUBLICADA DOU 30.9.1999.

4. Agência Nacional do Petróleo, Gás Natural e Biocombustível (ANP). Disponível em: http://www.anp.gov.br. Acessado em Janeiro de 2013.

5. ABNT NBR 14066 (ASTM D4628). Determinação de Cálcio, Magnésio e Zinco em óleos lubrificantes novos por Espectrometria de Absorção Atômica, Brasil, 2008.

6. ZMOZINSKI, A. V.; DE JESUS, A.; VALE MARIA, G. R.; ET AL. Determination of calcium, magnesium and zinc in lubricating oils by flame atomic absorption spectrometry using a three-component solution. Talanta, v. 83, p. 637-643, 2010.

7. RAPOSO, J. L. JR.; OLIVEIRA, S. R.; GOMES, N. J. A.; ET AL. Determination of silicon in lubricant oil by high-resolution continuum source flame atomic absorption spectrometry using least-square background correction and internal standardization . Analytical letters, v. 44, p. 2150-2161, 2011.

8. DE SOUZA, R. M., MELIANDE , A. L. S., SILVEIRA , C. L. P. DA, AUCÉLIO, R. Q. Determination of Mo, Zn, Cd, Ti, Ni, V, Fe, Mn, Cr and Co in crude oil using inductively coupled plasma optical emission spectrometry and sample introduction as detergent less micro emulsions. Departamento de Química da Pontifícia Universidade Católica do Rio de Janeiro (PUC-RJ), 2006.

9. DE SOUZA, J. R.; DOS SANTOS, E. F.; DUYCK, C. B.; ET AL. Trace determination of vanadium and nickel in saudi-arabian petroleum and petroleum-products by micro emulsion icp-ms. Spectrochimica, Acta part batomic spectroscopy, V. 66, p. 356-361, 2011.

10. ZARARSIZ A; KIRMAZ R; ARIKAN P. Determination of wear metals in used lubricating oils by X-ray fluorescence spectrometry. Nuclear instruments \& methods in physics research section b-beam interactions with materials and atoms, v. 108, p. 385-388, 1996.

11. DE SOUZA, R. M., MELIANDE , A. L. S., SILVEIRA , C. L. P. DA, AUCÉLIO, R. Q. The determination of trace metals in lubricating oils by atomic spectrometry. Spectrochimica Acta Part B, v. 62, p. 952-961, 2007. 
12. COSTA, L. M.; FERREIRA, S. L. C.; NOGUEIRA, A. R. A.; NOBREGA, J. A.; Use of Factorial Design for Optimization of Microwave-Assisted Digestion of Lubricating Oil. Journal of the Brazilian Chemical Society, Vol. 16, No. 6A, 1269-1274, 2005.

13. BRESSANI. F. A. Desenvolvimento de procedimentos de digestão para óleos lubrificantes. 2005. Dissertação (mestrado) - Universidade Federal de São Carlos.

14. JESUS, ALEXANDRE DE. Desenvolvimento de método analítico para determinação de metais em biodiesel e óleo vegetal por espectometria de absorção atômica com chama. 2008. Dissertação (mestrado) - Universidade Federal do Rio Grande do Sul.

15. ALBUQUERQUE, O. P. A. L. Lubrificação, Editora Mc Graw-Hill do Brasil Ltda., São Paulo, 1973.

16. MOURA, C. R. S. Lubrificantes e lubrificação. Rio de Janeiro: LTD. 1975.

17. CREMEC - TEXACO. Curso de lubrificação. Belo Horizonte: IPUC, [S.D.].

18. PETROBRAS. Lubrificantes: Fundamentos e Aplicações. [S.L.]: Gerencial Industrial. 2005.

19. Supreme Lubrificantes. Análise de óleo. Disponível em: http://www.supremelub.com.br/espaco_lubrificacao/apostilas.aspx. Acessado em Março de 2013.

20. STEPINA, V.; VESELY, V. Lubricants and special fluids; Tribology series 23. Elsevier.1992.

21. TOTTEN, G. E.; WESTBROOK, S. R.; SHAH, R. J. Fuels and lubricants handbook: Technology, Properties, Performance and testing. ASTM Manual series, Glen Bunie, 2003.

22. NADKAR,R. A. Modern Instrumental Methods of Elemental Analysis of Petroleum Products and Lubricants. ASTM Publication, 1991.

23. WELZ, B.; SPERLING, M.; Atomic Absorption Spectrometry - Third, Completely Revised Edition, Wiley-VCH Verlag GmbH: Weinheim, 1999.

24. LIENEMANN, C. P.; DREYFUS, S.; PECHEYRAN, C. and DONARD, O. F. X. Trace Metal Analysis in Petroleum Products: Sample Introduction Evaluation in ICP-OES and Comparison with an ICP_MS Approach. Oil \& Gas Science and Technology, v. 62, p. 69-77, 2007. 
25. BRECH, F \& CROSS, L. Optical Microemission Stimulated by a Ruby MASER. Appl. Spectrosc., v.16, p.59, 1962.

26. RUNGE, E. F.; MINCK, R. W. \& BRYAN, F. R. Spectrochemical analysis using a pulsed laser source. Spectrochim, Acta B, v.20, p.733, 1964.

27. WINEFORDNER, J. D; GORNUSHKIN, I. B; CORRELL, T; GIBB, E; SMITH, B. W \& OMENETTO, N. Comparing several atomic spectrometric methods to the super stars: Special emphasis on laser induced breakdown spectrometry, LIBS, a future super star. Journal of Analytical Atomic Spectrometry, v. 19, p. 1061-83, 2004.

28. Web of knolodge. Disponível em: https://isiknowledge.com. Acessado em junho de 2013.

29. RUSSO, R. E. Laser-ablation. Applied Spectroscopy, Bound Brook, v. 49, p. A14-A28, 1995.

30. Training Handout. Applied Spectra. Fremont. 2010.

31. CREMERS, D. A.; RADZIEMSKI, L. J. Handbook of laser-induced breakdown spectroscopy. Chichester: John Wiley \& Sons, 2006).

32. Figura adaptada de $<$ http://www.appliedphotonics.co.uk.>. Acesso em 03/01/13.

33. HAHN, D. W.; OMENETTO, N. Laser-Induced Breakdown Spectroscopy (LIBS), Part II: Review of Instrumental and Methodological Approaches to Material Analysis and Applications to Different Fields. Applied Spectroscopy, v.66, p. 247-419, 2012.

34. RUSSO, R. E; MAO, X. L; LIU, H. C; YOO, J. H.; MAO, S. S. Time-resolved plasma diagnostics and mass removal during single pulse laser ablation. Appl. Phys, p. S887-S894, 1999.

35. SIRVEN, J. B.; MAUCHIEN, P.; SALLÉ, B. Analytical optimization of some parameters of a Laser-Induced Breakdown Spectroscopy experiment. Spectrochimica Acta Part B - Atomic Spectroscopy, Oxford, v. 63, p. 10771084, 2008.

36. Site da Applied Spectra. Disponível em: http://www.appliedspectra.com/index.html. Acesso em 15/04/2013.

37. RUSSO, R. E.; MAO, X. L.; MAO, S. S. The physics of laser ablation in microchemical analysis. Analytical Chemistry, Washington, v. 74, p. 70A77A, 2002. 
38. DOS SANTOS, D.; TARELHO, L. V. G.; ET AL. Espectrometria de Emissão Óptica com Plasma Induzido por Laser (LIBS) - Fundamentos, aplicações e perspectivas. Revista Analytica, v. 24, p.72-81, 2006.

39. RUSSO, R. E.; MAO, X.; LIU, H.; GONZALEZ, J.; MAO, S. S. Laser ablation in analytical chemistry--a review. Talanta, London, v. 57, p. 425-451, 2002.

40. VADILlO, J. M.; ROMERO, J. M. F.; RODRÍGUEZ, C.; LASERNA, J. J. Effect of plasma shielding on laser ablation rate of pure metals at reduced pressure. Surface and Interface Analysis, New York, v. 27, p. 1009-1015, 1999.

41. SIRVEN, J. B.; MAUCHIEN, P.; SALLÉ, B. Analytical optimization of some parameters of a Laser-Induced Breakdown Spectroscopy experiment. Spectrochimica Acta Part B - Atomic Spectroscopy, Oxford, v. 63, p. 10771084. 2008.

42. DOQ-CGCRE - 008 - Orientação sobre validação de métodos analíticos, INMETRO, Revisão 04 - JUL/2011. - era 53

43. Conostan. Disponivel em: http://www.conostan.com/multi-element.aspx. Acessado em Dez,2014.

44. NIST. Dispovível em: http://www.nist.gov/srm/. Acessado em out,2014.

45. Join Comitee for Guides in Metrology. Evaluation of measurement data guide to the expression. of uncertainty in measurement. s 1.; JCGM 100, 2008.

46. ESTEVES, E. Introdução à Estatística Aplicada e Estatística Descritiva. Departamento de Engenharia Alimentar, Instituto Superior de Engenharia da Universidade do Algarve, Campus da Penha, Portugal, 2009.

47. BARROS, M. V. G. \& REIS, R. S. Análise de dados em atividade física e saúde. Londrina: Mediograf, 2003.

48. Classificadores Baeysianos. Disponível em: http://www.facom.ufu.br/ backes/pgc204/Aula05ClassificadoresBaeysianos.pdf. Acessado em fev de 2015.

49. LI, J.; LU, J.; LIN, Z.; GONG, S.; XIE, C.; CHANG, L.; YANG, L.; LI, P. Effects of experimental parameters on elemental analysis of coal by laserinduced breakdown spectroscopy. Optics \& Laser Technology, Guildford, v. 41, p. 907-913, 2009.

50. GONDAL, M. A.; HUSSAIN, T.; YAMANI, Z. H.; BAIG. M. A. Detection of heavy metals in Arabian crude oil residue using laser induced breakdown spectroscopy. Talanta, v. 69, p. 1072-1078, 2006. 
51. CHUI, Q. S. H e ZUCCHINI, R. R. Qualidade de medições em química analítica. estudo de caso: determinação de cádmio por espectrofotometria de absorção atômica com chama. Quimica Nova, Vol. 24, No. 3, p. 374-380, 2001.

52. GUILHEN, S. N.; PIRES, M. A. F.; E ETC. Validação de metodologia analítica para determinação de mercúrio total em amostras de urina por espectrometria de absorção atômica com geração de vapor frio (CV-AAS). Estudo de caso. Química Nova, v. 33, p. 0100-4042, 2010.

53. SILVEIRA, E. L. C.; CALAND, L. B.; MOURA, C. V. R.; MOURA, E. M. Determinação de contaminantes em óleos lubrificantes usados e em esgotos contaminados por esses lubrificantes. Quimica Nova, v. 29, p. 1193-1197, 2006.

54. ZHENG, L.; CAO, F.; ET AL. On the performance of laser-induced breakdown spectroscopy for direct determination of trace metals in lubricating oils. Spectrochimica Acta Part B: Atomic Spectroscopy, v. 99, Pages 1-8, 2014.

55. MARTINEZ, M.; LOBINSKI, R.; BOUYSSIERE, B.; ET AL. Determination of $\mathrm{Ni}$ and $\mathrm{V}$ in Crude Oil Samples Encapsulated in Zr Xerogels by Laser-Induced Breakdown Spectroscopy. Energy Fuels, 2015. 
14 ANEXOS

ANEXO A: CERTIFICADO DE ANÁLISE DO MATERIAL DE REFERÊNCIA

$1084 \mathrm{~A}$

\author{
Aiational Institute of Standard̀s \& Terhnology \\ Uertifirate of Analugitz \\ Standard Reference Material 1084a \\ Wear-Metals in Lubricating Oil
}

This Standard Reference Material (SRM) is intended primarily for use in the calibration of apparatus and in the evaluation of methods used in the analysis of engine lubricating oils for metal content. SRM 1084a consists of a blend of fourteen constituent elements in a base oil (VB5167) at a nominal concentration of $100 \mu \mathrm{g} / \mathrm{g}$.

A unit of this SRM consists of five 5-mL amber borosilicate ampoules each containing approximately $1.6 \mathrm{~g}$ of the oil blend. The certified values are given below and are based on a minimum sample size of $0.5 \mathrm{~g}$.

\begin{tabular}{|c|c|c|c|c|c|}
\hline Element & $\begin{array}{l}\text { Certified } \\
\text { Value }^{1} \\
\mu \mathrm{g} / \mathrm{g}\end{array}$ & $\begin{array}{l}\text { Methods } \\
\text { Used }\end{array}$ & Element & $\begin{array}{l}\text { Certified } \\
\text { Value }^{1} \\
\mu \mathrm{g} / \mathrm{g}\end{array}$ & $\begin{array}{l}\text { Methods } \\
\text { Used }\end{array}$ \\
\hline $\mathrm{Al}$ & $(104)^{2}$ & [a] & $\mathrm{Ni}$ & $99.7 \pm 1.6$ & b, [d] \\
\hline $\mathrm{Ag}$ & $101.4 \pm 1.5$ & $b, c$ & $\mathrm{~Pb}$ & $101.1 \pm 1.3$ & b, [d] \\
\hline $\mathrm{Cr}$ & $98.3 \pm 0.8$ & b,c & Sn & $97.2 \pm 2.6$ & $\mathrm{~b},[\mathrm{c}]$ \\
\hline $\mathrm{Cu}$ & $100.0 \pm 1.9$ & $a, b$ & $\mathrm{Ti}$ & $100.4 \pm 3.8$ & $b,[c]$ \\
\hline $\mathrm{Fe}$ & $98.9 \pm 1.4$ & {$[a], b$} & V & $95.9 \pm 9.4$ & $a, c$ \\
\hline $\mathrm{Mg}$ & $99.5 \pm 1.7$ & {$[\mathrm{a}], \mathrm{b}$} & $\mathrm{s}$ & $(1700)^{2}$ & [c] \\
\hline Mo & $100.3 \pm 1.4$ & $b, c$ & $\mathrm{Si}$ & $(103)^{2}$ & [e] \\
\hline
\end{tabular}

Methods

a. Inductively Coupled Plasma (ICP)

b. Inductively Coupled Plasma Mass Spectrometry (ICP-MS)

c. Instrumental Neutron Activation Analysis (INAA)

d. Flame Atomic Absorption Spectrometry (FAAS)

e. X-ray Fluorescence Spectrometry (XRF)

${ }^{1}$ The certitied value was determined using the indicated method(s) with the method in brackets used for confirmatiun and to cotimate the sys-

tematic error.

The uncertainty of the certified value is obtained from a $95 \%$ confidence interval plus an allowance for systematic error among the method(s) used.

${ }^{2}$ Value in parenthesis is nut certified but pruvided for iaformation only.

The material preparation was performed by P. Pei and Lin-Sien Lum of the NIST Ceramic Division.

Analyses for certification were performed in the Inorganic Analytical Research Division by E.S. Beary, R. Demiralp (guest scientist), M.S. Epstein, K.M. Garrity, K.E. Hehn, P.J. Paulsen, P.A. Pella, T.A. Rush, L.J. Wood, and R. Zeisler.

Certification analyses were coordinated through W.F. Koch of the Inorganic Analytical Research Division.

Statistical analysis was provided by S.B. Schiller of the Statistical Engineering Division.

The technieal and support aspects invulved in the preparation, certification, and issuance of this Standard Refercnce. Material were coordinated through the Standard Reference Materials Program by T. E. Gills.

Gaithersburg, MD 20899

William P. Reed, Chief April 15, 1991 Standard Reference Materials Program 


\section{ANEXO B: CERTIFICADO DE ANÁlISE DO PADRÃO DA CONOSTAM 500PPM}

\section{CONOSTAEN}

Oil Analysis Standards

A division of SCP SCIENCE / Une division de SCP SCIENCE

\section{Certificate of Analysis}

DESCRIPTION: CONOSTAN Multi-Element Standard

S-21:500 ppm

Catalogue Number: $\quad$ 150-021-011/150-021-031

Lot Number: $\quad \mathbf{2 1 4 1 9 5 0 0}$

Matrix Base Oil $75 \mathrm{cSt}$

Expiration Date: 12 months from date of shipment

2.0 CERTIFIED VALUES AND ASSOCIATED UNCERTAINTY:

Certified Concentrations, ppm $(\mu g / g)$ :

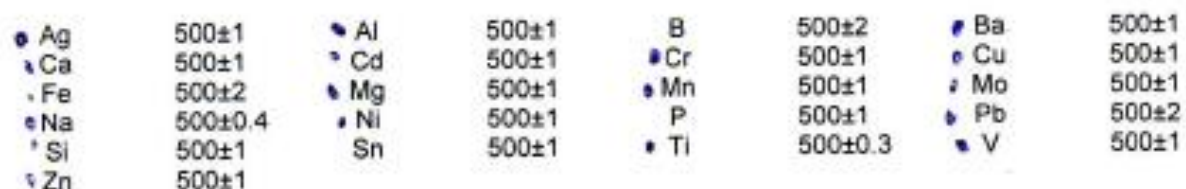

Method of analysis and traceability:
This standard was prepared by weight messulements originating from assoyed element Concentrotes. A precursor blend was verfied by atomic emission or absorption spectioscopy Element concentratiors for this standard are based on the Concentrate assay values and were prepared to within the uncurtainty values listed above at the $95 \%$ Confidenco Irtertal, at determined by weight measurements of blend components conducted en balances calbraled and verified with NIST traceable weights.

-Esch element Concentrate wos assayed by classicel wet chemical methods. Precision of assay measurement is 10.5 percent maximum, but typicaly \pm 0.3 percent, or less. Assay accuracy is within one percent of measured value, but fyoically much less, as determined by co-measuremem of and traceabieity to. NIST Standards, of Certified Analyocol Reagent Grate Chemicals, If no auilable NIST atondards ovists

3.0 REFERENCE VALUES:

None

4.0 APPROVAL AND DATE OF CERTIFICATION:

Certification Date:

March 22, 2011

Certification Approvat: AYman w/assef

Ayman Wassef

Conostan Production Supervisor 


\section{CONOST $\triangle N^{\circ}$}

Oil Analysis Standards

A divisian of SCP SCIENCE $/$ Une division de SCP SCIENCE

\section{Certificate of Analysis}

1.0 DESCRIPTION: CONOSTAN Element Blank Oil, 20 Viscosity

Catalogue Number: $\quad$ 150-020-001/150-020-002/150-020-005

Lot Number: $\quad 44$

Matrix: N/A

Expiration Date: $\quad 12$ months from date of shipment

2.0 CERTIFIED VALUES AND ASSOCIATED UNCERTAINTY:

Trace Element Concentrations, ppm $(\mu \mathrm{g} / \mathrm{g})$ :

$\begin{array}{llllllll}\mathrm{Ag} & <0.01 & \mathrm{Al} & <0.02 & \mathrm{~B} & <0.02 & \mathrm{Ba} & <0.01 \\ \mathrm{Be} & <0.01 & \mathrm{Bi} & <0.02 & \mathrm{Ca} & <0.03 & \mathrm{Cd} & <0.01 \\ \mathrm{Co} & <0.02 & \mathrm{Cr} & <0.01 & \mathrm{Cu} & <0.01 & \mathrm{Fe} & <0.01 \\ \mathrm{In} & <0.03 & \mathrm{~K} & <0.03 & \mathrm{La} & <0.01 & \mathrm{Li} & <0.03 \\ \mathrm{Mg} & <0.01 & \mathrm{Mn} & <0.01 & \mathrm{Mo} & <0.01 & \mathrm{Na} & <0.02 \\ \mathrm{Ni} & <0.01 & \mathrm{P} & <0.02 & \mathrm{~Pb} & <0.01 & \mathrm{Sb} & <0.01 \\ \mathrm{Sc} & <0.01 & \mathrm{Si} & <0.01 & \mathrm{Sn} & <0.02 & \mathrm{Sr} & <0.01 \\ \mathrm{~T} & <0.01 & \mathrm{~V} & <0.01 & \mathrm{~W} & <0.04 & \mathrm{Y} & <0.01 \\ \mathrm{Zn} & <0.01 & & & & & & \end{array}$

Method of analysis and traceability:
Trace element values were determined by atomic emission spectroscopy and are traceable to the applicable NIST 31 series Standard Reference Materials.

3.0 REFERENCE VALUES:

None

4.0 APPROVAL AND DATE OF CERTIFICATION:

Certification Date: $\quad$ January 25, 2011

Certification Approval: $\quad$ AYman wass of

Ayman Wassef

Conostan Production Supervisor 


\section{APÊNDICE}

\section{APÊNDICE A - Teste não paramétrico de Kruskal-wallis}

Comparação múltipla

classes para $\mathrm{Cu}$.

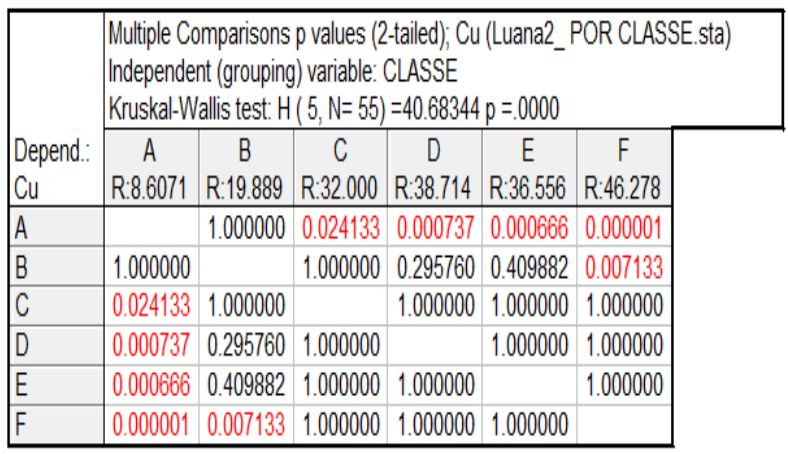

Comparação múltipla

entre as classes para $\mathbf{P b}$.

\begin{tabular}{|c|c|c|c|c|c|c|}
\hline \multirow[b]{2}{*}{$\begin{array}{l}\text { Depend: } \\
\mathrm{Pb}\end{array}$} & \multicolumn{6}{|c|}{$\begin{array}{l}\text { Multiple Comparisons p values (2-tailed); Pb (Luana2_POR CLASSE.sta) } \\
\text { Independent (grouping) variable: CLASSE } \\
\text { Kruskal-Wallis test: } \mathrm{H}(5, \mathrm{~N}=55)=42.96921 \mathrm{p}=.0000\end{array}$} \\
\hline & $\begin{array}{c}\text { A } \\
R: 8.5714\end{array}$ & $\begin{array}{c}\text { B } \\
\text { R:19.111 }\end{array}$ & $\begin{array}{c}C \\
\text { R:32.286 }\end{array}$ & $\begin{array}{c}\text { D } \\
\text { R:35.500 }\end{array}$ & $\begin{array}{c}E \\
R: 37.833\end{array}$ & $\begin{array}{c}F \\
R: 48.111\end{array}$ \\
\hline$A$ & & 1.000000 & 0.020784 & 0.004234 & 0.000287 & 0.000000 \\
\hline B & 1.000000 & & 1.000000 & 0.635498 & 0.197619 & 0.001846 \\
\hline C & 0.020784 & 1.000000 & & 1.000000 & 1.000000 & 0.749746 \\
\hline D & 0.004234 & 0.635498 & 1.000000 & & 1.000000 & 1.000000 \\
\hline$E$ & 0.000287 & 0.197619 & 1.000000 & 1.000000 & & 1.000000 \\
\hline $\mathrm{F}$ & 0.000000 & 0.001846 & 0.749746 & 1.000000 & 1.000000 & \\
\hline
\end{tabular}

Comparação múltiplentreas

as classes para $\mathrm{Cr}$.

\begin{tabular}{|c|c|c|c|c|c|c|}
\hline \multirow[b]{2}{*}{$\begin{array}{l}\text { Depend: } \\
\mathrm{Cr}\end{array}$} & \multicolumn{6}{|c|}{$\begin{array}{l}\text { Muttiple Comparisons p values (2-tailed); Cr (Luana2_POR CLASSE.sta) } \\
\text { Independent (grouping) variable: CLASSE } \\
\text { Kruskal-Wallis test: } \mathrm{H}(5, \mathrm{~N}=55)=30.63199 \mathrm{p}=.0000\end{array}$} \\
\hline & $\begin{array}{c}\text { A } \\
\text { R:12.500 }\end{array}$ & $\begin{array}{c}\text { B } \\
\text { R:20.556 }\end{array}$ & $\begin{array}{c}C \\
\text { R:30.286 }\end{array}$ & $\begin{array}{c}D \\
\text { R:35.071 }\end{array}$ & $\begin{array}{c}E \\
\text { R:36.000 }\end{array}$ & $\begin{array}{c}F \\
\text { R:44.278 } \\
\end{array}$ \\
\hline$A$ & & 1.000000 & 0.247121 & 0.035073 & 30.008946 & 0.000052 \\
\hline B & 1.000000 & & 1.000000 & 1.000000 & 0.612819 & 0.025250 \\
\hline C & 0.247121 & 1.000000 & & 1.000000 & 01.000000 & 1.000000 \\
\hline D & 0.035073 & 1.000000 & 1.000000 & & 1.000000 & 1.000000 \\
\hline$E$ & 0.008946 & 0.612819 & 1.000000 & 1.000000 & & 1.000000 \\
\hline $\mathrm{F}$ & 0.000052 & 0.025250 & 1.000000 & 1.000000 & 01.000000 & \\
\hline
\end{tabular}

\section{Comparação múltipla entre}

as classes para $\mathrm{Fe}$.

\section{Comparação múltipla entre as} classes para Mo

\section{Comparação múltipla entre}

as classes para $\mathrm{Mg}$.
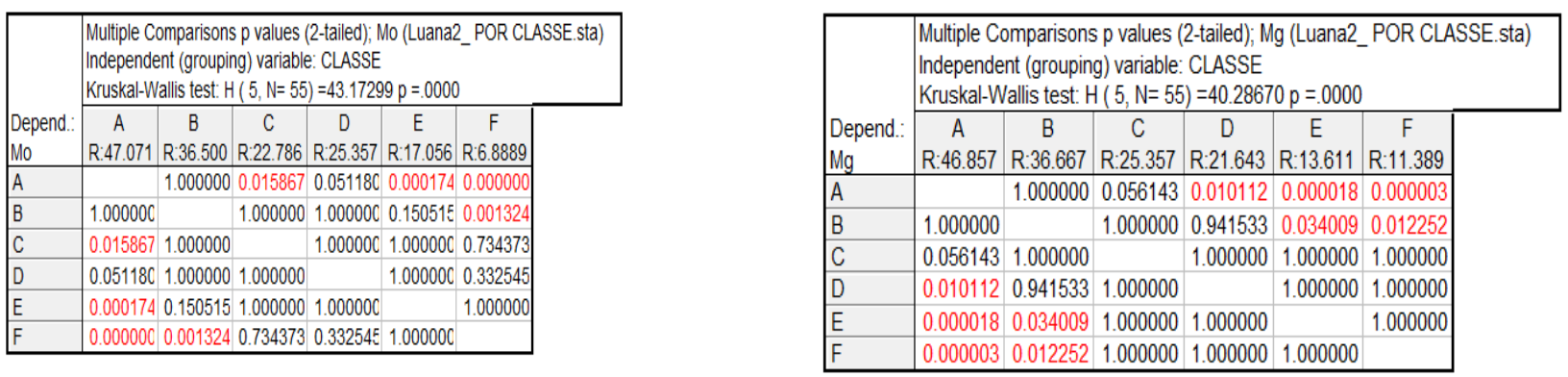